\title{
Development and operational experience of magnetic horn system for T2K experiment
}

T. Sekiguchi ${ }^{\mathrm{a}, 1, *}$, K. Bessho ${ }^{\text {a }}$, Y. Fujii ${ }^{\mathrm{a}}$, M. Hagiwara ${ }^{\mathrm{a}}$, T. Hasegawa ${ }^{\mathrm{a}}$, K. Hayashi ${ }^{\mathrm{a}}$, T. Ishida ${ }^{\mathrm{a}}$, T. Ishii ${ }^{\mathrm{a}}$, H. Kobayashi ${ }^{\mathrm{a}}$, T.

Kobayashi $^{a}$, S. Koike ${ }^{\mathrm{a}, 2}$, K. Koseki ${ }^{\mathrm{a}}$, T. Maruyama ${ }^{\mathrm{a}}$, H. Matsumoto ${ }^{\mathrm{a}}$, T. Nakadaira ${ }^{\mathrm{a}}$, K. Nakamura ${ }^{\mathrm{a}}$, K. Nakayoshi ${ }^{\mathrm{a}}$, K.

Nishikawa $^{\mathrm{a}}$, Y. Oyama ${ }^{\mathrm{a}}$, K. Sakashita ${ }^{\mathrm{a}}$, M. Shibata ${ }^{\mathrm{a}}$, Y. Suzukia ${ }^{\mathrm{a}}$, M. Tada ${ }^{\mathrm{a}}$, K. Takahashi $^{\mathrm{a}}$, T. Tsukamoto ${ }^{\mathrm{a}}$, Y. Yamada ${ }^{\mathrm{a}}$, Y. Yamanoi $^{\mathrm{a}}$, H. Yamaoka ${ }^{\mathrm{a}}$, A.K. Ichikawa ${ }^{\mathrm{b}}$, H. Kubo ${ }^{\mathrm{b}}$, Z. Butcher ${ }^{\mathrm{c}, 3}$, S. Coleman ${ }^{\mathrm{c}}$, A. Missert ${ }^{\mathrm{c}}$, J. Spitz ${ }^{\mathrm{c}, 4}$, E.D. Zimmerman ${ }^{\mathrm{c}}$, M. $^{\circ}$ Tzanov $^{\mathrm{d}}$, L. Bartoszek ${ }^{\mathrm{e}}$

\author{
${ }^{a}$ High Energy Accelerator Research Organization (KEK), Tsukuba, Ibaraki, Japan \\ ${ }^{b}$ Kyoto University, Department of Physics, Kyoto, Japan \\ ${ }^{c}$ University of Colorado Boulder, Department of Physics, Boulder, Colorado, USA \\ ${ }^{d}$ Louisiana State University, Department of Physics and Astronomy, Baton Rouge, Louisiana, USA \\ ${ }^{e}$ Bartoszek Engineering, Aurora, Illinois, USA
}

\begin{abstract}
A magnetic horn system to be operated at a pulsed current of $320 \mathrm{kA}$ and to survive high-power proton beam operation at $750 \mathrm{~kW}$ was developed for the T2K experiment. The first set of T2K magnetic horns was operated for over 12 million pulses during the four years of operation from 2010 to 2013 , under a maximum beam power of $230 \mathrm{~kW}$, and $6.63 \times 10^{20}$ protons were exposed to the production target. No significant damage was observed throughout this period. This successful operation of the T2K magnetic horns led to the discovery of the $v_{\mu} \rightarrow v_{e}$ oscillation phenomenon in 2013 by the T2K experiment. In this paper, details of the design, construction, and operation experience of the T2K magnetic horns are described.
\end{abstract}

Keywords: Magnetic horn, Neutrino, Beamline, T2K, J-PARC

\section{Introduction}

$\mathrm{T} 2 \mathrm{~K}$ is the Tokai-to-Kamioka long-baseline neutrino oscil- ${ }^{24}$ lation experiment [1]. The physical motivations behind the T2K experiment are the determination of the value of oscillation parameter $\theta_{13}$, by searching for the $v_{\mu} \rightarrow v_{e}$ oscillation phenomenon, and a precise measurement of oscillation parameter $\theta_{23}$ by measuring $v_{\mu} \rightarrow v_{\mu}$ oscillation. The T2K experiment utilizes a highintensity neutrino beam from proton accelerators at the Japan Proton Accelerator Research Complex (J-PARC) [2], which have a design beam power of $750 \mathrm{~kW}$, and the Super-Kamiokande detector [3] as a far detector, which is at a $295-\mathrm{km}$ distance from J-PARC. An important feature of the T2K neutrino beam ${ }_{25}$ is that it is narrow-band and uses an off-axis beam method [4]. ${ }_{26}^{25}$ The beam axis direction is oriented at $2.5^{\circ}$ with respect to the ${ }_{27}$ direction of the Super-Kamiokande detector. In this case, the ${ }_{28}$ neutrino energy distribution at the Super-Kamiokande detector ${ }_{29}$ has a narrow distribution peaking at $0.6 \mathrm{GeV}$, for which the os- ${ }_{30}$ cillation probability at the $295-\mathrm{km}$ baseline is at a maximum. 31

A proton beam with kinetic energy of $30 \mathrm{GeV}$ (design in- ${ }_{2}$ tensity $=3.3 \times 10^{14}$ protons/pulse) is extracted from the Main ${ }_{33}$ Ring to the T2K neutrino beamline once every $2.1 \mathrm{~s}$, and is ex- ${ }_{34}$ posed to a production target composed of a graphite rod $\left(2.6_{35}\right.$

\footnotetext{
${ }^{*}$ Corresponding author

Email address: tetsuro.sekiguchi@kek.jp (T. Sekiguchi)

${ }^{1}$ Tel: +81-29-864-5200, ext. 4655

${ }^{2}$ Deceased.

${ }^{3}$ Now at University of Massachusetts, Amherst, Massachusetts, USA USA

${ }^{4}$ Now at Massachusetts Institute of Technology, Cambridge, Massachusetts, ${ }_{41}^{40}$
}

Preprint submitted to Nuclear Instruments and Methods in Physics Research A
${ }_{23} \mathrm{~cm}$ in diameter and $90 \mathrm{~cm}$ in length). Design parameters of the proton beam from the Main Ring are summarized in Table 11. Secondary particles such as pions and kaons are focused in

Table 1: Design parameters of proton beam from Main Ring.

\begin{tabular}{ll}
\hline Parameters & Value \\
\hline Kinetic energy & $30 \mathrm{GeV}$ \\
Beam intensity & $3.3 \times 10^{14}$ protons/pulse \\
Repetition cycle & $2.1 \mathrm{~s}$ \\
Beam power & $750 \mathrm{~kW}$ \\
Beam width $(1 \sigma)$ at target & $4.0 \mathrm{~mm}$ \\
\hline
\end{tabular}

the forward direction by three magnetic horns, where the target is embedded in the magnetic horn located the furthest upstream. The secondary particles decay in flight and produce muon neutrinos (purity 99\%) when they travel along a 100$\mathrm{m}$-long decay volume. A beam dump, which is composed of segmented graphite blocks, is positioned at the end of the decay volume to absorb all the hadrons. The target, magnetic horns, decay volume, and beam dump are enclosed in a gigantic iron vessel $\left(\sim 1,500 \mathrm{~m}^{3}\right)$, the inner volume of which is filled with 1 atm of helium gas in order to reduce tritium $\left({ }^{3} \mathrm{H}\right)$ and nitrogen oxide (NOx) production. The helium atmosphere also works to greatly reduce the oxidation of the graphite material of the beam dump. A schematic drawing of the T2K secondary neutrino beamline is shown in Fig. 1 and additional details of the $\mathrm{T} 2 \mathrm{~K}$ neutrino beamline are given in [5].

In this paper, details of the $\mathrm{T} 2 \mathrm{~K}$ magnetic horn system are 
provided. Introductory information is given in Section 2, elec- 88 trical properties in Section 3, cooling performance in Section 89 4 mechanical properties in Section 5 details of remote mainte- 9o nance issues in Section 6 and, finally, operational experience 91 during beam operation for physics data-taking is reported in 92 Section 7

\section{T2K magnetic horns}

The T2K magnetic horn system consists of three horns: horn-97 1 , horn-2, and horn-3, in order from upstream. Secondary par- 98 ticles are emitted from the target with high angles of a few hun- 99 dred $\mathrm{mrad}$ and low momenta of $1-4 \mathrm{GeV} / \mathrm{c}$. A field integral of ${ }_{100}$ $1.3 \mathrm{~T} \cdot \mathrm{m}$ is required in order to focus those particles efficiently.101 The target is inserted inside the inner conductor of horn- 1 so as ${ }_{102}$ to provide high collection efficiency, and a peak current of $320_{103}$ $\mathrm{kA}$ is adopted for the T2K magnetic horns in order to achieve ${ }_{104}$ high magnetic field strength. The design philosophy and design ${ }_{105}$ optimization of the T2K magnetic horns are described in [6]. ${ }_{106}$

The T2K horns consist of aluminum conductors, current ${ }_{107}$ feeding striplines, water and gas plumbing, and support frames.108 Figure 2 shows drawings of the T2K magnetic horns. The alu-109 minum conductors have coaxial conductor structures, with in-110 ner and outer conductors that are connected at the downstream ${ }_{111}$ end but insulated at the upstream end, as shown in Fig. $33_{112}$ The current first enters the inner conductor from the upstream end, returns through the outer conductor, and exits from the upstream end. A toroidal magnetic field is generated in the region between the inner and outer conductors. Drawings of the aluminum conductors of horn-1, horn-2, and horn-3 are shown in Fig. 4, while typical dimensions of the horn conductors are also listed in Table 2. The inner conductor thickness is set to $3 \mathrm{~mm}$

Table 2: Typical dimensions of T2K magnetic horn conductors.

\begin{tabular}{lccc}
\hline Parameters & horn-1 & horn-2 & horn-3 \\
\hline Inner diameter & $54 \mathrm{~mm}$ & $80 \mathrm{~mm}$ & $140 \mathrm{~mm}$ \\
Outer diameter & $380 \mathrm{~mm}$ & $1,000 \mathrm{~mm}$ & $1,330 \mathrm{~mm}$ \\
Length & $1,495 \mathrm{~mm}$ & $2,036 \mathrm{~mm}$ & $2,536 \mathrm{~mm}$ \\
\hline
\end{tabular}

in order to reduce interactions of the secondary particles, while ${ }^{114}$ the thickness of the outer conductors is $10 \mathrm{~mm}$.

The T2K magnetic horns are designed for a peak current of ${ }^{116}$ $320 \mathrm{kA}$. A sinusoidal pulsed current, with a pulse width of $2.4-^{117}$ $3.6 \mathrm{~ms}$, is applied to the conductors, and the beam is exposed ${ }^{118}$ for $5 \mu$ s at the peak of the sinusoidal waveform. The magnetic ${ }^{119}$ field inside the conductors is given by

$$
B=\frac{\mu I}{2 \pi r},
$$

where $I$ is the current, $\mu$ is the magnetic permeability, and $r^{124}$ is the radial distance from the central axis. The peak current 125 of $320 \mathrm{kA}$ produces a maximum magnetic field of $2.1 \mathrm{~T}$ at the126 outer surface of the horn-1 inner conductor $(r=3 \mathrm{~cm})$. The127 maximum magnetic fields at horn- 2 and horn-3 are 1.5 and $0.9_{128}$ $\mathrm{T}$, respectively. The electrical properties such as the current ${ }^{129}$ generation (power supply, transfer line, etc.) and the magnetic 130 field measurements are described in Section 3 .
The aluminum conductors (especially the inner conductors) are pressurized by the Lorentz force created by the current flow and magnetic field. The inner conductors are 3-mm thick, however, they must withstand the Lorentz force and also the thermal shock that will be described below. Magnetic horn conductors should have as low resistivity as possible for high-current operation and as low material density as possible to reduce interactions of secondary particles, however, they should also have high resistance to the Lorentz force and the heat shock from the beam exposure and Joule loss. Thus, the aluminum alloy, A6061-T6, which is often used for magnetic horns in various neutrino experiments, is selected as a conductor material. This alloy has tensile (yield) strength of $310 \mathrm{MPa}(275 \mathrm{MPa})$, which is a significantly higher value than that of pure aluminum (tensile strength $\sim 70 \mathrm{MPa})$, and has resistivity of $4.0 \times 10^{-8} \Omega \cdot \mathrm{m}$ (233\% $(161 \%)$ of that of pure copper (pure aluminum)). A characteristic of the alloy under fatigue shows a reduction in tensile strength to $95 \mathrm{MPa}$ after $5 \times 10^{8}$ cycle repetitive force is applied [7]. The mechanical properties of the T2K magnetic horns are explained in Section 5

When the secondary particles pass through the horn conductors, a large amount of heat deposit arises at the conductors. In addition, the $320-\mathrm{kA}$ pulsed current also produces a heat deposit due to Joule heating. The heat deposits in each horn from both beam exposure and Joule heating are summarized in Table 3 . For $750-\mathrm{kW}$ beam operation $\left(30 \mathrm{GeV}, 3.3 \times 10^{14}\right.$ pro-

Table 3: Summary of heat deposit in each horn. Heat deposit from beam exposure is based on the design intensity of $3.3 \times 10^{14}$ protons/pulse. Joule heating for each horn is estimated for pulse widths of 2.4 (horn-1) and $3.6 \mathrm{~ms}$ (horn-2 and horn-3). The calculation of the total heat deposit in units of $\mathrm{kW}$ is based on a 2.1-s cycle.

\begin{tabular}{l|c|c|c|c|c|c}
\hline & \multicolumn{2}{|c|}{ horn-1 } & \multicolumn{2}{c|}{ horn-2 } & \multicolumn{2}{c}{ horn-3 } \\
\cline { 2 - 7 } & inner & outer & inner & outer & inner & outer \\
\hline Beam $(\mathrm{kJ})$ & 14.7 & 9.7 & 4.1 & 7.6 & 1.1 & 2.4 \\
Joule $(\mathrm{kJ})$ & 11.7 & 0.6 & 6.1 & 0.4 & 4.1 & 0.2 \\
\hline Total $(\mathrm{kJ})$ & \multicolumn{2}{|c|}{36.7} & \multicolumn{2}{c|}{18.2} & \multicolumn{2}{c}{7.8} \\
Total $(\mathrm{kW})$ & \multicolumn{2}{|c|}{17.5} & \multicolumn{2}{c|}{8.7} & \multicolumn{2}{c}{3.7} \\
\hline
\end{tabular}

tons/pulse, 2.1-s cycle), the heat deposit in each horn is 17.5 , 8.7, and $3.7 \mathrm{~kW}$ for horn-1, horn-2, and horn-3, respectively. The 5 - $\mu$ s beam exposure creates an instantaneous increase in temperature, which then causes thermal stress. Joule heating also creates an instantaneous temperature increase. The instantaneous rise in temperature at each horn is shown in Fig. 5 These heat deposits are removed by water cooling, as water nozzles attached to the outer conductors spray water onto the inner conductors. Details of the cooling performance are given in Section 4

The inner and outer conductor assembly is supported by aluminum frames. The central axis of the conductors is angled downward by $3.637^{\circ}$ in order to obtain an off-axis angle for the Super-Kamiokande detector of $2.5^{\circ}$. The aluminum support structures consist of four vertical columns and a top frame. There are water cooling channels inside the vertical columns. The outer conductors are both supported and insulated by four alumina ceramic blocks embedded in the vertical columns, as 
shown in Fig. 6 The ceramic blocks in the upstream columns 185 are fixed, while those in the downstream columns are free to 186 slip along the axis to absorb the thermal expansion of the outer ${ }_{187}$ conductor.

The T2K magnetic horns are located inside the upstream ${ }_{189}$ section of the Helium Vessel (HV), and a schematic figure of 190 the HV including the magnetic horns is shown in Fig. 7] The ${ }_{191}$ magnetic horns are suspended by iron structures called support ${ }_{192}$ modules and can be disconnected from them remotely. The sup-193 port modules are placed inside the HV with four support points.

Iron shielding blocks are inserted inside the box-shape support ${ }_{194}$ module, and a concrete shielding block is placed on top of the ${ }_{195}$ iron blocks, as shown in Fig. 8. All the shielding blocks are in- ${ }_{196}$ dependently supported by the $\mathrm{HV}$ at the upper position. In the ${ }_{197}$ case of one-year beam operation with the design beam power of ${ }_{198}$ $750 \mathrm{~kW}$, all the equipment below the shielding blocks becomes highly irradiated to the order of a few tens of Sv/h. Therefore, one cannot access the radioactive equipment and perform maintenance or repair work. If an instrument is broken, the shielding ${ }_{202}$ blocks are moved using a remotely operated overhead crane, ${ }_{20}$ the broken equipment is removed from the HV, and new apparatus is installed. This movement of the radioactive equipment ${ }_{205}$ is also performed by remote operation. More information on ${ }_{206}$ the remote maintenance is provided in Section 6

\section{Electrical properties}

The electrical properties of the T2K magnetic horns are de-211 scribed in this section. The rated peak current of these horns is 212 $320 \mathrm{kA}$ and two power supplies that were used to operate the $\mathrm{e}_{213}$ horns in the K2K experiment [8] (produced in 1994 and 1998) 214 were refurbished for use in the T2K experiment. Since there are 215 three magnetic horns in the T2K experiment, one power supply ${ }_{216}$ is used to drive horn-1 only, while another is used to drive both 217 horn- 2 and horn- 3 connected in series. In the transition from the $e_{218}$ $\mathrm{K} 2 \mathrm{~K}$ to the $\mathrm{T} 2 \mathrm{~K}$ experiments, some improvements were made 219 to the power supplies, e.g., modifications to increase the rated 220 current from the $250 \mathrm{kA}$ used in $\mathrm{K} 2 \mathrm{~K}$ to the $320 \mathrm{kA}$ required ${ }_{221}$ for the $\mathrm{T} 2 \mathrm{~K}$ experiment. A schematic diagram of the electric $\mathrm{C}_{222}$ circuit used for the T2K magnetic horns is shown in Fig. 9

\subsection{Current flow and power supply}

A charging unit in the power supply charges a set of capac-226 itors, at $5 \mathrm{mF}(6 \mathrm{mF})$, up to $5.8 \mathrm{kV}(6.9 \mathrm{kV})$ for horn-1 (horn-2 $2^{227}$ and horn-3), and the stored energy of $84 \mathrm{~kJ}$ for horn-1 $\left(143^{228}\right.$ $\mathrm{kJ}$ for horn-2 and horn-3) is released by turning on a series of ${ }^{229}$ three thyristor switches simultaneously. This outputs a pulsed ${ }^{230}$ current of $32 \mathrm{kA}$. The output current is transferred to a pulse $\mathrm{e}^{231}$ transformer through six pairs of 100-m-long high-voltage ca-232 bles (twisted-pair cables with a rated voltage of $\mathrm{V}_{D C}=11 \mathrm{kV}$; 233 one cable is used as a supply line and another as a return line). ${ }^{234}$ The pulse transformer amplifies the pulsed current by a factor ${ }^{235}$ of ten. Four pairs of aluminum striplines (eight parallel plates; ${ }^{236}$ four for the supply line and four for the return line), made of ${ }^{237}$ A6061-T6, are used as a transfer line between the pulse trans-238 former and the magnetic horn, and they carry a $320-\mathrm{kA}$ pulsed ${ }^{239}$ current to the horns. Horn-2 and horn-3 are connected in series in the secondary circuit of the pulse transformer. The pulsed current then returns to the capacitor bank in the power supply. Because of Joule loss, approximately $50 \%$ of the stored energy is returned to the capacitor bank and the capacitors are inversely charged. In this power supply system, however, the recovered energy is not recycled for the next pulse, but is totally consumed by a series of dump resistors located inside the power supply. The maximum rate of the power supply cycle is $0.5 \mathrm{~Hz}$.

\subsection{Striplines}

The striplines consist of eight parallel aluminum conductors with $1-\mathrm{cm}$ thickness, $40-\mathrm{cm}$ width, and 2-cm gap spacing. Eight stripline plates are bundled by long M16 bolts and Spiralock ${ }^{\circledR}$ hex flange nuts, which are insulated with 2 -cm-thick disks and tubes composed of alumina ceramic, as shown in Fig. 10] The striplines are clamped by insulators placed at $30-\mathrm{cm}$ intervals. The spacing was determined, considering the required mechanical strength against the Lorentz force, using a finite element stress analysis. In this configuration, the inductance and dc resistance per unit length are $0.063 \mu \mathrm{F} / \mathrm{m}$ and $10 \mu \Omega / \mathrm{m}$, respectively. The length of the striplines is approximately $18 \mathrm{~m}$ (36 m) for horn-1 (horn-2 and horn-3), respectively. The serial striplines for horn-2 and horn-3 are designed to have the same lengths in both horns. The stripline plate junctions are bolted connections, with the same scheme as that of the stripline clamping, as shown in Fig. 10. A silver plating is applied to the contact surfaces to reduce joint resistance.

Since the pulse transformers and magnetic horns are located outside and inside the $\mathrm{HV}$, respectively, the striplines penetrate the wall of the HV via feedthroughs. Each magnetic horn has its own feedthrough, and the feedthroughs are located in the upper part of the HV, so the radiation level is not high during beam exposure ( 30 Gy for 1 year of operation). The stripline plates of the feedthroughs are insulated from their steel flanges by glass-epoxy laminated plate (G10). The edges of all the contact surfaces of the G10 insulators and the steel flange are sealed with an adhesive bond. The definition of vacuum tightness is a leak rate of $<10^{-7} \mathrm{~Pa} \cdot \mathrm{m}^{3} / \mathrm{s}$ at the $10-\mathrm{Pa}$ level.

Since the withstanding voltage is expected to be reduced in a helium atmosphere, the withstanding voltage for the striplines with $2-\mathrm{cm}$ spacing and using ceramic insulators was measured using mockup striplines. The results revealed that the withstanding voltage was $3.5 \mathrm{kV}$ in the helium atmosphere. Because all the aluminum conductors (the magnetic horns and striplines) are operated below $1 \mathrm{kV}$, the withstanding voltage value of 3.5 $\mathrm{kV}$ is sufficiently high for insulation between conductors and between a conductor and the ground. The supply and return striplines are connected via $7.5-\Omega$ resistors and the neutral point is grounded, as shown in Fig. 9. The supply (return) striplineto-ground voltage is maintained below a maximum of +500 $\mathrm{V}(-500 \mathrm{~V})$. In the early stages of the experiment, this neutral grounding did not exist, which caused a voltage breakdown of the striplines inside the HV. This neutral grounding scheme is essential to preventing a voltage breakdown in the helium atmosphere. 
Figure 1: Schematic drawing of T2K secondary beamline.

Figure 2: Drawings of T2K magnetic horns: horn-1 front view (top left), horn- $1^{246}$ side view (top right), horn-2 front view (middle left), horn-2 side view (middle247 right), horn-3 front view (bottom left), and horn-3 side view (bottom right).

Figure 3: Cross section of horn-1 conductors showing current and magnetic field directions.

Figure 4: Aluminum conductors of horn-1 (top), horn-2 (middle), and horn-3 (bottom).

Figure 5: Instantaneous temperature increase at inner conductors as a function of longitudinal position for horn-1 (top), horn-2 (middle), and horn-3 (bottom). The instantaneous temperature increases due to beam exposure and Joule heating are represented by triangles and crosses, respectively. The total instantaneous increases in temperature are also indicated by circles.

Figure 6: Horn support components: 1. Support pin; 2. Support fixture attached to vertical frame; 3 . Ceramic insulation block; and 4 . Outer conductor.

Figure 8: Schematic diagram of horn-3 and its support module. Support points ${ }_{263}$ are enclosed by circles.

Figure 9: Schematic diagram of electric circuit for T2K magnetic horns.

Figure 10: Striplines of T2K magnetic horn system. The top (bottom) figure27s shows the striplines at a normal (joint) section. The direction of current flow at each stripline plate is shown by the arrows in the upper right figure.

Figure 7: Schematic diagram of the HV. The magnetic horns are also shown in this figure.

\subsection{Magnetic horns}

The four striplines are attached to the most upstream part of each magnetic horn, as shown in Fig. 2. The four supply striplines are connected to the inner conductor and the four return striplines to the outer conductor. In order to focus positively charged secondary particles, the current enters the inner conductor and exits from the outer conductors as shown in Fig. 3. The magnetic field is proportional to both $I$ and $1 / r$, as expressed in Equation (1). The inner and outer conductors are insulated at the upstream end with a 30-mm-thick large ceramic ring made of alumina ceramics with $99.5 \%$ purity, with inner (outer) diameters of $370(530) \mathrm{mm}, 980(1,110) \mathrm{mm}$ and 1,310 $(1,430) \mathrm{mm}$ for horn-1, horn-2, and horn-3, respectively, while the inner and outer conductors are connected at the downstream end by bolted joints consisting of M16 bolts and Spiralock ${ }^{\circledR}$ hex flange nuts, both made of A6061-T6.

The typical circuit parameters of the T2K magnetic horn system are listed in Table 4.

Table 4: Summary of circuit parameters for T2K magnetic horn system.

\begin{tabular}{l|r|r|r|r}
\hline \multirow{2}{*}{ Components } & \multicolumn{2}{|c|}{ horn-1 } & \multicolumn{2}{r}{ horn-2 + horn-3 } \\
\cline { 2 - 5 } & $\begin{array}{r}L \\
(\mu \mathrm{H})\end{array}$ & $\begin{array}{r}R \\
(\mathrm{~m} \Omega)\end{array}$ & $\begin{array}{r}L \\
(\mu \mathrm{H})\end{array}$ & $\begin{array}{r}R \\
(\mathrm{~m} \Omega)\end{array}$ \\
\hline Horn & 0.47 & 0.100 & 0.46 & 0.035 \\
& & & +0.53 & +0.023 \\
Striplines & 0.28 & 0.100 & 0.60 & 0.210 \\
Transformer & 0.30 & 0.040 & 0.30 & 0.040 \\
\hline Total (secondary) & 1.05 & 0.240 & 1.89 & 0.308 \\
Total (seen from primary) & 105 & 24.0 & 208 & 34.0 \\
Cable & 15 & 4.0 & 17 & 4.3 \\
Total (primary) & 120 & 28.0 & 223 & 38.3 \\
\hline Pulse width & $2.4 \mathrm{~ms}$. & $3.6 \mathrm{~ms}$. \\
Peak current & $320 \mathrm{kA}$ & $320 \mathrm{kA}$ \\
Capacitance of capacitors & \multicolumn{2}{|c|}{$5 \mathrm{mF}$} & $6 \mathrm{mF}$ \\
Charging voltage at capacitors & $5.8 \mathrm{kV}$ & $6.9 \mathrm{kV}$ \\
Stored energy at capacitors & $84 \mathrm{~kJ}$ & $143 \mathrm{~kJ}$ \\
\hline
\end{tabular}

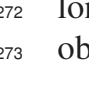

\subsection{Current monitoring}

The pulsed current sent to each horn is monitored with custom Rogowski coil 5 whose signal is digitized by $200 \mathrm{kHz}$ FADCs. One Rogowski coil is wound around each stripline plate and four independently measured current values are summed to obtain a total current for each horn. If any current deviation $( \pm 3 \%$ from the nominal current) is observed by one Rogowski coil or more, then the power supply operation is stopped by an interlock system. Typical current waveforms for horn-1 and for horn-2 and horn-3 are shown in Fig. 11 .

The Rogowski coils are calibrated by the production company with $\pm 1 \%$ precision. The shape of the "loop" of the Rogowski coil may cause a $1 \%$ change in gain. FADCs and related electronics are calibrated with better than $1 \%$ precision. During long-term beam operation, a peak current variation of $2 \%$ was observed, mainly due to temperature variation, since the power

\footnotetext{
${ }^{5}$ Manufactured by Power Electronic Measurements (PEM) Ltd.
} 
cables partly run along building exteriors $\left(\sim 50 \mathrm{~m}\right.$ of the $100-\mathrm{m}_{31}$ total). Uncertainties on the absolute horn-current measurement is summarized in Table 5 [9].

Table 5: Uncertainties on the absolute horn-current measurement. In the total error calculation, full width (FW) errors are scaled by $1 / \sqrt{12}$ to estimate $1 \sigma$ uncertainty.

\begin{tabular}{ll}
\hline & Uncertainty \\
\hline Coil calibration & $\pm 1 \%(\mathrm{FW})$ \\
Coil setting & $\pm 1 \%(\mathrm{FW})$ \\
Electronics calibration & $<1 \%$ \\
Monitor stability & $2 \%(\mathrm{FW})$ \\
\hline Total & $1.3 \%$ \\
\hline
\end{tabular}

The uncertainty on the absolute horn-current measurement ${ }^{32}$ is estimated to be $\pm 1.3 \%$, however, this uncertainty contributes ${ }^{326}$ the uncertainty of less than $1 \%$ to the neutrino flux prediction, ${ }^{327}$ which is less than the uncertainties from other sources [9].

\subsection{Magnetic field measurement}

The outer conductors have holes ( 4 for horn- 1 and horn- $3^{33}$ and 9 for horn-2) for some service uses, which are covered by aluminum plates for beam operation. A magnetic field probe can be inserted into the inner volume of the horns through the service holes to measure the magnetic fields inside the horns. The magnetic field probe used is a 3 -axis hall probe6. Its specifications are a linear range of $\pm 2 \mathrm{~T}$, an accuracy of $0.5 \%$, and a bandwidth of $25 \mathrm{kHz}$. A custom-made jig for magnetic field ${ }_{339}$ measurement was produced to insert the field probe into the interior of the device. The field probe is enclosed inside housing attached to the end of a G10 rod. The G10 rod can be moved in a radial direction so that field measurements can be conducted in various positions. A fixture for the $\mathrm{G} 10$ rod is attached to the service ports at the outer conductors.

The magnetic field measurements for all three magnetic horns were performed at a current-testing stand. The measured mag- ${ }_{347}$ netic fields and their discrepancies from the expected value are shown in Figs. 12 and 13 as a function of radial position. $\mathrm{As}_{349}$ measurement errors, the calibration errors $(0.2 \%)$, radial posi- ${ }_{350}$ tion precision $(0.5 \mathrm{~mm})$, intrinsic measurement precision of the field probe $(0.5 \%)$, and current measurement precision $(1 \%)_{35}$ were allocated. Smaller magnetic fields than predicted were measured near the outer conductor inner surface (at $0.18 \mathrm{~m}$ for horn-1, $0.49 \mathrm{~m}$ for horn-2, and $0.65 \mathrm{~m}$ for horn-3). A leakage ${ }_{355}$ of magnetic flux from the holes through which the field probe was inserted caused a reduction in the magnetic field. The expected magnetic fields are in good agreement by taking into account the fringe field correction. These measurements indicate that the measured magnetic field values are consistent with those expected based on the measured current values, within $\mathrm{a}_{36}$ measurement precision of $1-2 \%$.

\footnotetext{
${ }^{6}$ Manufactured by SENIS AG (The Three-Axis Field Transducer $x-H 3 x-{ }^{364}$ xxE3A-25kHz-0.1-2T).
}

\section{Cooling performance}

The technical cooling issues of the $\mathrm{T} 2 \mathrm{~K}$ magnetic horns and the cooling performance are described in this section. The tensile strength of A6061-T6 decreases as the temperature increases, as shown in Fig. 14. It can be seen that the strength drastically decreases above $100^{\circ} \mathrm{C}$. Therefore, the maximum permitted temperature of the $\mathrm{T} 2 \mathrm{~K}$ magnetic horns is set to $80^{\circ} \mathrm{C}$, to prevent conductor strength degradation. Cooling of the $\mathrm{T} 2 \mathrm{~K}$ magnetic horns is conducted using two methods: one is water cooling, used for the inner conductors and vertical frames, and the other is cooling of the striplines using a forced helium flow.

\subsection{Horn-conductor water cooling}

Water cooling of the inner conductors is performed by spraying water from spray nozzles onto the inner conductors. The water nozzles are attached to the outer conductors and face inward, as shown in Fig. 15. Horn-1 and horn-2 have 24 spray nozzles, with six longitudinally spaced nozzles at each of four azimuthal locations, and the nozzles are connected to four manifolds surrounding the outer conductors with bent tubes. This bent shape plays an important role in absorbing vibration from the outer conductors and preventing the tubes from experiencing a mechanical break. The sprayed water is collected into a drain tank located below the outer conductors and pumped upwards by suction pumps. The horn-1 nozzles have a flat spray pattern to match the cylindrical inner conductor, while horn-2 and horn-3 nozzles have a cone spray pattern to disperse the cooling water widely. The water nozzles, made of stainless steel, are insulated from the outer conductors to prevent both a high voltage breakdown and Galvanic corrosion due to contact between different metals (e.g. aluminum and stainless steel). Two seals are used in the nozzle ports to prevent Galvanic corrosion: one is the aluminum knife-edge seal, which is used between the ceramic parts and aluminum conductors, and the other is a Helicoflex seal with a silver jacket, which is used between the ceramic parts and the stainless steel flanges. Insulation is achieved using alumina ceramic parts, and the same scheme is also applied to the water drain ports. Details of the water nozzle ports and water drain ports are shown in Fig. 16 Also, this insulation scheme utilizes bolted joints instead of brazed joints. A brazed joint between ceramic parts and metals is commonly used for the sealing of water plumbing, however, the brazing joint often fails in an environment that is affected by vibration, which causes a water leak. The bolted fixation used here is mechanically strong and can withstand vibration. Another concern regarding the potential loosening of such small bolts then exists, but this can be solved by taking appropriate measures (e.g., welding the bolts to prevent loosening). Since tiny gaps exist between the ceramic insulators and outer conductors, water can be trapped within them, especially at the bottom nozzle flanges, and the trapped water can corrode metal seals. The bottom flanges have auxiliary drain ports connected to the drain tank in order to prevent water from accumulating. Figure 17 shows the auxiliary drain port attached to the bottom nozzle flange in detail. 
For the horn conductor assemblies, several types of water seals are embedded, as shown in Fig. 18, At the upstream part, aluminum gaskets are used between the inner conductor and upstream endplate. At both ends of the ceramic insulator ring, Aluminum knife-edge seals are used for horn-1 and Helicoflex seals with aluminum jackets are used for horn-2 and horn-3. At the downstream end, an aluminum gasket is used for horn-2 and a Helicoflex seal with an aluminum jacket is used for horn3 , however, no seal is embedded in horn-1. This is because the tight fit of the downstream flanges between the inner and outer conductors works well as a water seal. No leak has been observed at the downstream end of horn-1 for four years of beam operation. However, a water leak was observed at the upstream end of this horn, details of which are given in Section 7.4

The cooling performance of the T2K magnetic horns was measured during current testing at the test stand. Temperatures were measured with infrared thermometers at several inner conductor positions in order to evaluate the heat transfer coefficients. Figure 19 shows the measured heat transfer coefficients for horn-1 as a function of the water flow rate. For a nominal water flow rate of $60 \mathrm{~L} / \mathrm{min}$, a heat transfer coefficient of $7.9 \mathrm{~kW} / \mathrm{m}^{2} \cdot \mathrm{K}$ is achieved. The heat transfer coefficients obtained during current testing are summarized in Table 6 . From

Table 6: Summary of measured heat transfer coefficients for horn-1, horn-2, and horn-3 in several water flow conditions and at several positions. The origin of the longitudinal position is the center of the horns.

\begin{tabular}{c|c|c|c}
\hline & $\begin{array}{c}\text { Flow rate } \\
\text { (L/min.) }\end{array}$ & $\begin{array}{c}\text { Longitudinal } \\
\text { position } \\
(\mathrm{cm})\end{array}$ & $\begin{array}{c}\text { Heat transfer } \\
\text { coefficient } \\
\left(\mathrm{kW} / \mathrm{m}^{2} \cdot \mathrm{K}\right)\end{array}$ \\
\hline horn-1 & 40 & 50 & 5.9 \\
& 60 & 50 & 7.9 \\
& 80 & 50 & 8.8 \\
\hline horn-2 & 40 & 20 & 1.0 \\
& 40 & 70 & 0.2 \\
\hline horn-3 & 40 & 10 & 1.3 \\
& 40 & 75 & 0.1 \\
& 50 & 10 & 2.2 \\
& 50 & 75 & 0.2 \\
\hline
\end{tabular}

the measured heat transfer coefficients, the maximum temperature for $750-\mathrm{kW}$ operation is estimated to be 49.0 (horn-1), 50.3 (horn-2), and $29.6^{\circ} \mathrm{C}$ (horn-3), respectively, as summarized in Table 7. The estimated maximum temperatures are much lower

Table 7: Estimation of maximum temperatures at horn-1, horn-2, and horn-3 for $750-\mathrm{kW}$ operation.

\begin{tabular}{lrrr}
\hline & horn-1 & horn-2 & horn-3 \\
\hline Instantaneous temperature rise & $18.0{ }^{\circ} \mathrm{C}$ & $5.9{ }^{\circ} \mathrm{C}$ & $1.8{ }^{\circ} \mathrm{C}$ \\
(beam exposure) & $11.0^{\circ} \mathrm{C}$ & $1.1{ }^{\circ} \mathrm{C}$ & $0.1{ }^{\circ} \mathrm{C}$ \\
(Joule heating) & $7.0^{\circ} \mathrm{C}$ & $4.8{ }^{\circ} \mathrm{C}$ & $1.7{ }^{\circ} \mathrm{C}$ \\
Steady state temperature rise & $6.0^{\circ} \mathrm{C}$ & $19.4{ }^{\circ} \mathrm{C}$ & $2.8{ }^{\circ} \mathrm{C}$ \\
Coolant water temperature & $25.0^{\circ} \mathrm{C}$ & $25.0^{\circ} \mathrm{C}$ & $25.0^{\circ} \mathrm{C}$ \\
\hline Maximum temperature & $49.0^{\circ} \mathrm{C}$ & $50.3{ }^{\circ} \mathrm{C}$ & $29.6{ }^{\circ} \mathrm{C}$ \\
\hline
\end{tabular}

than the allowable maximum temperature of $80^{\circ} \mathrm{C}$. Therefore, a cooling performance appropriate for $750-\mathrm{kW}$ operation was
Figure 11: Typical current waveform for horn-1 (top) and for horn-2 and horn-3 (bottom).

Figure 12: Measured magnetic fields as functions of radial distance from center axis for horn-1 (top), horn-2 (middle), and horn-3 (bottom). The solid lines represent the expected field by taking into account a fringe effect. The dashed lines represent the expected magnetic fields calculated by Equation (1). The curves represent the magnetic fields expected from the operation currents of 320 kA (horn-1), $250 \mathrm{kA}$ (horn-2), $320 \mathrm{kA}$ (horn-3).

Figure 13: The discrepancies between the measured and expected magnetic fields, $\left(B_{\text {meas. }}-B_{\text {exp. }}\right) / B_{\text {exp. }}$, as functions of radial distance from the center axis for horn-1 (top), horn-2 (middle), and horn-3 (bottom). The expected magnetic fields are taken into account the fringe effect.

Figure 14: Temperature dependence of aluminum alloy A6061-T6 tensile strength. Data points are taken from [7].

Figure 15: 3D model of horn-1 showing water nozzles attached to outer conductor (top), and its cross-section (bottom).

Figure 16: Detailed pictures of water nozzle ports (left) and water drain ports (right).

Figure 17: Detailed figure of auxiliary drain port attached to bottom nozzle flange. The coolant-water path is represented by a solid line and the auxiliary drain paths are shown using dashed lines.

Figure 18: Schematic figure of the horn conductor assembly showing several water seals.

Figure 19: Measured heat transfer coefficients for horn-1 as a function of water flow rate. The data points are fitted with a linear function. 
achieved.

Although total heat deposits at the outer conductors are not small as shown in Table 3, heat deposits per unit weight are quite small $\left(0.33 \mathrm{~J} / \mathrm{g}\right.$ (horn-1), $0.08 \mathrm{~J} / \mathrm{g}$ (horn-2), and $0.01 \mathrm{~J} / \mathrm{g}_{450}$ (horn-3) at maximum 7 ). A cooling test was performed to investigate temperature at the horn-1 outer conductor. Heat load, corresponding to $0.33 \mathrm{~J} / \mathrm{g}$ or more, was applied to a part of the horn- 1 outer conductor by heater at test stand, and temperature at several points of the outer conductor was measured. Maximum temperature was measured to be at most $33^{\circ} \mathrm{C}$. Therefore, it is concluded that no forced cooling is needed for the outer conductors 8

The cooling water flow rates of horn-1, horn-2, and horn3 are 60,50 , and $50 \mathrm{~L} / \mathrm{min}$, respectively. Water circulation is achieved as follows: a circulation pump supplies coolant water to each horn and the water is sprayed on the inner conductors; the sprayed water is collected by a drain tank below the outer conductor and then pumped upwards by another suction pump ${ }^{455}$ located 6-8 $\mathrm{m}$ above the drain tank; the pumped water then re- ${ }^{456}$ turns to a surge tank in a machine room. Each horn has its own ${ }^{457}$ suction pump. A schematic diagram of the water circulation ${ }^{458}$ system of the T2K magnetic horns is shown in Fig. 20. The ${ }^{459}$ use of suction pumps to lift the drained water to an $8-\mathrm{m}$ height ${ }^{460}$ and also the use of two independent pumps (a circulation and $a^{461}$ suction pump) for circulation are considerable challenges. The ${ }^{462}$ most important consideration in this system is to balance the ${ }^{463}$ flow rates of the supply and suction water so as to avoid emp- ${ }^{46}$ tying or filling the magnetic horns. This raising of the water ${ }^{46}$ by $8 \mathrm{~m}$ using a suction pump was evaluated with a mockup and ${ }^{466}$ finally tested on the actual horn configuration, which was sus- ${ }^{467}$ pended by the support modules at the test stand. It was found ${ }^{468}$ that, provided the flow rate of the return water is first adjusted, ${ }^{469}$ the flow rate is then automatically balanced in such a way that ${ }^{470}$ it is reduced by air bubble contamination if too much water is ${ }^{471}$ pumped upwards and the drain tank is then emptied. All of ${ }^{472}$ the tests were successfully completed and this scheme was then ${ }^{473}$ adopted as the circulation system. Thereafter, no problems re- ${ }^{474}$ lated to coolant water circulation have occurred during several ${ }^{475}$ years of operation of this system.

\subsection{Vertical frame water-cooling}

Since four vertical support frames are located adjacent to ${ }^{479}$ the outer conductor, the frames have non-negligible heat de-- 480 posits. The heat deposits at the frames are estimated to be $\mathrm{at}^{481}$ most 0.15 (horn-1), 0.07 (horn-2), and $0.01 \mathrm{~W} / \mathrm{g}$ (horn-3). For ${ }^{482}$ cooling of the frames, four rectangular stainless steel pipes are ${ }^{483}$ attached to the inner corners of each frame and are clamped $\mathrm{at}^{484}$ $10-\mathrm{cm}$ intervals. This yields good contact pressure, as shown ${ }^{485}$ in Fig. 21 A mockup test for cooling of the vertical frame ${ }^{486}$ resulted in a heat transfer coefficient of at least $1.1 \mathrm{~kW} / \mathrm{m}^{2} \cdot \mathrm{K},{ }^{487}$ which is larger than the value required for $750-\mathrm{kW}$ operation by ${ }^{488}$ a factor of 3.8 .

\footnotetext{
${ }^{7}$ Instantaneous temperature rise is also as small as $0.35^{\circ} \mathrm{C}$ (horn- 1 ), $0.08^{\circ} \mathrm{C}^{491}$ (horn-2), and $0.01^{\circ} \mathrm{C}$ (horn-3).

${ }^{8}$ Actually, coolant water sprayed to the inner conductor runs at the bottom of the outer conductor and flows into the drain tank. This water stream can work to cool the bottom part of the outer conductor.
}

\subsection{Stripline cooling by helium}

Non-negligible heat deposits occur at the striplines, mostly due to defocused negatively charged pions. Many negative pions defocused by horn-1 pass through horn- 2 striplines and hit the walls of the HV beside horn-2. The horn- 2 striplines have the largest heat deposits among the three horns. In addition, Joule heating also contributes to the total heat deposits at the striplines. The maximum heat fluxes per stripline layer at striplines are summarized in Table 8 , and occur at the striplines

Table 8: Summary of heat fluxes per stripline layer at striplines near horn conductors.

\begin{tabular}{lrrr}
\hline & horn-1 & horn-2 & horn-3 \\
\hline Beam $\left(\mathrm{J} / \mathrm{m}^{2}\right)$ & 140.5 & 895.0 & 106.0 \\
Joule heating $\left(\mathrm{J} / \mathrm{m}^{2}\right)$ & 96.0 & 47.7 & 32.5 \\
\hline Total $\left(\mathrm{J} / \mathrm{m}^{2}\right)$ & 236.5 & 942.7 & 138.5 \\
\hline
\end{tabular}

near the horn conductors. Cooling of the striplines is performed using a forced helium flow. The striplines inside the HV, especially those around the magnetic horns and support modules, are enclosed within aluminum ducts through which helium gas flows. Figure 22 shows a cross section of stripline surrounded by a duct. The heat transfer coefficient calculated according to the fluid dynamics formula is shown as a function of helium velocity in Fig. 23 At 750-kW operation, the heat flux for horn-2 is estimated to be $942.7 \mathrm{~J} / \mathrm{m}^{2}$. Coolant helium temperature at the inlet of the ducts is $18^{\circ} \mathrm{C}$, and the helium temperature is increased by $11.6^{\circ} \mathrm{C}$ due to Joule heating when the helium flows throughout ducts. When the coolant helium at $30^{\circ} \mathrm{C}$ reaches the striplines near the horn conductors, the heat transfer coefficient for horn- 2 is required to be over $9.0 \mathrm{~W} / \mathrm{m}^{2} \cdot \mathrm{K}$ in order to maintain a maximum stripline temperature of below $80^{\circ} \mathrm{C}$. A velocity of $2.2 \mathrm{~m} / \mathrm{s}$ is required to achieve the above heat transfer coefficient.

Before installation of the magnetic horns into the HV, an air flow test was performed using the full stripline ducts from the support modules to the horns. Since the ducts around the remote stripline clamp system could not be tightly connected, because the structure around the stripline remote connection was very complicated (as shown in Fig. 24), a significant amount of air exited the duct connection gaps (more than $60 \%$ ). Hence, the expected flow rate was not achieved at the duct exits. Although the expected stripline cooling performance was not achieved, no modification of the duct connection was made, because the necessary design modification was not completed by the date of installation.

After installation into the $\mathrm{HV}$, an in-situ helium flow measurement was performed. The measured flow rates at the inlet of the HV were 17.0 (horn-1), 15.6 (horn-2), and $16.0 \mathrm{~m}^{3} / \mathrm{min}$ (horn-3), which corresponded to exit velocities of 1.10 (horn-1), 1.07 (horn-2), and $0.73 \mathrm{~m} / \mathrm{s}$ (horn-3), respectively. However, the actual helium flow rate at the exit could not be estimated correctly because of the helium leak at the stripline remote connection. Therefore, the actual heat transfer coefficient is estimated to be $2.69 \mathrm{~W} / \mathrm{m}^{2} \cdot \mathrm{K}$. This must be improved by a factor of 3 in the future, and several modifications to the next magnetic 
horn production design are necessary. The duct shapes, espe-550 cially the duct cross sections, should be optimized to achieve 551 an even helium velocity distribution inside the ducts. Another important modification is a leak-tight duct connection in the re-- ${ }^{52}$ mote stripline clamp system.

\subsection{Production of radioactivity, hydrogen, and nitrogen oxide ${ }^{554}$}

Since secondary particles are also exposed to the cooling ${ }_{556}$ water, many kinds of radioactive nuclei are produced in it [10].557 Dominant contributors to radioactivity in the coolant water are ${ }_{558}$ ${ }^{7} \mathrm{Be}$ and ${ }^{3} \mathrm{H}$ (Tritium or $\mathrm{T}$ ), which have half-lives of $53.3 \mathrm{~d}$ and $12.3 \mathrm{y}$, respectively. The production rates of ${ }^{7} \mathrm{Be}$ and ${ }^{3} \mathrm{H}$ are estimated to be 300 and $150 \mathrm{GBq}$, respectively, for 1 year of ${ }^{559}$ operation at $750 \mathrm{~kW}$, which is equivalent to $1.56 \times 10^{21}$ pro- $_{560}$ tons on target (POT). Since ${ }^{7}$ Be exists as cations in the water, it ${ }_{561}$ can be removed using an ion exchanger. First, radioactive water is circulated through the ion exchanger and also the horns. ${ }_{563}$ It is found that $1 \%$ of the ${ }^{7} \mathrm{Be}$ cannot be removed by ion exchangers because the majority of the remaining ${ }^{7} \mathrm{Be}$ cations are ${ }_{565}^{564}$ absorbed by metal-oxide colloids and are electrically neutral. In the first stage, the reduction efficiency is measured as $99 \%$ [11]. In order to further remove ${ }^{7} \mathrm{Be}$, another water tank (called ${ }_{568}^{567}$ a buffer tank) was constructed for radioactivity reduction, after ${ }_{569}$ beam operation for physics data-taking began in 2010. In this system, after the first ion-exchange operation, the radioactive water is moved to the buffer tank and sulfuric acids are added, so that the metal-oxide colloids with ${ }^{7} \mathrm{Be}$ cations are degraded under strong acidity conditions. Then, the water is circulated ${ }_{574}^{573}$ through the ion exchanger so that the remaining ${ }^{7} \mathrm{Be}$ cations are removed. A total reduction efficiency of $99.9 \%$ is achieved $_{576}^{575}$ by two stages of ion-exchange operation. For drainage of the processed water, sodium hydroxides are added to neutralize the water. Details of the dual-stage ${ }^{7} \mathrm{Be}$ reduction system are given in [12]. On the other hand, ${ }^{3} \mathrm{H}(\mathrm{T})$ exists as molecules of HTO in the water, therefore, it is not removed by an ion exchanger; instead, it is simply diluted below the regulation level and disposed of, so as to reduce the amount of tritiated water in the water circulation system. Additional information on the obser- ${ }^{582}$ vation and estimation of radioactivity in the horn cooling water ${ }^{583}$ is given in [11].

The beam exposure to the coolant water also creates hydro- ${ }^{585}$ gen gas through water radiolysis. Its production rate is approxi- ${ }^{586}$ mately $40 \mathrm{~L} / \mathrm{d}$ at $750-\mathrm{kW}$ operation and it is primarily produced at horn-1. The inner volumes of the magnetic horns and cover gas region in the surge tank are filled with helium gas at 1 atm., and both regions are connected by the single-path plumbing for each horn, as shown in Fig. 20, The total volume of the helium gas region is approximately $5.5 \mathrm{~m}^{3}$. The produced hydrogen gas is removed by a hydrogen recombination catalyst that is adapted to the water circulation system in order to prevent a hydrogen gas explosion. This system was adopted after beam operation for physics data-taking was initiated, and is being improved to achieve superior removal. Details of the hydrogen reduction are given below, in Section 7

Beam exposure to nitrogen in the air produces nitrogen oxide. Once these particles are dissolved in the coolant water, ${ }_{588}^{58}$ nitric acids are produced and the water is acidized [13], following

$$
2 \mathrm{NO}_{2}+2 \mathrm{H}_{2} \mathrm{O} \rightarrow 2 \mathrm{HNO}_{3}+\mathrm{H}_{2}
$$

For aluminum, such acidic conditions are very dangerous, because aluminum corrosion proceeds dramatically in strongly acidic conditions (e.g. $\mathrm{pH}<4$ ) [7]. The helium environment inside the magnetic horns significantly reduces the production of nitrogen oxides. The aluminum corrosion occurring during beam operation will be described below, in Section 7

\section{Mechanical properties}

The mechanical properties of the $\mathrm{T} 2 \mathrm{~K}$ magnetic horns are described in this section. The horn conductors experience both a Lorentz force and a thermal shock due to beam exposure. Design optimization was performed based on stress analyses conducted using the finite element method (FEM).

The tensile strength of A6061-T6 is $310 \mathrm{MPa}$ and the yield strength is $275 \mathrm{MPa}$. The $\mathrm{T} 2 \mathrm{~K}$ magnetic horns are expected to be used for over five years and the accumulated number of pulses during the five-year operation is designed to be $10^{8}$ or more. Fatigue due to repetitive forces must be considered in the mechanical design of magnetic horns. The fatigue strength of A6061-T6 after $5 \times 10^{8}$ cycle of the repetitive forces is $95 \mathrm{MPa}$ [7]. The magnetic horns are water-cooled, thus, the inner surfaces of the inner and outer conductors make contact with the coolant water. The aluminum strength is reduced by constant exposure to water. An empirical factor of 0.43 was used to reduce the fatigue strength of the wet aluminum in the horns, and the allowable stress was further reduced in order to $25 \mathrm{MPa}$ to increase the confidence level for fatigue failure from $50 \%$ to $97.5 \%$, and to account for the effect of the fatigue stress ratio.

\subsection{Stress analyses}

Design optimization was first performed using static stress analyses and confirmations were made based on dynamic stress analyses. For a thermal stress analysis, energy deposits in the conductors are calculated using the MARS [14] simulation code. For analysis of the stress due to the Lorentz force, the pressure on the inner conductors is calculated from

$$
\begin{aligned}
i(r) & =\frac{I}{\pi\left(r_{2}^{2}-r_{1}^{2}\right)}, \\
B(r) & =\frac{\mu_{0}}{2 \pi} \frac{I}{r_{2}^{2}-r_{1}^{2}} \frac{r^{2}-r_{1}^{2}}{r}, \\
p & =\frac{1}{2 \pi r_{2}} \int_{0}^{2 \pi} \int_{r_{1}}^{r_{2}} i(r) \times B(r) d r(r d \phi) \\
& =\frac{1}{r_{2}} \int_{r_{1}}^{r_{2}} \frac{\mu_{0}}{2 \pi} \frac{I^{2}}{\pi\left(r_{2}^{2}-r_{1}^{2}\right)^{2}} \frac{r^{2}-r_{1}^{2}}{r} r d r \\
& =\frac{\mu_{0}}{2 \pi} I^{2} \frac{1}{3 \pi} \frac{r_{2}+2 r_{1}}{r_{2}\left(r_{2}+r_{1}\right)^{2}},
\end{aligned}
$$

where $r$ is the radial position, $r_{1}$ and $r_{2}$ are the inner and outer radii of the inner conductors, respectively, $i(r)$ and $B(r)$ are the 
current density and magnetic field inside the inner conductors at $r$, respectively, and $p$ is the pressure on the inner conductors. For $I=320 \mathrm{kA}$, Equation (5) gives a simple approximation formula

$$
p \approx \frac{1690}{r_{2}[\mathrm{~mm}]^{2}}[\mathrm{MPa}],
$$

where $t \equiv r_{2}-r_{1}=3 \mathrm{~mm}$. In later stress analyses for Lorentz forces, Equation (6) is used to calculate the pressures on the conductors.

The static stress analyses for the Lorentz forces were performed using the ANSYS [15] simulation code. Figures 25]27] show the results of the static stress analyses for horn-1, horn-2, and horn-3, respectively. The values for the Von Mises equivalent stresses obtained from the static stress analyses are summarized in Table 9, along with the maximum pressures calculated

Table 9: Summary of maximum Von Mises equivalent stress from static stress analyses considering Lorentz force.

\begin{tabular}{cccc}
\hline & horn-1 & horn-2 & horn-3 \\
\hline Maximum pressure (MPa) & 1.88 & 0.91 & 0.32 \\
Maximum stress (MPa) & 19.2 & 24.4 & 19.5 \\
Maximum displacement (mm) & 0.06 & 0.16 & 0.25 \\
Position at maximum stress & cylinder & neck & neck \\
\hline
\end{tabular}

from Equation (6). For horn-1, the maximum stress of 19.2 $\mathrm{MPa}$ arises at the straight cylindrical section. For both horn-2 and horn-3, the maximum stress of 24.49 and $19.5 \mathrm{MPa}$ arise at the "neck" section, where their diameters are at a minimum.

Dynamic stress analyses were performed for horn-1 and horn-3 by Hitachi Engineering Co., Ltd 10 The dynamic analyses take into account both thermal stresses due to beam exposure and Joule heating and stresses due to the Lorentz force. For horn-1, the dynamic stress analyses were performed with old conductor shapes only, which were not optimized, and the value of the Von Mises equivalent stress was slightly larger than $25 \mathrm{MPa}$, which is consistent with the static analysis result when the same conductor shape is used. The results of the dynamic stress analyses are shown in Figs. 28 and 29 and summarized in Table 10 Thermal stress is expressed as following;

$$
\sigma_{t h}=E \alpha \Delta T,
$$

where $\sigma_{t h}$ is thermal stress, $E$ is Young's modulus, $\alpha$ is linear expansion coefficient, and $\Delta T$ is instantaneous temperature rise. Equation (7) gives approximately $34 \mathrm{MPa}$ for $\Delta T=21^{\circ} \mathrm{C}$. From the dynamic thermal analysis of horn-1, instantaneous temperature rise of $\Delta T=21^{\circ} \mathrm{C}$ results in thermal stress of $30 \mathrm{MPa}$, which is consistent with the above calculation. Although beam energy of $50 \mathrm{GeV}$ and pulse width of $0.4 \mathrm{~ms}$ in this analysis are different from the actual condition $(30 \mathrm{GeV}$ and $2.4 \mathrm{~ms})$, the

\footnotetext{
${ }^{9}$ For the horn-2 inner conductor, the conductor shape was slightly modified in the manufacturing design. After horn-2 production, stress analysis was performed based on the actual manufacturing drawing, and it was found that the maximum stress reached $30 \mathrm{MPa}$.

${ }^{10}$ The company name has now been changed to Hitachi Power Solutions Co.,
}

Figure 20: Schematic diagram of water circulation system of T2K magnetic horns. The temperatures in this diagram are design values.

Figure 21: Cross-section of vertical frame with cooling channels.

Figure 22: Cross sections of striplines covered by ducts. The duct fixtures are attached to some of the clamps.

Figure 23: Estimated heat transfer coefficients as a function of helium velocity. The velocity of $1.2 \mathrm{~m} / \mathrm{s}$ is the critical velocity from laminar to turbulent flow. The heat transfer coefficient is constant in a laminar flow and, in a turbulent flow, it is calculated using Gnielinski's formula. A dashed horizontal line shows the required heat transfer coefficient for $750-\mathrm{kW}$ operation.

Figure 24: Helium flow around remote stripline clamp system.

Figure 25: Simulation results of static stress analysis showing Von Mises equivalent stresses due to Lorentz force for horn-1.

Figure 26: Simulation results of static stress analysis showing Von Mises equivalent stresses due to Lorentz force for horn-2.

Figure 27: Simulation results of static stress analysis showing Von Mises equivalent stresses due to Lorentz force for horn-3.

Figure 28: Results of dynamic stress analyses for horn-1. Top figure: Von Mises equivalent stress at horn-1 conductors immediately after beam exposure. Bottom figures: principal stress perpendicular to longitudinal direction around cylindrical part immediately after beam exposure (left) and time variation of principal stress at a point on the cylindrical part, in units of $\mathrm{MPa}$ (vertical) and ms (horizontal), respectively (right).

Figure 29: Results from dynamic stress analyses for horn-3. Top figure: Von Mises equivalent stress for full horn-3 conductors. Middle figures: Magnification of top figure around neck part (left) and time variation of Von Mises equivalent stress around neck part in units of MPa (vertical) and ms (horizontal), respectively. Bottom figures: displacement in longitudinal direction around downstream endplate (left) and time variation of displacement around endplate in units of $\mathrm{mm}$ (vertical) and $\mathrm{ms}$ (horizontal), respectively. 
Table 10: Summary of dynamic stress analyses for horn-1 and horn-3. The ${ }^{649}$ stresses shown in this table are Von Mises equivalent stresses.

\begin{tabular}{lrr}
\hline & horn-1 & horn-3 \\
\hline Time duration (ms) & 0.5 & 5.0 \\
Time step (ms) & 0.001 & 0.01 \\
Peak current (kA) & 320 & 320 \\
Pulse width (ms) & 0.4 & 2.0 \\
Time at beam exposure (ms) & 0.2 & 1.0 \\
Beam kinetic energy (GeV) & 50 & 50 \\
Maximum stress (MPa) & 30.0 & 18.3 \\
Position at maximum & cylinder & neck \\
Time at maximum (ms) & 0.208 & 1.00 \\
\hline
\end{tabular}

smaller total temperature rise (approximately $18^{\circ} \mathrm{C}$ ) would give smaller thermal stress. Therefore, the maximum stress in the ${ }_{663}$ actual condition should not be so different from the result of the ${ }_{664}$ above dynamic analysis.

\subsection{Vibration measurements}

Vibrations at the horn conductors during pulsed current op-668 erations were measured during current testing before installa-669 tion. The vibration measurements were performed with laser670 displacement meters made by Keyence Cooperation, and the 671 operation currents for the vibration measurements were 320672 (horn-1), 250 (horn-2), and $266 \mathrm{kA}$ (horn-3). The vibrations673 at several inner-conductor positions, for example, the upstream674 endplates, conductor centers, downstream endplates, and so on,675 were measured, and the measured displacements are summa-676 rized in Table 11. Figure 30 shows the time variations of the

677

Table 11: Summary of vibration measurements. The expected value for horn2 (horn-3) at 250-kA (266-kA) operation was obtained by scaling against the 678 current value. No measurement was conducted for the center of horn-1 since $_{679}$ the laser can not reach inside the cylinder. Larger measurement errors for horn2 and horn- 3 are due to small signal sizes $(10-20 \mathrm{mV})$ compared with electrical ${ }^{68}$ noise $(\sim 5 \mathrm{mV})$

\begin{tabular}{|c|c|c|c|}
\hline & horn-1 & horn-2 & horn-3 \\
\hline Laser displacement meter & LK-G400 & LK-80 & LK-80 \\
\hline Measurement range $(\mathrm{mm})$ & $400 \pm 100$ & $80 \pm 15$ & $80 \pm 15$ \\
\hline Intrinsic precision $(\mu \mathrm{m})$ & \pm 2 & \pm 3 & \pm 3 \\
\hline Sampling rate $(\mathrm{kHz})$ & 50 & 1 & 1 \\
\hline Operation current $(\mathrm{kA})$ & 320 & 250 & 266 \\
\hline Upstream: meas. $(\mu \mathrm{m})$ & $35 \pm 2$ & $33 \pm 18$ & $21 \pm 18$ \\
\hline Upstream: exp. $(\mu \mathrm{m})$ & 45 & 31 & 69 \\
\hline Middle: meas. $(\mu \mathrm{m})$ & - & $54 \pm 18$ & $28 \pm 18$ \\
\hline Middle: exp. $(\mu \mathrm{m})$ & - & 60 & 58 \\
\hline Downstream: meas. $(\mu \mathrm{m})$ & $12 \pm 2$ & $440 \pm 18$ & $180 \pm 18$ \\
\hline Downstream: exp. $(\mu \mathrm{m})$ & 50 & 427 & 166 \\
\hline
\end{tabular}

of the inner conductors, especially for horn-2, a very large displacement was observed, as expected from the simulation. Ribs will be added to the upstream and downstream endplates in the next version of horn-2 in order to reduce the large displacement.

\subsection{Manufacturing of conductors}

Since the inner conductors are very thin in spite of their large dimensions, the manufacturing process of these components is very important, as the designed conductor shapes must be achieved. A brief description of the conductor manufacturing process is given in this subsection.

Each of the horn-1 inner and outer conductors was machined from a forged A6061-T6 block. The horn-2 inner conductor was made from three components: a central neck section and upstream and downstream taper and endplate sections. Each section was machined from a forged A6061-T6 block and welded by friction stir welding (FSW). The horn-3 inner conductor was composed of five pieces: a central neck section, upstream and downstream taper sections, and upstream and downstream endplate sections. The taper sections were made from rolled A6061-T6 plate, while each of the other sections was machined from a forged A6061-T6 block. All the sections were welded with TIG welding. For both horn-2 and horn-3 inner conductors, the welding positions were chosen so that the mechanical stresses at the positions were small. The horn-2 and horn-3 outer conductors were made from rolled A6061-T6 plates and assembled with TIG welding. All the manufacturing of the conductors was successful and the full magnetic horn assemblies were completed in 2008.

\section{Remote maintenance issues}

Details of the remote connection system used for the T2K magnetic horns are given in this section.

Irradiated magnetic horns or other instruments inside the $\mathrm{HV}$ can be removed from the vessel using a numerically-controlled overhead crane in the Target Station (TS), as shown in Fig. 31. In the TS building, there is an area where radiated instruments can be handled (maintenance area). The maintenance area has two sections; one is a human-access space, with an area of $4 \times 1.5 \mathrm{~m}^{2}$, and another is a $4 \times 4-\mathrm{m}^{2}$ space, where radioactive equipment are set. The two sections are separated by a 1-m-thick concrete wall, while a lead glass window located in the wall gives clear views of the radioactive equipment from the human-access area. Two manipulators are fabricated in the maintenance area and used for the handling of radioactive materials, other than the horn 11 .

If one of the magnetic horns is found to be defective, it is moved to the maintenance area. Then, the horn itself is disconnected from its support module and stored in a storage area located inside the TS. Thereafter, a new horn is set up in the maintenance area and connected to the support module. The

\footnotetext{
${ }^{11}$ Remote handling of the horns is not performed using the manipulators but by manual operation from the top of the maintenance area.
} 
support modules can be reused even if the horns are broken.749 After connection, the new horn is moved to the HV.

The support modules, as shown in Figs. 8 and 32, have a751 box-shaped structure. Both the upstream and downstream walls 752 are made of 75-mm-thick steel plates and while the side walls $\mathrm{s}_{73}$ are 9 -mm-thick steel plates. The thick steel plates have several 754 through-holes with diameters of 50-65 mm. For the connection 755 of the horns and their support modules, two guide pins define a 756 relative position between the horns and support modules. A re-757 producibility of $0.3 \mathrm{~mm}$ for the relative position can be achieved $\mathrm{d}_{758}$ by the guide pins. Once the horns are aligned to the support 759 modules, they are connected with bolted joints. Four 4-m-long $g_{760}$ stainless rods with M30 threads at the bottom end penetrate the ${ }_{761}$ through-holes, and the four M30 brace nuts at the top frame 762 of the horns can be tightened by turning the rods. Water and ${ }_{763}$ gas plumbing components also penetrate the through-holes and $\mathrm{d}_{764}$ are connected to the horn plumbing via Swagelok connectors.765 The penetrating plumbing has a double-tube structure, the in-766 ner tubes of which function as water and gas plumbing and the $\mathrm{T}_{767}$ outer tubes of which, with a hex-socket shape at the bottom, are 768 used to turn the female nuts of the Swagelok connectors. Be-769 cause of this double tube structure, the Swagelok connectors at 770 the bottom of the support modules can be loosened and tight-771 ened from the top of the support modules. Thermocouple wires 772 are drawn with two guide tubes penetrating the through-holes773 and connected to the horn thermocouples via ceramic thermo-774 couple connectors. Alignment of the thermocouple connectors 775 is achieved using guide pins and guide holes. Figures 33 and $347_{76}$ show these connections in detail.

The striplines are also detachable at the bottom of the sup-778 port modules. Figure 35 shows the remote stripline clamp sys-779 tem located at the bottom frames of the support modules 12 . The 780 mechanism of this system is similar to a car jack, in that the ${ }_{781}$ rotation of a threaded rod changes torque to a horizontal force. 782 The remote clamp can load 15 tons of clamping force, equiva-783 lent to $5 \mathrm{MPa}$ pressure, onto the stripline joints. By rotating the $\mathrm{e}_{784}$ threaded rod with 4-m-long rod, with a box socket at the end 785 on top of the support module, the stripline clamping force is ${ }_{786}$ released, which allows remote disconnection of the striplines. 787

During connection and disconnection work at the mainte-788 nance area, a concrete shielding block is inserted inside the ${ }_{789}$ support module to provide radiation protection. Workers can ${ }_{790}$ stand on the concrete block, where the radiation level is a few tens of $\mu \mathrm{Sv} / \mathrm{h}$ or less.

\section{Operation experiences}

Operational experience involving use of the $\mathrm{T} 2 \mathrm{~K}$ magnetic ${ }_{795}$ horn system is described in this section.

\subsection{Development period}

Development of the $\mathrm{T} 2 \mathrm{~K}$ magnetic horn system began in ${ }_{79}$ 2003, when design optimization of the horn conductor shapes and several component tests were performed [6].

\footnotetext{
${ }^{12}$ The remote stripline clamp system of the NuMI magnetic horns at FNAL [16] is used as a reference for this system by courtesy of NuMI beamline group.
}

The first production of the prototype magnetic horn (horn-1) was completed in March 2006 and the first pulsing of the prototype horn-1 at 320-kA was achieved in June 2006. Various performance tests such as a field measurement, cooling test, and vibration test were performed on the prototype. A long-term operation test (three months) was conducted in 2007 and 0.85 million pulses were successfully applied to the prototype horn1. During the long-term operation test, loosening of small bolts at the water nozzle flanges occurred at approximately 0.5 million pulses. After measures were taken to prevent this, no further bolts were loosened. Cracks in the ceramic insulator disks used for stripline fixation were also found during the long-term test. Alumina ceramic disks with $96 \%$ purity were used for the test stand and were replaced with alumina ceramic disks with higher purity (over 99.5\%), which have slightly higher flexural strength (380 MPa for $>99.5 \%$ and $350 \mathrm{MPa}$ for $96 \%$ [17]). The other modification was to improve the conditions of contact between the ceramic disks and fixation parts. Both of the modifications were effective in preventing cracking of the ceramic disks and, thereafter, no cracks were found. Prototype horn-3 was produced in March 2007. Then, a pulsing test was established with a series configuration of horn- 1 and horn-3 in order to evaluate the series operation of dual magnetic horns. Performance tests for horn-3 were also successfully completed. A long-term test with dual horn operation was also performed and 0.45 million pulses were successfully applied to both prototype horns. No bolt loosening occurred during the long-term test.

In the final stage of the development period, from October 2007 to May 2008, a mockup test was conducted for a full configuration of prototype horn-3 suspended by its support module. A 10-meter-high large test stand was constructed for this purpose. Using the mockup, a water-circulation test to confirm 8-m-high pumping of the drain water, validation of the remote connection system, development of the magnetic horn handling system, and current testing with a full configuration, were performed. During the current testing, vibrations were measured at various positions on the horn. Even when supported from an 8-m height, similar to a pendulum, the measured oscillation of the entire horn was, at most, $5 \mu \mathrm{m}$, which is acceptable.

Performance tests for horn-2 were performed with a production version in 2008 and adequate performance was confirmed.

\subsection{Installation}

The production version of the $\mathrm{T} 2 \mathrm{~K}$ magnetic horns was completed in 200813. Horn-1 and horn-3 were produced in Japan, while horn-2 was manufactured in the U.S. and then shipped to Japan. Pictures of the production version of the T2K magnetic horns can be seen in Fig. 36

The installation work began in August 2008. All the infrastructure used for the current testing in KEK was transported to J-PARC and set up in the TS building. The horns and support

\footnotetext{
${ }^{13}$ With collaboration between KEK and T2K colleagues in the United States (the main efforts were made by a group at The University of Colorado at Boulder)
} 
modules were assembled and aligned at the test stand placed on the ground floor of the TS. Then, current testing was performed with the horns connected to the support modules at the test stand. Horn-1 was installed in the HV in January 2009. After water connection, stripline connection, and cabling work between the power supply and transformer, the first in-situ operation of horn-1 was successfully conducted in April 2009. The first beam commissioning with horn-1 only was achieved on April 23rd, 2009 and the first neutrino beam was produced at the neutrino beamline of J-PARC. After beam commissioning, installation of horn-2 and horn-3 was accomplished by August 2009. The striplines, with the series configuration used for the prototype testings, were transported to the TS and used as striplines for series operation of horn-2 and horn-3. After setup, in-situ current testing and also field measurements were performed on both horns. The full installation of the T2K magnetic horn system was completed in October 2009. Then, evacuation of the HV was performed and the device was filled with helium gas. The T2K magnetic horns were operated in a helium atmosphere for the first time in November 2009. However, a ground fault problem occurred during the current operation. After several investigations conducted over two weeks, it was found that the voltage-to-ground at the secondary circuit of the transformers reached $3 \mathrm{kV}$ and, therefore, a breakdown occurred. By adding a neutral grounding scheme to the secondary circuit, the voltages were reduced dramatically to several hundred volts, as described in Section 3. Thereafter, no further ground fault problems occurred.

\subsection{Beam-operation experience}

\subsubsection{Beam-operation conditions}

The T2K experiment began its physics data-taking in January 2010. For the physics data-taking operation, the magnetic horns were operated at $250 \mathrm{kA}$. The beam power at the beginning of the $\mathrm{T} 2 \mathrm{~K}$ experiment was $20 \mathrm{~kW}$, which was gradually increased up to $240 \mathrm{~kW}$ as of May 2013. The integrated number of delivered protons on target (POT) during the physics data-taking run is shown in Fig. 37. The beam conditions for each run period are summarized in Table 12 The accelerator operation cycle was gradually shortened from 3.52 (Run1) to $2.48 \mathrm{~s}$ (Run4).

\subsubsection{Stability of horn operation current}

The stability of the operation current for each horn during each run period is shown in Fig. 38. Although the measured current values for each horn varied by $2 \%$ during each run period, mainly because of variation in the power cable resistance due to the external temperature, very stable operation of the T2K magnetic horns was achieved and the observed operation current satisfied the requirement for physics analysis at $250 \pm$ $5 \mathrm{kA}$. By the end of Run4, the first set of T2K magnetic horns was operated over $1.2 \times 10^{7}$ pulses. No significant damage was observed at the magnetic horn conductors.

\footnotetext{
${ }^{14}$ The expected neutrino flux at the Super-Kamiokande detector at $250-\mathrm{kA}$ decreases by $10 \%$ compared to that at $320-\mathrm{kA}$.
}

Figure 30: Time variations of measured displacements at downstream parts of inner conductors for horn-1 (top), horn-2 (middle), and horn-3 (bottom). The operation currents for these measurements are 320 (horn-1), 250 (horn-2), and $266 \mathrm{kA}$ (horn-3).

Figure 31: Picture of horn-3, which was moved to the maintenance area using a remote horn-handling machine (left). The picture shows the remote hornhandling machine and its guide frames attached on the top of the HV.

Figure 32: Horn-3 attached to its support modules: front view (left) and side view (right).

Figure 33: Detailed schematic of remote connections.

Figure 34: Pictures of remote connections for horn and water pipes (top left), guide system (top right), and thermocouples (bottom).

Figure 35: Detailed drawing of remote stripline clamp system.

Figure 36: Pictures of T2K magnetic horns: horn-1 side view (top left), horn-1 upstream end view (top right), horn-2 side view (middle left), horn-2 upstream end view (middle right), horn-3 downstream end view (bottom left), and horn-3 upstream end view (bottom right).

Figure 37: History of integrated number of delivered POT (solid line) and beam power (dot).

Figure 38: Current stability for each horn during T2K run periods. In the early stage of Run3, the horns were operated at $200 \mathrm{kA}$ because of a power supply problem. 
Table 12: Summary of beam conditions for each T2K run period. Beam width ${ }^{88}$ shown in this table is the one in the position at the entrance of collimator located ${ }^{888}$ upstream of horn-1.

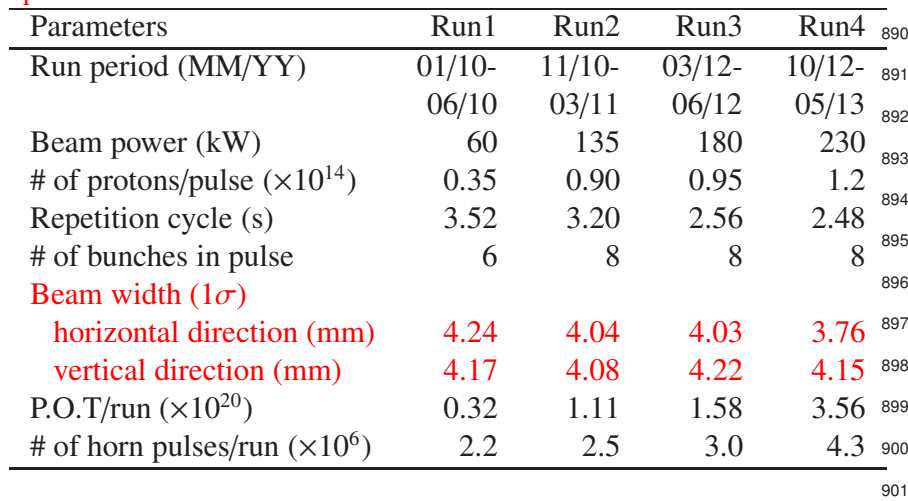

\subsubsection{Activation of cooling water}

The beam powers as of Run4 were still much lower than904 the design beam power of $750 \mathrm{~kW}$, while the heat depositions905 at the magnetic horns were significantly lower. However, the 906 number of delivered protons per pulse was significantly higher 907 than that of the other proton beam facilities in the world 15 and,908 thus, many problems related to the high-intensity proton beams909 were experienced during the $\mathrm{T} 2 \mathrm{~K}$ run periods. As the beam 910 power gradually increased, many problems related to the water ${ }_{11}$ circulation system were observed. The ion exchangers were not912 operated continuously during beam operation until the middle 913 of Run 4 and, thus, radioactive ${ }^{7} \mathrm{Be}$ ions were gradually accu-914 mulated. As a result, a residual radiation level around the water 915 tank of $\sim 300 \mu \mathrm{Sv} / \mathrm{h}$ (maximum) was observed at $150-\mathrm{kW}$ beam916 operation in Run3. This radiation level caused many difficul-917 ties during maintenance work and many routine maintenance 918 tasks such as a helium gas flushing, operation of the ion ex-919 changers, and water drainage and supply were automated and $\mathbf{9}_{20}$ remotely performed by modifying the water circulation system.921 As a result of the automation and remote operation, access t0922 the water circulation units in the underground machine room923 (where access is prohibited during beam operation) is no longer924 necessary. This has resulted in less downtime for maintenance 925 and a lower radiation dose during maintenance work. Since the 926 middle of Run4, ion exchangers have been continuously oper-927 ated during beam operation, as will be described below. As a928 result, the radiation level of the circulated water has been signif-929 icantly reduced to the level of a few $\mu \mathrm{Sv} / \mathrm{h}$, even with $220-\mathrm{kW}_{930}$ continuous operation. However, the ion exchangers were highly9з1 activated. Therefore, the ion exchangers were shielded with $10_{932}$ cm-thick iron plates.

\subsubsection{Hydrogen production problem}

As described in Section 4 hydrogen gas is produced inside the magnetic horns by water radiolysis, with an expected pro-936 duction rate of $40 \mathrm{~L} / \mathrm{d}$ for $750-\mathrm{kW}$ operation. Hydrogen gas can 937 combust explosively under a hydrogen density of between $4 \% 938$

${ }^{15} 1.2 \times 10^{14}$ protons/pulse is the world record for the number of extracted protons per pulse for proton synchrotrons.

and $75 \%$ in an air environment. Since the hydrogen explosion limit in a helium atmosphere contaminated with oxygen is unknown, the hydrogen density inside the magnetic horns should be reduced to less than $2 \%$ in the interests of safety.

In the early days of $\mathrm{T} 2 \mathrm{~K}$ beam operation, with a beam power of less than $50 \mathrm{~kW}$, helium gas flushing in the water tank was performed once during every half-day beam stop for maintenance (roughly once a week), so as to reduce the hydrogen gas in the helium atmosphere. For operation at a higher beam power, a hydrogen recombination system was introduced. A helium circulation loop through a hydrogen recombination catalyst (alumina pellets with $0.5 \% \mathrm{Pd}$ ) was attached to the water tank, as shown in Fig. 39 (a), and the helium gas flowed at 50 $\mathrm{L} / \mathrm{min}$. A helium gas sampling port was added to the water tank to measure the hydrogen density inside the tank. Using this hydrogen recombination system, the measured hydrogen density in the water tank after 1 week of beam operation at $150 \mathrm{~kW}$ was approximately $0.5 \%$. For a beam power greater than $150 \mathrm{~kW}$, the hydrogen density gradually increased because the helium flow rate to the catalysts was insufficient. In this system, the helium inside each magnetic horn was connected to the water tank by a single tube, thus, the produced hydrogen gas was expected to reach the water tank by diffusion rather than forced circulation. Since the actual hydrogen density inside the magnetic horns could not be measured, weekly helium gas flushing was still implemented so as to reduce the hydrogen density. In order to improve the hydrogen recombination rate, the single path connection between the magnetic horns and water tank was partially modified to achieve forced circulation, as shown in Fig. 39 (b). In this system, forced circulation was available outside the $\mathrm{HV}$ and the helium flow rate was greatly improved, to 800 $\mathrm{L} / \mathrm{min}$. A helium gas sampling port was added near the $\mathrm{HV}$ to measure the hydrogen density near the magnetic horns. During beam operation in Run4, the hydrogen density was measured near the HV after 1 week of continuous beam operation at 220 $\mathrm{kW}$. The measured density was $1.6 \%$ at horn- 1 , however, the estimated hydrogen production was $1.5 \%$. This means that the majority of the hydrogen produced inside the magnetic horns did not diffuse to the circulation line and, therefore, the hydrogen accumulated gradually. From the middle of Run4, the helium gas flushing scheme was modified so that flushed helium gas could pass through the inner volume of the magnetic horns using the water supply line. To achieve this, water circulation was stopped on weekly maintenance days and helium flushing through the magnetic horns was performed as a temporary solution. Forced helium circulation inside the horns is necessary for higher-power beam operation. This will be realized in the next version of the magnetic horns through the addition of a forced circulation line to the magnetic horns and support modules.

\subsubsection{Air contamination and acidification of cooling water}

The interiors of the magnetic horns and gas region of the water tank were filled with helium gas and both were connected with a single tube. Before helium gas was added to the interiors of the horns, the internal spaces were first evacuated to a level of 1,000 $\mathrm{Pa}$ when the HV was evacuated. The interiors were then 
filled with helium gas 16 . The air contamination was essentially992 $1 \%$ inside the horns. Filling of the helium gas into the water ${ }_{993}$ tank was performed by helium gas flushing, because the walls of the water tank were not sufficiently thick to withstand exter-994 nal pressure by evacuation. An air contamination level of a few ${ }_{995}$ percent was possible. Such air contamination leads to acidifica- ${ }_{996}$ tion of the coolant water through the following process: Beam ${ }_{997}$ exposure to nitrogens creates nitrogen oxides, which are dis- ${ }_{998}$ solved in water, and nitric acids can then be created, causing ${ }_{999}$ the water to become acidized.

During Run3, it was found that the coolant water was whitened after two months of beam operation. Through several investi- ${ }_{\overline{1} 002}$ gations, the contents were found to be aluminum oxides with $\mathrm{a}_{003}$ density of $51 \mathrm{mg} / \mathrm{L}$ in the water. This corresponded to a total amount of $138 \mathrm{~g}$ in the entire water $\left(2.7 \mathrm{~m}^{3}\right)$. The hydrogen ion concentration $(\mathrm{pH})$ of the whitened water was $\sim 3.8$, which is strongly acidic. Therefore, it is believed that the aluminum ox $_{\overline{100}}$ ides in the water were created because of aluminum corrosion since the corrosion rate of aluminum in strong acid $(\mathrm{pH}<4)$ is $_{009}$ higher than in neutral conditions $(5<\mathrm{pH}<7)$. The reduction in aluminum conductor thickness was estimated to be only 4.9 $9_{1011}$ $\mu \mathrm{m}\left(0.16 \%\right.$ of the original thickness), assuming corrosion $\mathrm{oc}_{\overline{1012}}$ curred evenly along the entire conductor surface. This amount of thickness reduction did not affect the mechanical strength of the conductors.

In the shutdown period between Run3 and Run4, a pH monitor system was adopted to the water circulation system. This $\$_{017}$ monitor system can measure the $\mathrm{pH}$ of the circulated water by $\mathrm{y}_{1018}$ sampling a few liters of the water rather than requiring the $\operatorname{cir}_{-101}$ culating water to be continuously passed through the monitor ${ }_{1020}$ A series of $\mathrm{pH}$ measurement procedures can now be conducted automatically from a remote control panel at the ground floor of the TS. Since Run4, a portion of the circulating water has been continuously passed through ion exchangers to remove nitric ${ }_{1024}$ acid ions and to neutralize the water. The $\mathrm{pH}$ of the circulat ${ }_{1025}$ ing water has been frequently remotely measured, although ap ${ }_{\overline{1026}}$ proximately $4 \mathrm{~L}$ of the circulating water is drained each time ${ }_{1027}$ Even though the $\mathrm{pH}$ is not monitored continuously, it can be inferred from the water conductivity, which is monitored on $a_{20}$ continuous basis. Figure 40 shows a two dimensional plot of the $\mathrm{pH}$ and conductivity of the circulating water measured during $\mathrm{g}_{03}$ Run4. There is a clear relationship between the $\mathrm{pH}$ and $\mathrm{con}_{\overline{1032}}$ ductivity, therefore, the $\mathrm{pH}$ of the circulating water can be $\mathrm{es}_{1033}^{-}$ timated using the water conductivity. During continuous beam po34 $_{4}$ operation in Run4, the $\mathrm{pH}$ of the circulating water remained at approximately 5.7 , because of the ion exchanger path. $\mathrm{Un}_{\overline{1}}{ }^{1035}$ der these conditions, the aluminum corrosion rate is very small ${ }_{1037}$ Thereafter, the $\mathrm{pH}$ remained at $\sim 5.7$ throughout Run4, which $_{1038}$ meant minor air contamination occurred continuously at some point in the helium gas plumbing. However, this minor con $_{\overline{1040}}$

\footnotetext{
${ }^{16}$ This procedure was conducted because the magnetic horn conductors are not designed to withstand external pressure caused by evacuation of the interior. ${ }^{1042}$

${ }^{17}$ For precise measurement of $\mathrm{pH}$ of pure water, a solution including a few 043 percent of $\mathrm{KCl}$ is usually used as a reference. $\mathrm{Cl}^{-}$cations dramatically increase the corrosion rate, thus, the measured water is not typically returned to the circulation line, but it is instead drained away.
}

tamination did not lead to aluminum corrosion because of the continuous operation of the ion exchangers.

\subsection{Water leak}

During the Run4 period, it was found that the water level in the water tank gradually decreased at a rate of $\sim 10 \mathrm{~L} / \mathrm{d}$. Since no leak was found in any of the exterior plumbing outside the $\mathrm{HV}$, it was more likely that the magnetic horns were leaking. The leaked water was contained inside the HV and no external leaks occurred. Since the helium gas inside the HV is circulated by a helium compressor, water vapor is condensed after passing through the compressor and collected at a drain tank in the helium circulation line. The rate of increase in the condensed water in the drain tank was almost the same as the water leakage rate, thus, the amount of accumulated leaked water at the bottom of the vessel was expected to have been very small compared to the total amount of leaked water. However, a small fraction of the leaked water still remained at the bottom of the $\mathrm{HV}$ and actually corroded the bottom steel plate.

Water circulation tests were performed several times to investigate which horn was leaking. The investigation was conducted by circulating water for one horn only and by checking the water level. The results indicated that a decrease in the water level occurred at horn-3. In the shutdown period after Run4, an opportunity to open the top lid of the HV was provided. Since no direct access to the horns is permitted, visual inspection was performed using a camera controlled by a wireless network. The camera was attached to the bottom end of an 8-m-long rod, and the rod was lowered through 3-cm gaps between shielding blocks to obtain access to the level of the horns. This visual inspection was conducted for all three horns and it was found that horn-1 was leaking, while no leakage was observed at horn-2 and horn-3. Water drops from upstream of the horn-1 conductors were visible, rather than from the water nozzles or drain ports. Upstream of the conductors, two aluminum knife-edge seals were used on both sides of the large ceramic ring. There are two possible causes of the leak: one is corrosion of the aluminum knife-edge seals, which occurred when the water with $\mathrm{pH}<4$ was circulated during Run3; the other may be that the seals were not sufficiently compressed when horn-1 was assembled. In this case, when the axial forces of the aluminum bolts used to compress the aluminum knife-edge seals were reduced by the thermal expansions due to beam heating, a leak would occur. During the shutdown period after Run4, all three magnetic horns were replaced with second-version horns, primarily for upgrade purposes. Thus, the leak problem was solved. For countermeasures against a water leak, the upstream aluminum knife-edge seals of the second horn-1 were sufficiently compressed, which would decrease the probability of a leak developing. Alternative seal designs are also studied for future horn-1 production.

\subsection{Power supply issues}

From Run1 to Run4, there were several changes in power supply and operation configuration. At the beginning of the T2K experiment, two power supplies that were previously used 
for the K2K magnetic horns, which were manufactured in 1994 and 1998, were refurbished. Horn-1 was operated by one power supply and horn-2 and horn-3, connected in series, were operated by another power supply.

A new power supply was fabricated in summer 2010 and began operation during Run2. The new power supply was designed to operate all three magnetic horns simultaneously and had a rated output current of $35 \mathrm{kA}$, a rated operation voltage of $10 \mathrm{kV}$, and a capacity of $7.5 \mathrm{mF}$. It also had an energy recovery system. Details of this new power supply are given in [18]. Because the total resistance and inductance are large due to the three-horn operation powered by one power supply, the pulse width expanded to $4.6 \mathrm{~ms}$. This power supply was operated $\mathrm{at}^{t^{10}}$ 250-kA for physics data-taking throughout Run2, without any ${ }^{1102}$ complications.

The power supply experienced a serious problem due to $\mathrm{d}^{104}$ malfunction in December 2011. Several IGBT switches located ${ }^{105}$ between the charging unit and the capacitor bank were broken ${ }^{106}$ as a result of this problem. One of the $\mathrm{K} 2 \mathrm{~K}$ power supplies was ${ }^{107}$ reinstalled for operation of the three horns in series. Since the $\mathrm{d}^{108}$ three-horn operation is a heavy requirement for the $\mathrm{K} 2 \mathrm{~K}$ power ${ }^{1109}$ supply, several measures were taken to ensure safe operation. ${ }^{1110}$ The power supply was operated with a charging voltage of $6.7^{111}$ $\mathrm{kV}$ and charging current of $20 \mathrm{~A}$, both of which are close to the ${ }^{112}$ rated values. Three-horn operation powered by the K2K power ${ }^{113}$ supply was initiated at the beginning of Run3 in early March $^{114}$ 2012. Several days later, the power supply suddenly stopped as ${ }^{115}$ a result of a thyristor problem. One of three thyristors with $\mathrm{a}^{116}$ rated voltage of $4 \mathrm{kV}$ was shorted by some fault. After replace ${ }^{1117}$ ment with a spare thyristor stack with the same specifications as ${ }^{111}$ the broken device, the power supply began operation with a re ${ }^{1119}$ duced current of $200 \mathrm{kA}$ for safety. It was thought that, because of the high-voltage operation at $6.7 \mathrm{kV}$, a higher voltage than ${ }_{120}$ specified may have been applied to one of the thyristors as a result of an unexpected voltage unbalance among the thyristors:121 Two weeks later, the thyristor stack was replaced with a stack ${ }^{122}$ with a higher rated voltage $(7 \mathrm{kV})$, which can withstand such $\mathrm{a}^{123}$ voltage unbalance, even with one thyristor. After the replace ${ }^{124}$ ment, the power supply was operated without any difficulty for ${ }^{125}$ a year (the remainder of Run3 and half of Run4).

1126

The new power supply was reintroduced in January 2013, a a $^{127}$ year after the initial problem. Then, the horn operation was re ${ }^{1128}$ turned to a two-power-supply configuration, with the new sup ${ }^{129}$ ply being used for horn-1 and the old supply powering horn-2 2130 and horn-3. This was to reduce the operation voltages, which ${ }^{131}$ could greatly help to lower the risk of failure. The two-power ${ }^{132}$ supply configuration continued for the latter half of Run4. Ta+133 ble 13 summarizes the operation configurations for the Run1-4134 periods.

\section{Conclusion}

A magnetic horn system to realize a high-intensity neutrind ${ }^{13}$ beam was developed for the T2K experiment, and an electrical $\left.\right|_{139} ^{138}$ system for 320-kA operation was constructed. The heat transfer ${ }_{140}$ coefficient at the inner conductor surface following the use of 141 sprayed water as a coolant is as high as $7.9 \mathrm{~kW} / \mathrm{m}^{2} \cdot \mathrm{K}$. This is is $^{142}$
Table 13: Summary of operation configuration for Run1-4 periods.

\begin{tabular}{lllll}
\hline Period & Config. & Current & Voltage & Width \\
\hline Run1 & horn-1 (K2K) & $250 \mathrm{kA}$ & $4.5 \mathrm{kV}$ & $2.4 \mathrm{~ms}$ \\
& horn-2+3(K2K) & $250 \mathrm{kA}$ & $5.4 \mathrm{kV}$ & $3.6 \mathrm{~ms}$ \\
Run2 & horn-1+2+3(New) & $250 \mathrm{kA}$ & $6.2 \mathrm{kV}$ & $4.6 \mathrm{~ms}$ \\
Run3 (early) & horn-1+2+3(K2K) & $200 \mathrm{kA}$ & $5.4 \mathrm{kV}$ & $4.3 \mathrm{~ms}$ \\
Run3 (late) & horn-1+2+3(K2K) & $250 \mathrm{kA}$ & $6.7 \mathrm{kV}$ & $4.3 \mathrm{~ms}$ \\
Run4 (early) & horn-1+2+3(K2K) & $250 \mathrm{kA}$ & $6.7 \mathrm{kV}$ & $4.3 \mathrm{~ms}$ \\
Run4 (late) & horn-1 (New) & $250 \mathrm{kA}$ & $4.1 \mathrm{kV}$ & $3.1 \mathrm{~ms}$ \\
& horn-2+3(K2K) & $250 \mathrm{kA}$ & $5.4 \mathrm{kV}$ & $3.6 \mathrm{~ms}$ \\
\hline
\end{tabular}

sufficiently high to maintain maximum temperatures of below $50^{\circ} \mathrm{C}$. However, for the stripline cooling by helium, the required flow rate was not achieved because of a helium leak around the remote clamp, which will be modified in the next version of this device. The conductor shapes are optimized using FEM to ensure that the stress is maintained below an allowed value, and the measured vibrations are consistent with the predictions of the FEM analyses. Operation experience acquired during the $\mathrm{T} 2 \mathrm{~K}$ beam periods is also described. The T2K magnetic horns have been operated stably at $250 \pm 5 \mathrm{kA}$ overall, however, several problems such as hydrogen production and air contamination were observed. The majority of these issues were solved, but countermeasures against the hydrogen problem are still under development. The first set of T2K magnetic horns has been operated for over 12 million pulses during four years of operation, from 2010 to 2013, under a maximum beam power of 230 $\mathrm{kW}$. No significant damage has been observed during this period. This successful operation has led to the discovery of the $v_{\mu} \rightarrow v_{e}$ oscillation by the T2K experiment in 2013 [19].

\section{Acknowledgments}

The authors thank the Japanese Ministry of Education, Culture, Sports, Science, and Technology (MEXT) for their support of the T2K magnetic horn development. The T2K magnetic horns have been built and operated using funds provided by MEXT, Japan, and the Department of Energy, U.S.A. In addition, the development of the T2K magnetic horns was partly supported by Grands-in-Aid for Scentific Research in Japan.

The authors would like to acknowledge the tremendous support and effort from the J-PARC accelerator division, and would also like to thank Prof. Yoshioka, Prof. Kobayashi, and Prof. Matsumoto from KEK for their kind support and useful advice. Finally, the authors would like to appreciate many discussions with researchers, who work for neutrino beamlines in the world, and useful information from them.

\section{References}

[1] Y. Itow et al., arXiv:hep-ex/0106019 (2001).

[2] Y. Yamazaki et al., KEK Report 2002-13 (2003); Y. Yamazaki et al., JAERI-Tech 2003-44 (2003); Y. Yamazaki et al., J-PARC-03-01 (2003).

[3] S. Fukuda et al., Nucl. Instr. Meth. A501, 418 (2003).

[4] D. Beavis, A. Carroll, I. Chiang et al., Proposal of BNL AGS E-889, (1995).

[5] K. Abe et al., Nucl. Instr. Meth. A659, 106 (2011). 
1143 [6] A.K. Ichikawa, Nucl. Instr. Meth. A690, 27 (2012)

1144 [7] Japan Aluminum Association et al., Aluminum Handbook, 7th edition (2007), in Japanese.

[8] S.H. Ahn et al., Phys. Lett. B511, 178 (2001).

[9] K. Abe et al., Phys. Rev. D 87, 012001 (2013).

1148 [10] M. Hagiwara et al., Prog. Nucl. Sci. Tech., 3, 56 (2012)

1149 [11] K. Bessho et al., Proceedings of the Eleventh Meeting of the Task-Force on Shielding Aspects of Accelerators, Targets and Irradiation Facilities (SATIF11), page 61 (2013).

[12] Y. Oyama, Presentation at 8th International Workshop on Neutrino Beams and Instrumentation, CERN, Geneva, Switzerland, November 2012.

[13] Y. Kanda, T. Momose, M. Taira, Radiat. Phys. Chem., 48, 49 (1996).

[14] MARS Code System, http://www-ap.fnal.gov/MARS/ .

[15] ANSYS, http://www.ansys.com .

[16] NuMI Technical Design Handbook, http://wwwnumi.fnal.gov/numwork/tdh/tdh_index.html

[17] Characteristic of Kyocera Technical Ceramics, http://global.kyocera.com/prdct/fc/product/pdf/material.pdf

${ }_{1160}$ http://global.kyocera.com/prdct/fc/product/pdf/mo

${ }_{1162}$ [19] K. Abe et al., Phys. Rev. Lett. 112, 061802 (2014)
Figure 39: Schematic diagrams of hydrogen recombination system. (a) First version (top) and (b) modified version of the system (bottom).
Figure 40: Two-dimensional plot of $\mathrm{pH}$ (horizontal axis) and conductivity (vertical axis) of circulating water measured during Run 4. 


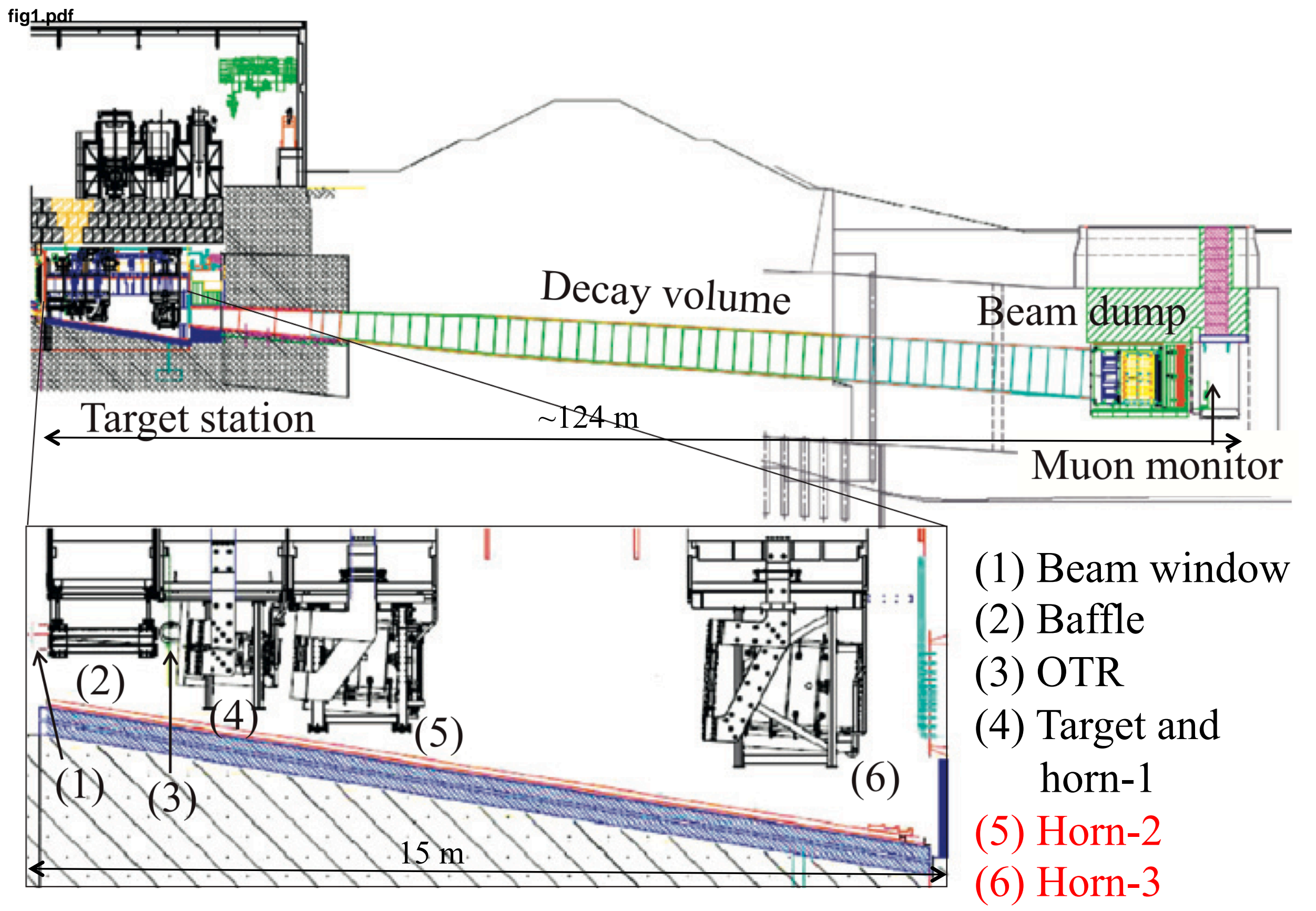


1.poft

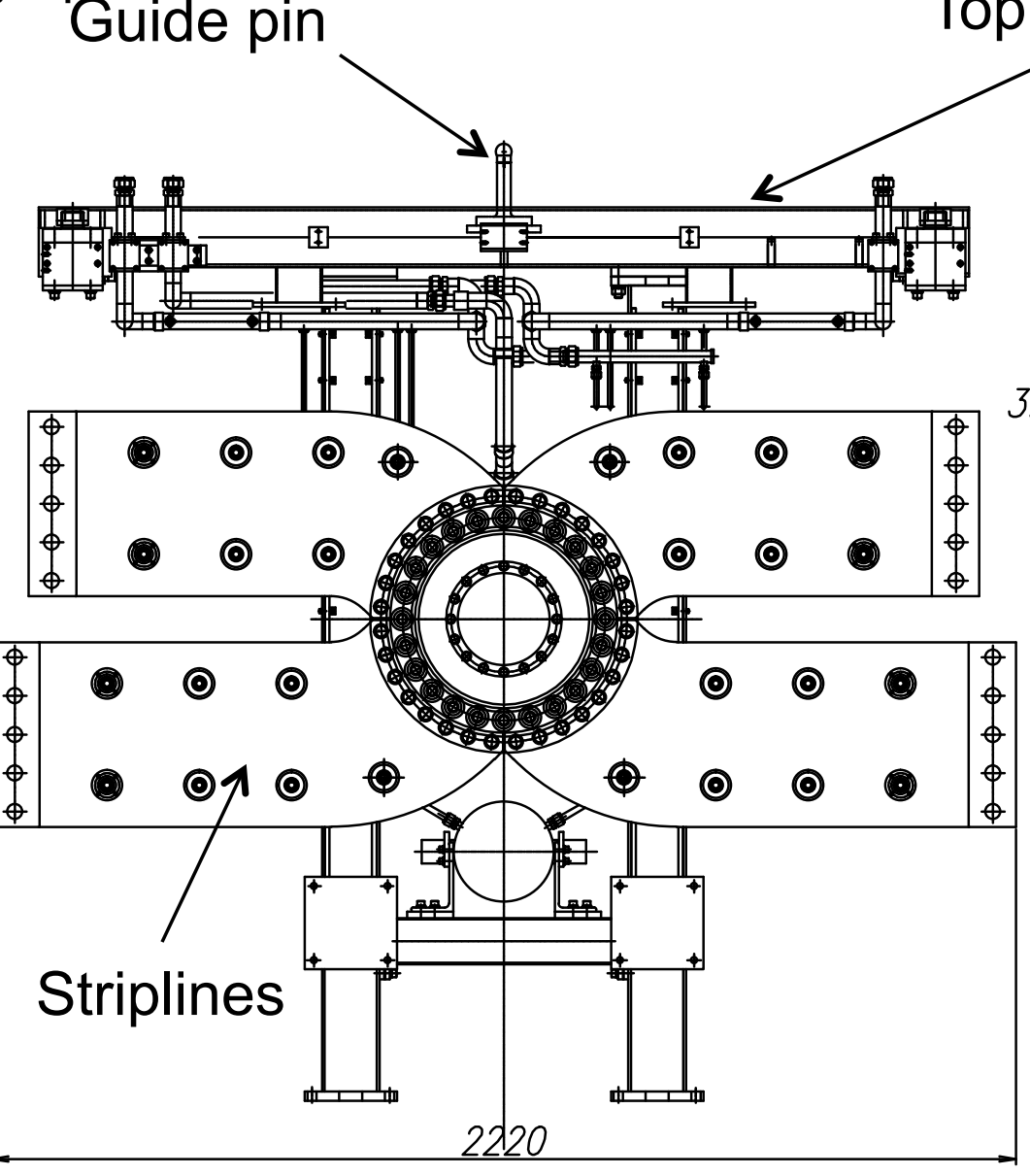

Aluminum conductors

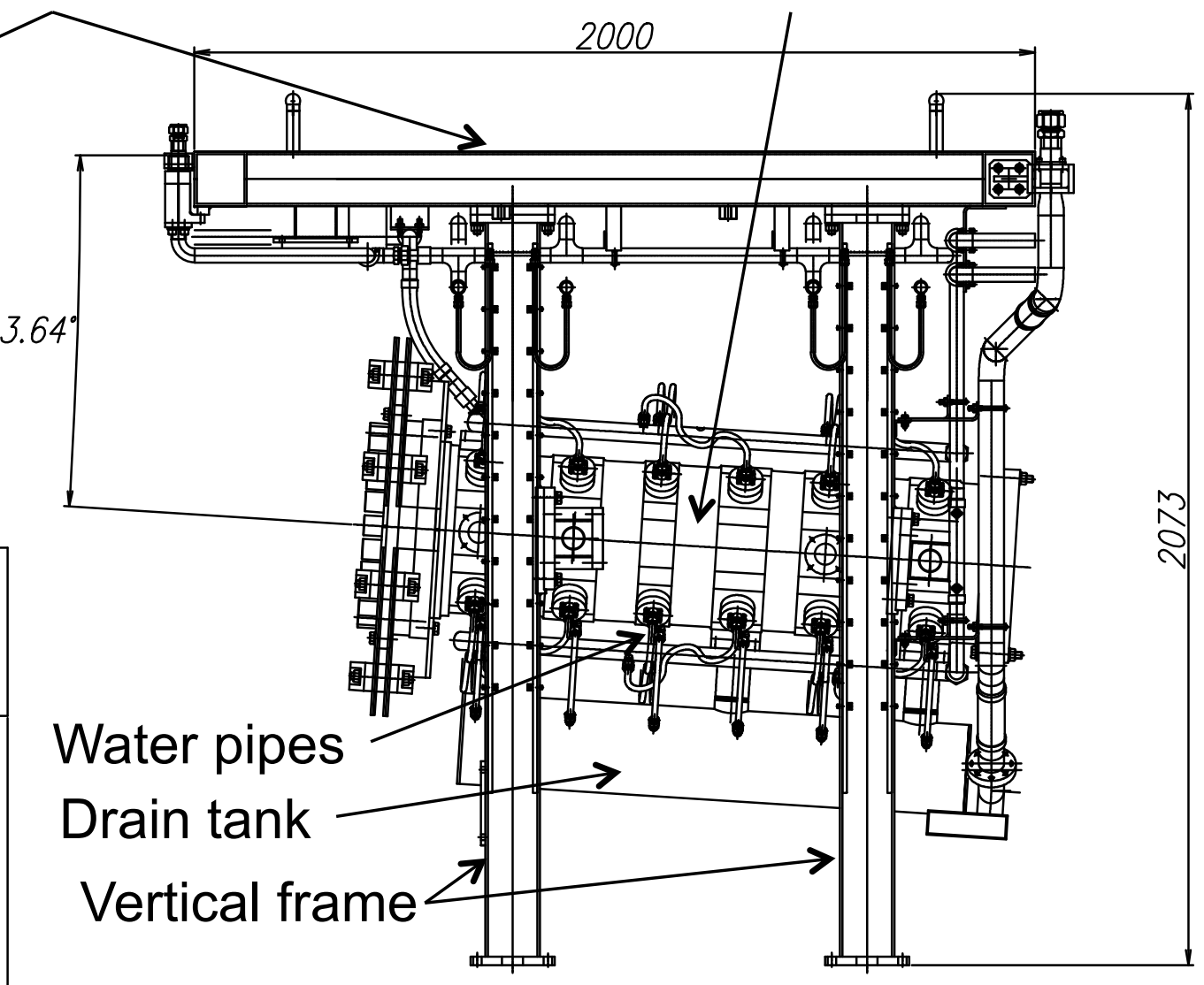




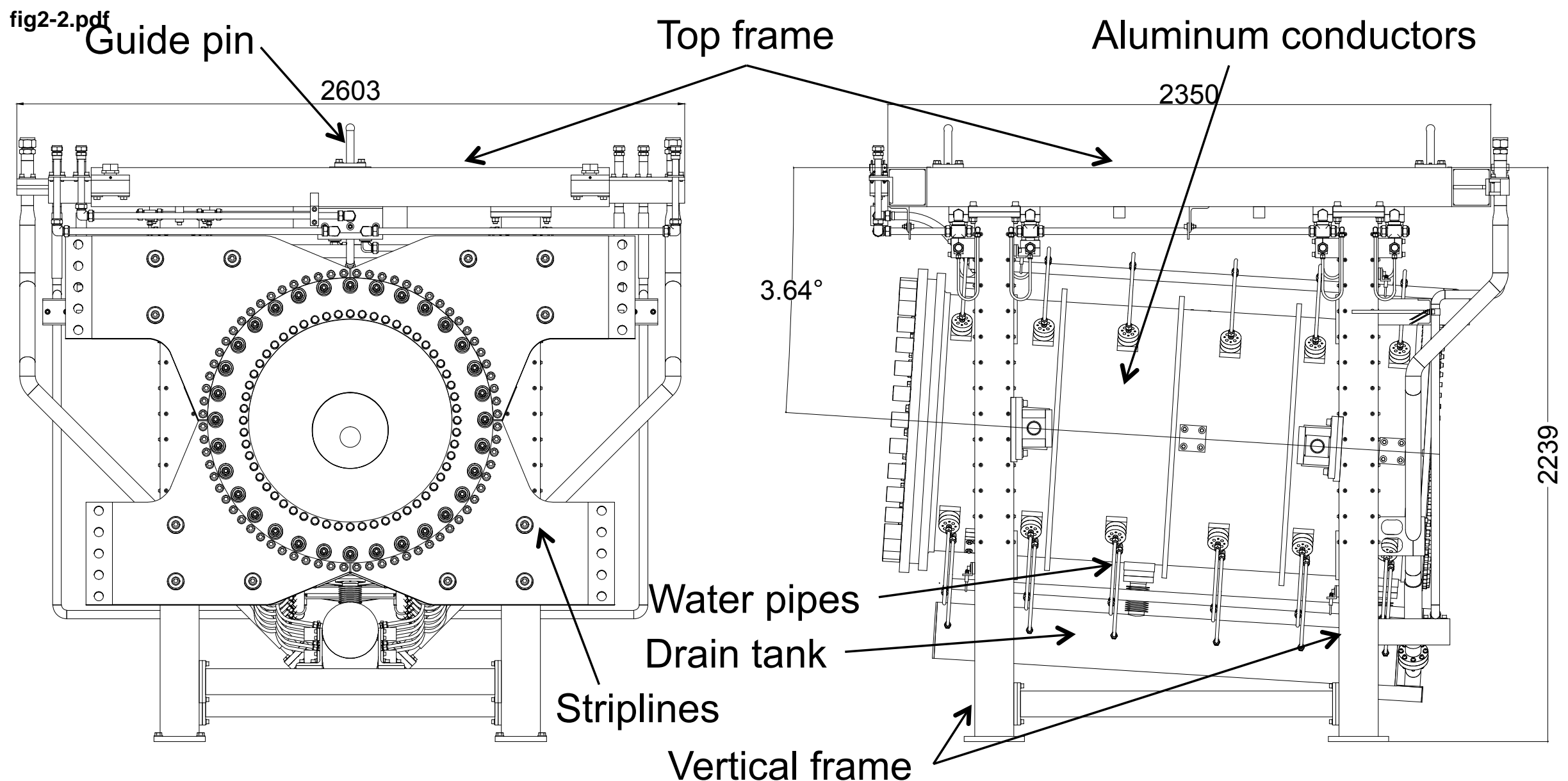


Ceramic insulator ring

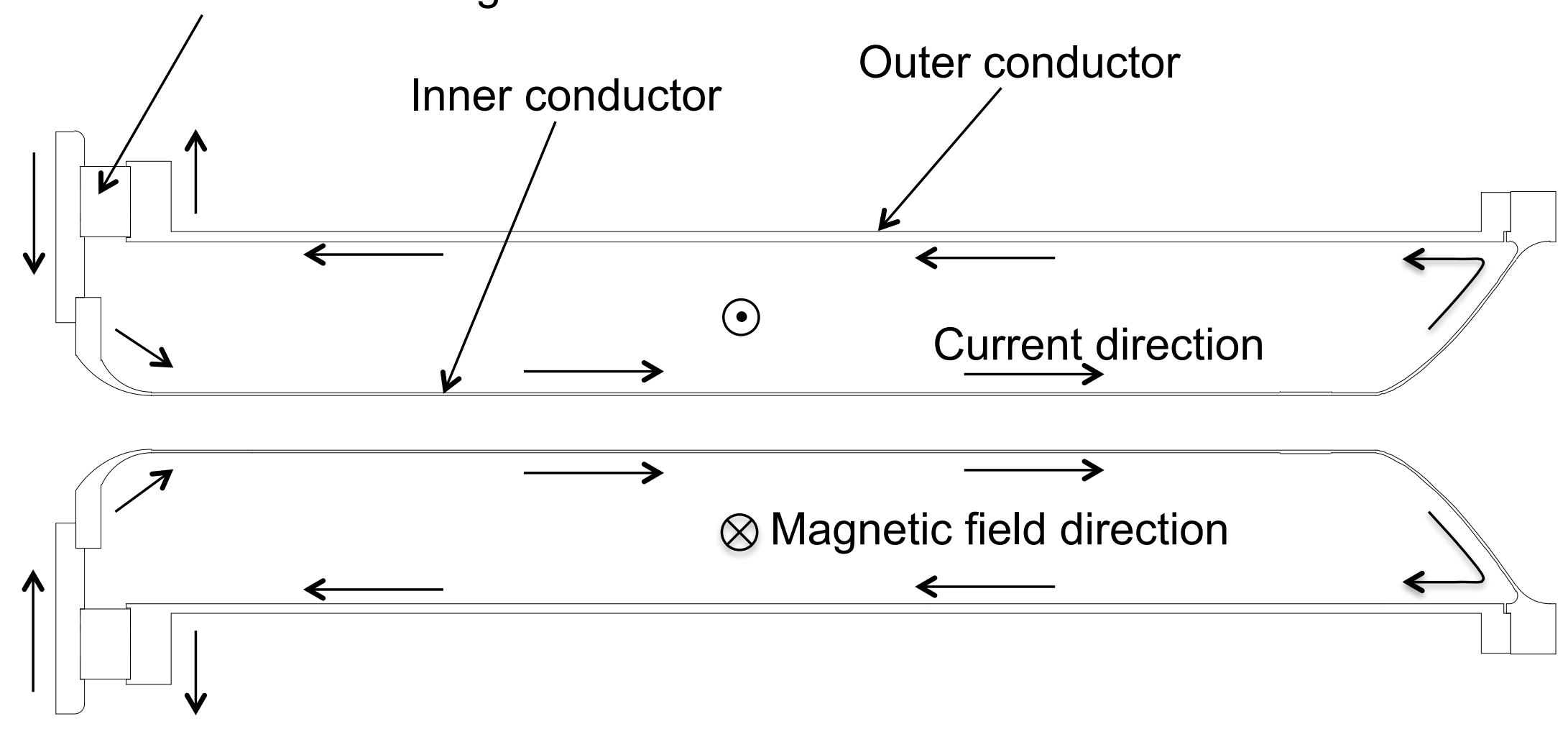




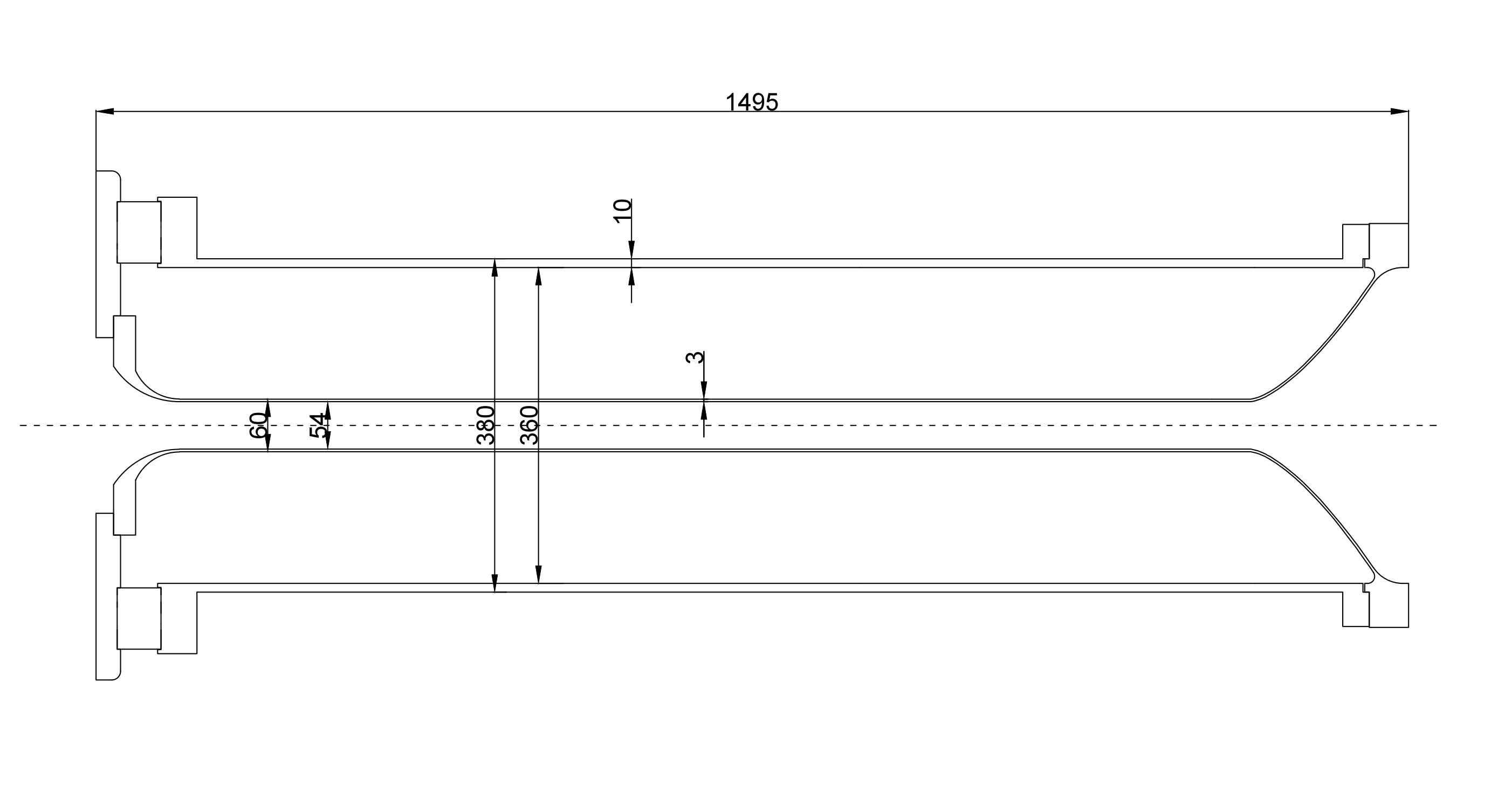

ff

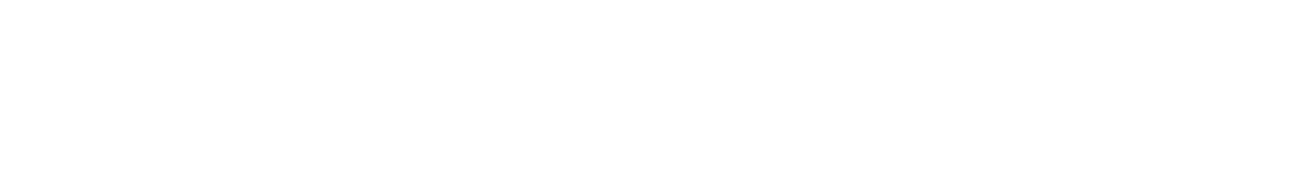

.

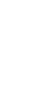
(

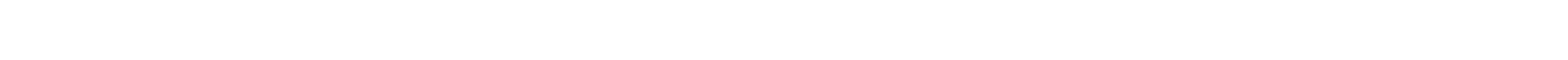


2036

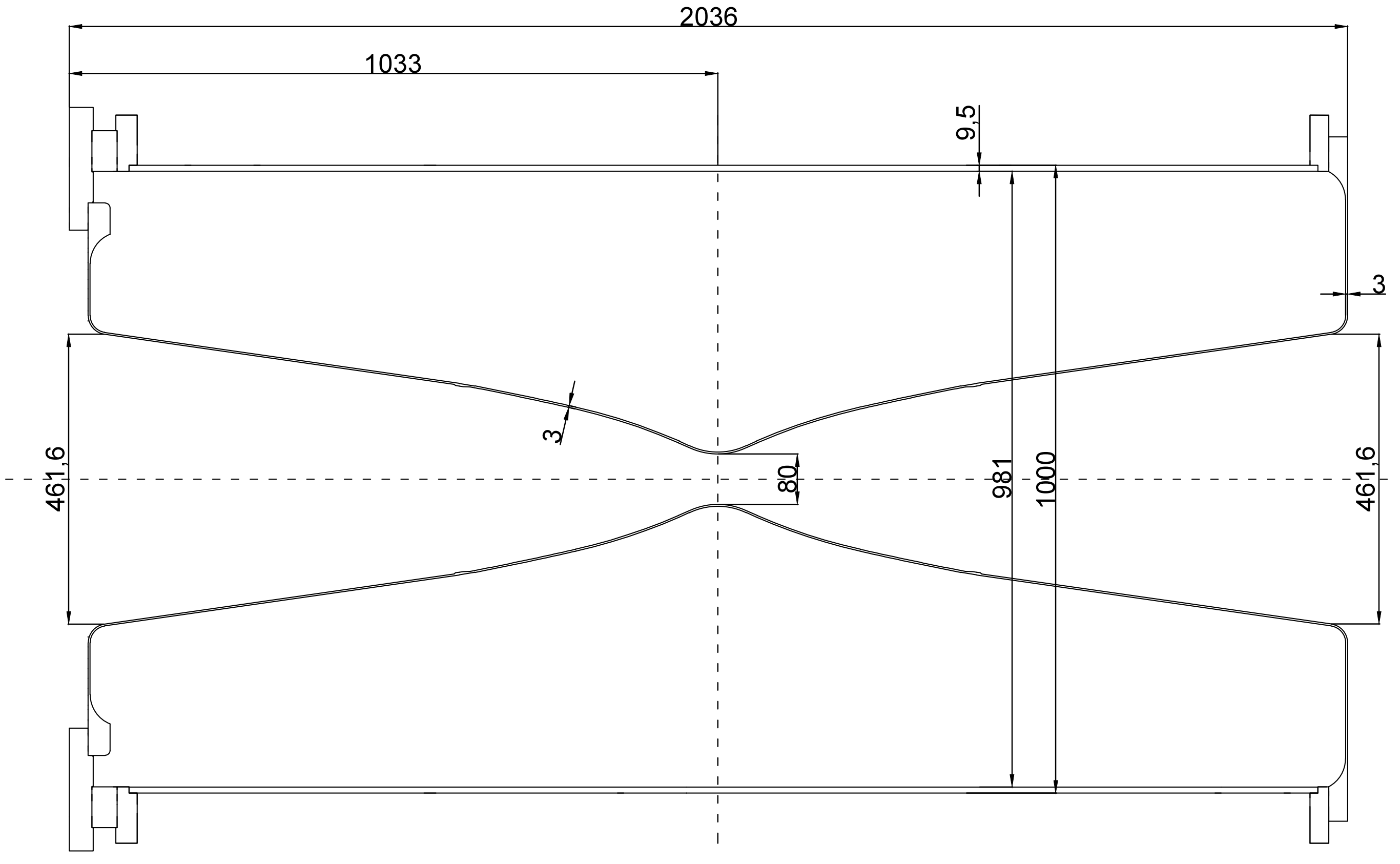


2536

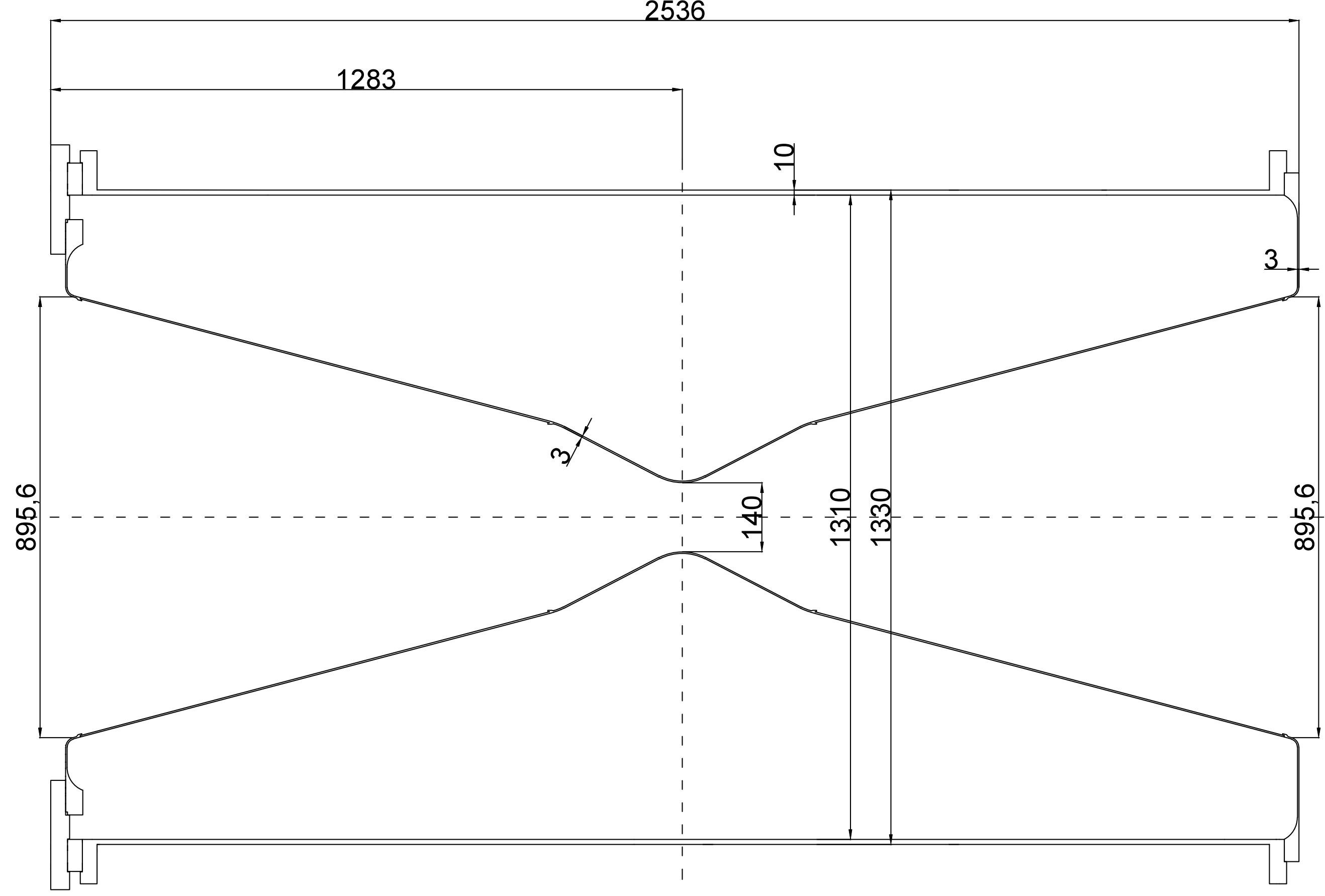




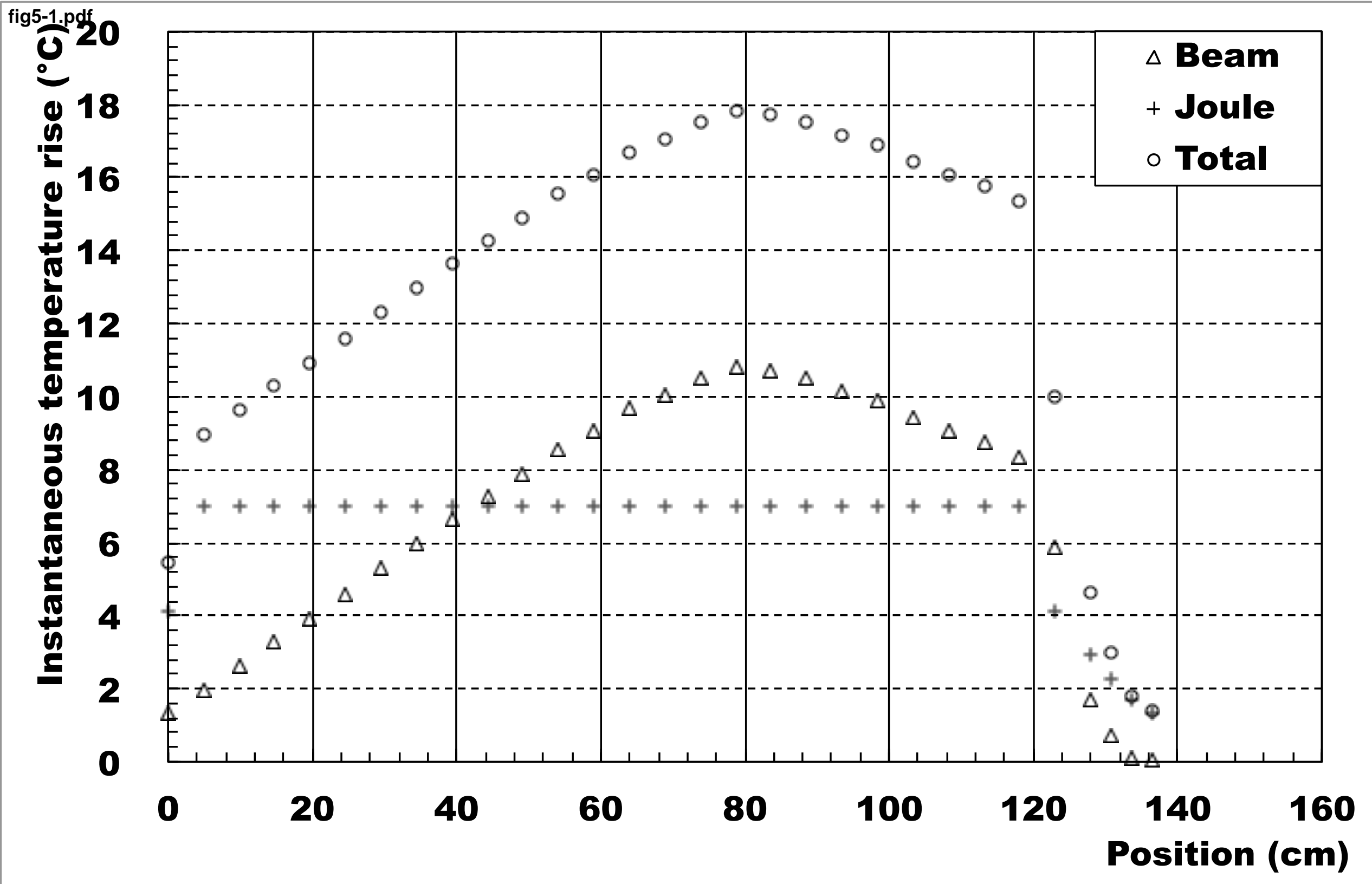




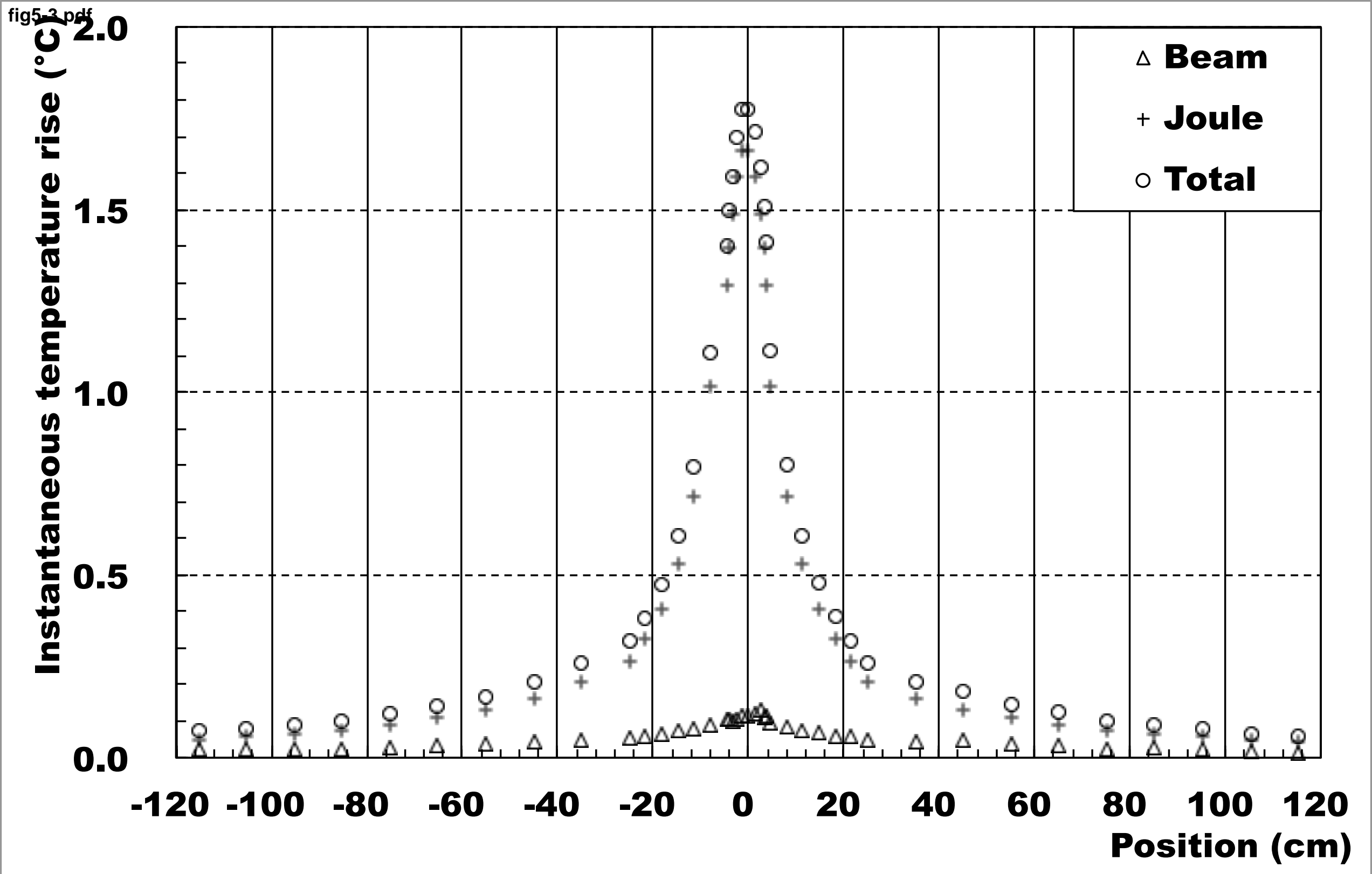




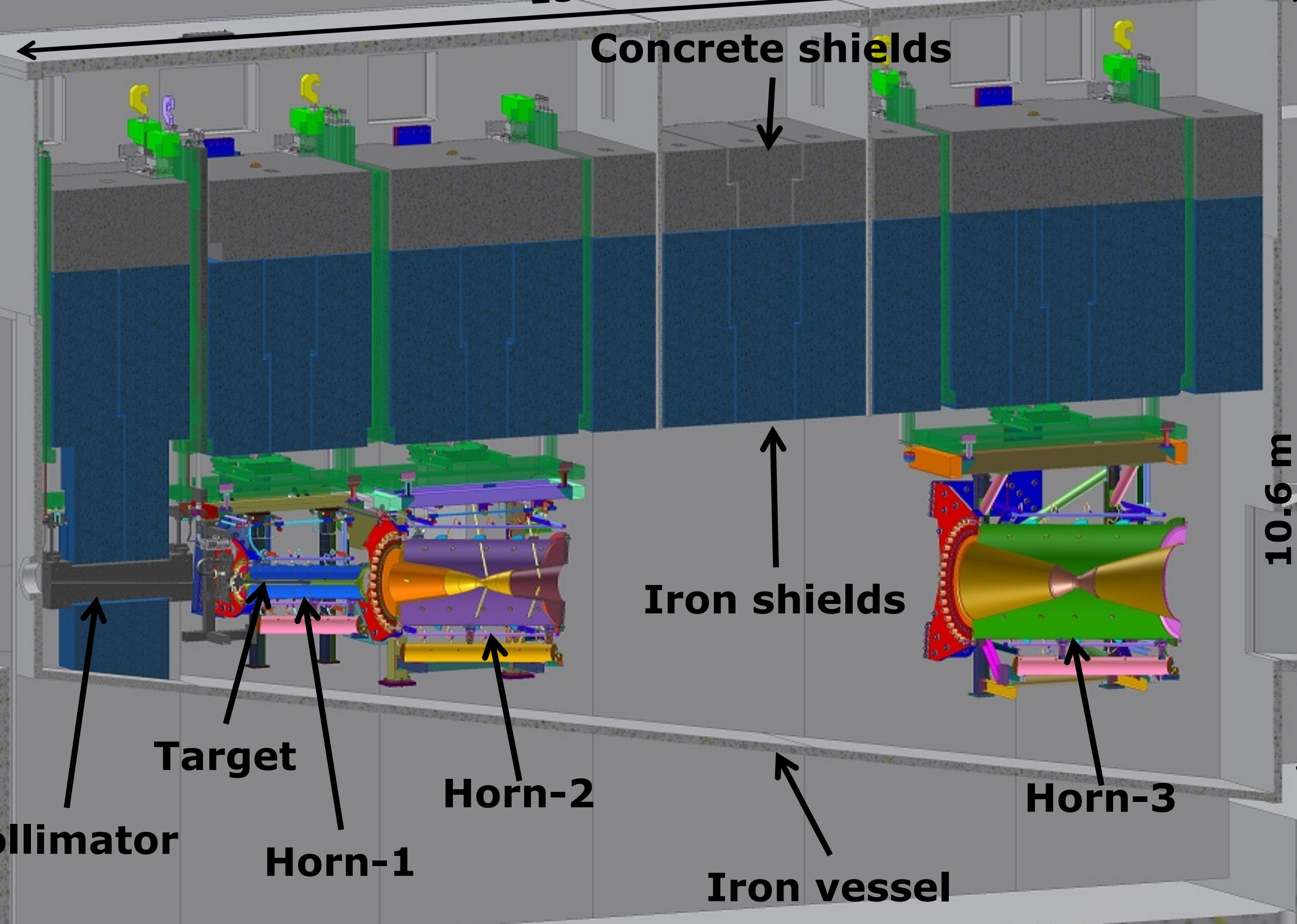


fig8.pdf

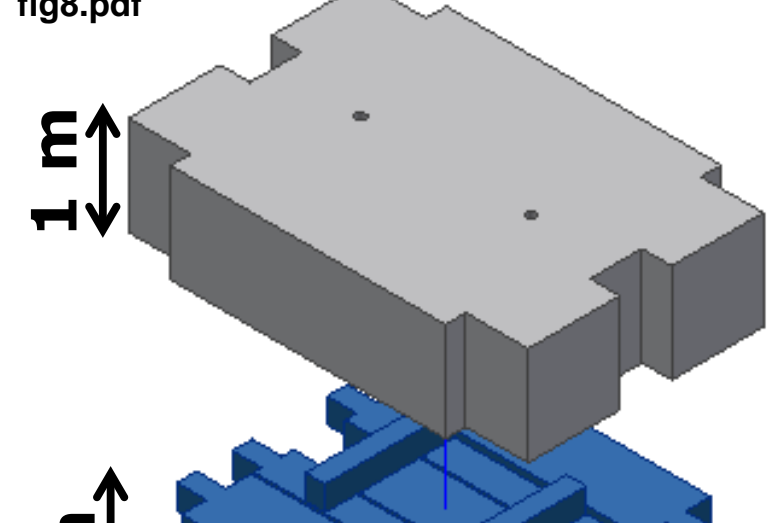

Concrete shields

Iron shields

N

Supported

$K$ here

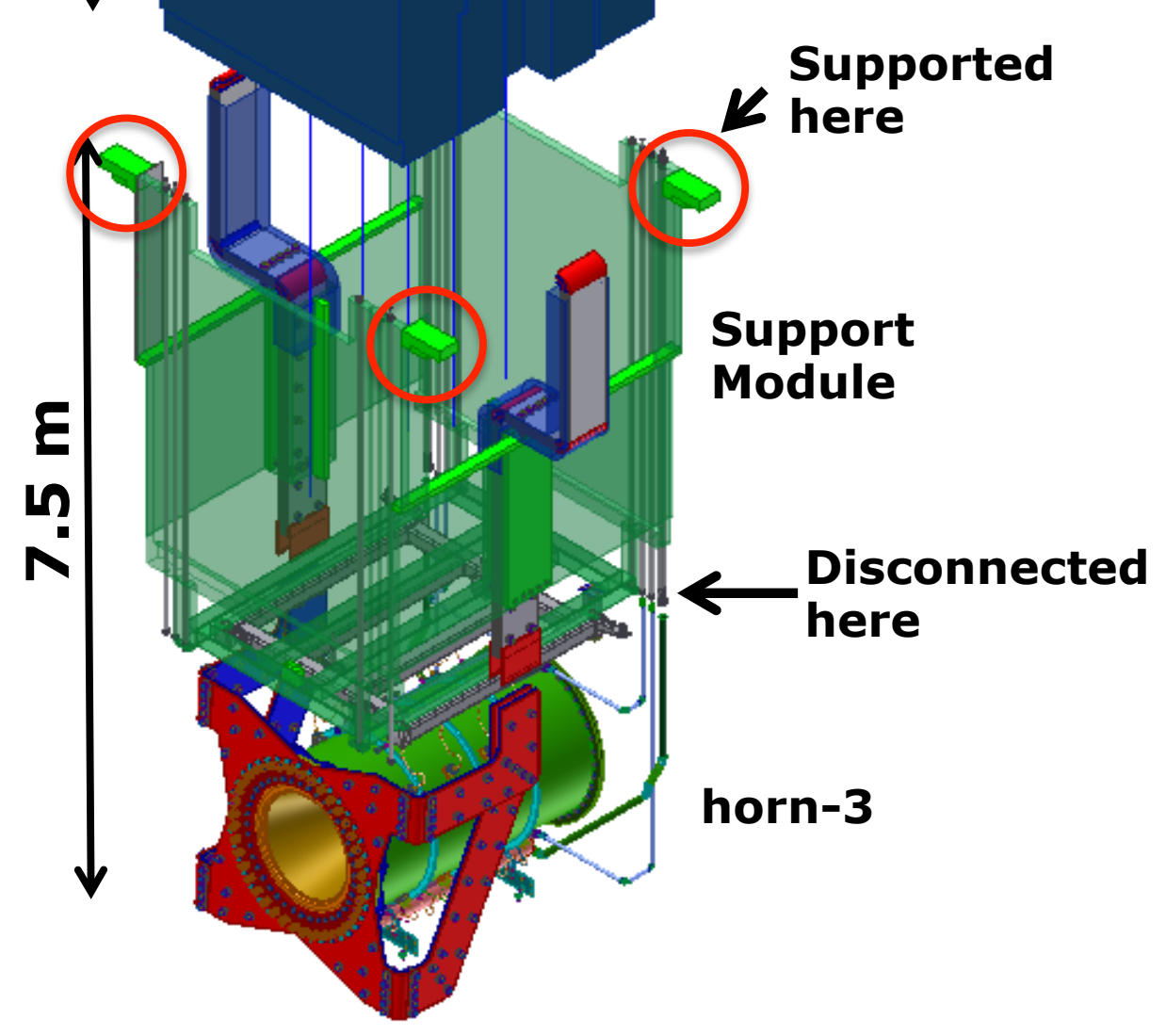




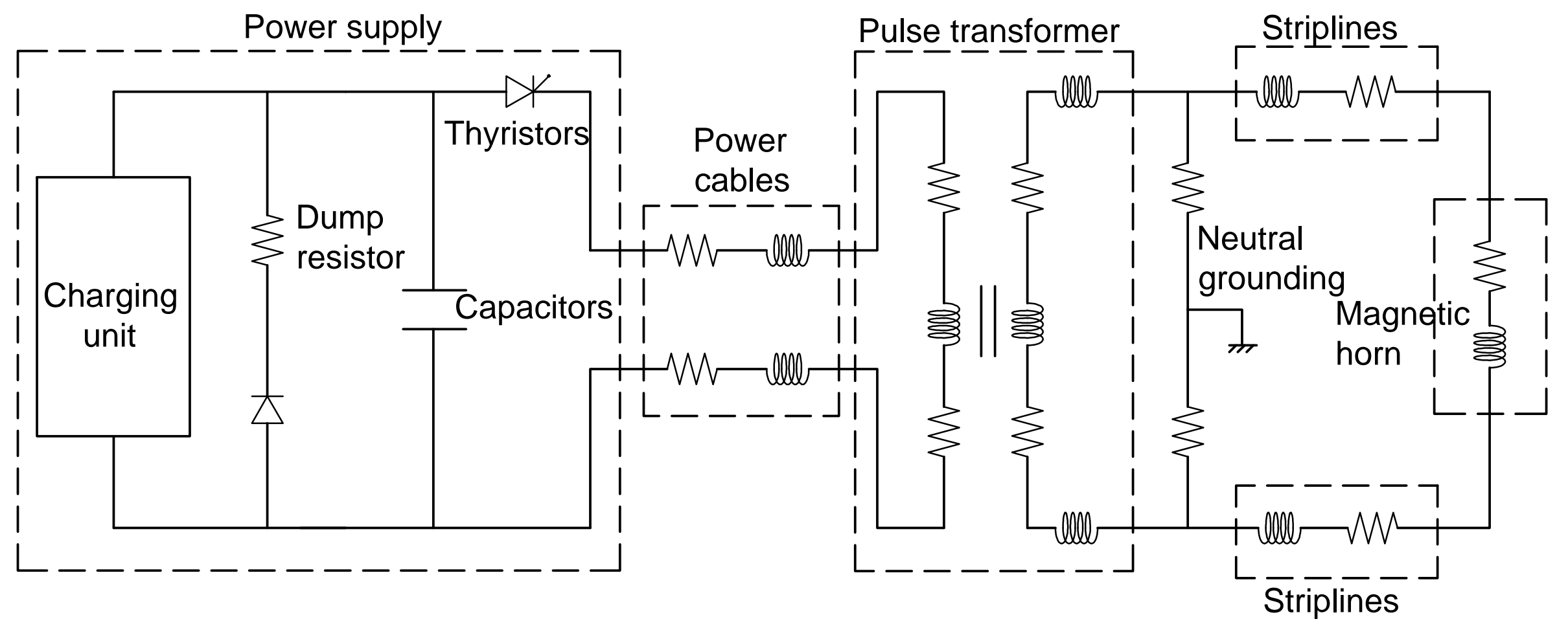




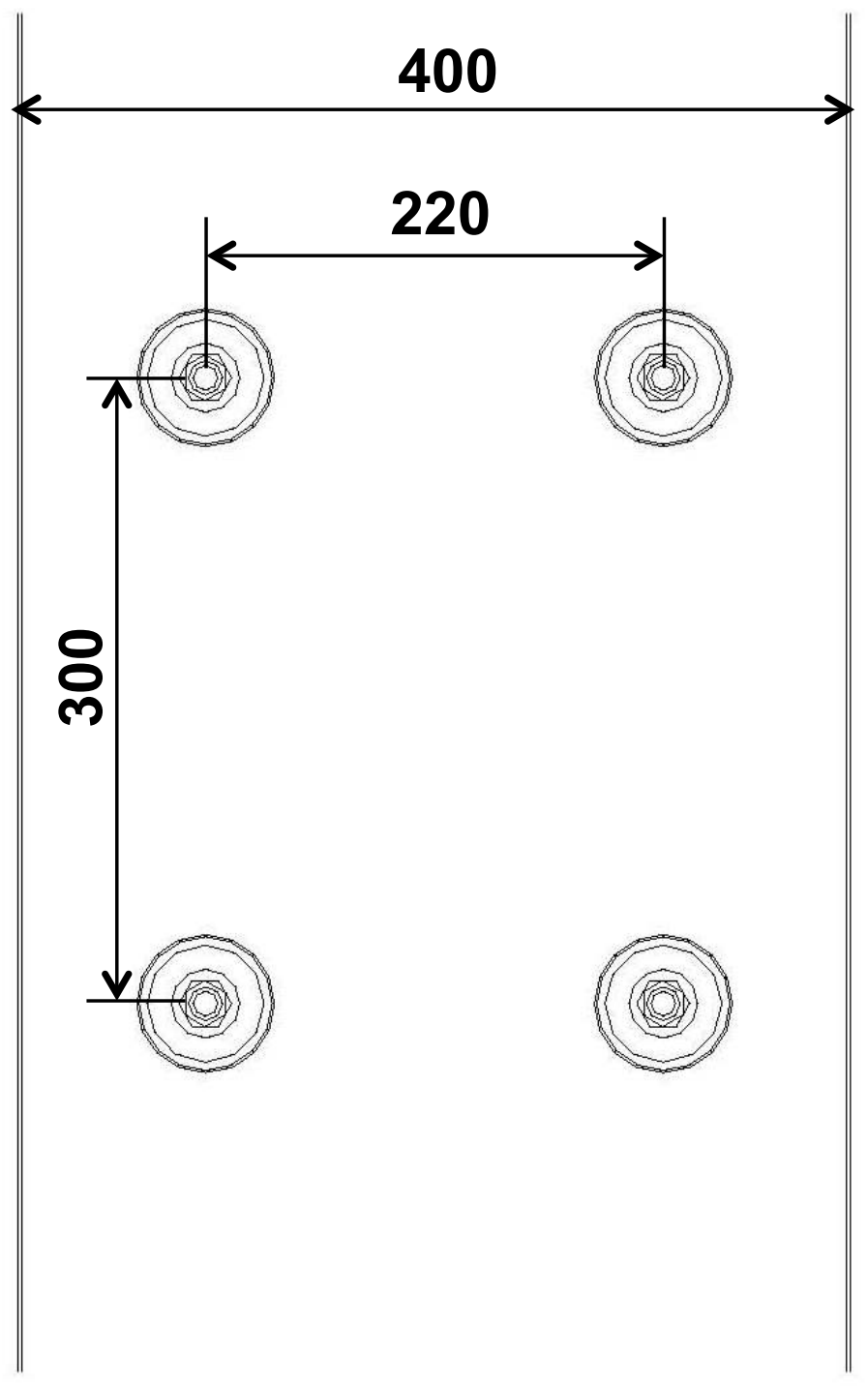

Spiralock ${ }^{\circledR}$ hex flange nut

Striplines

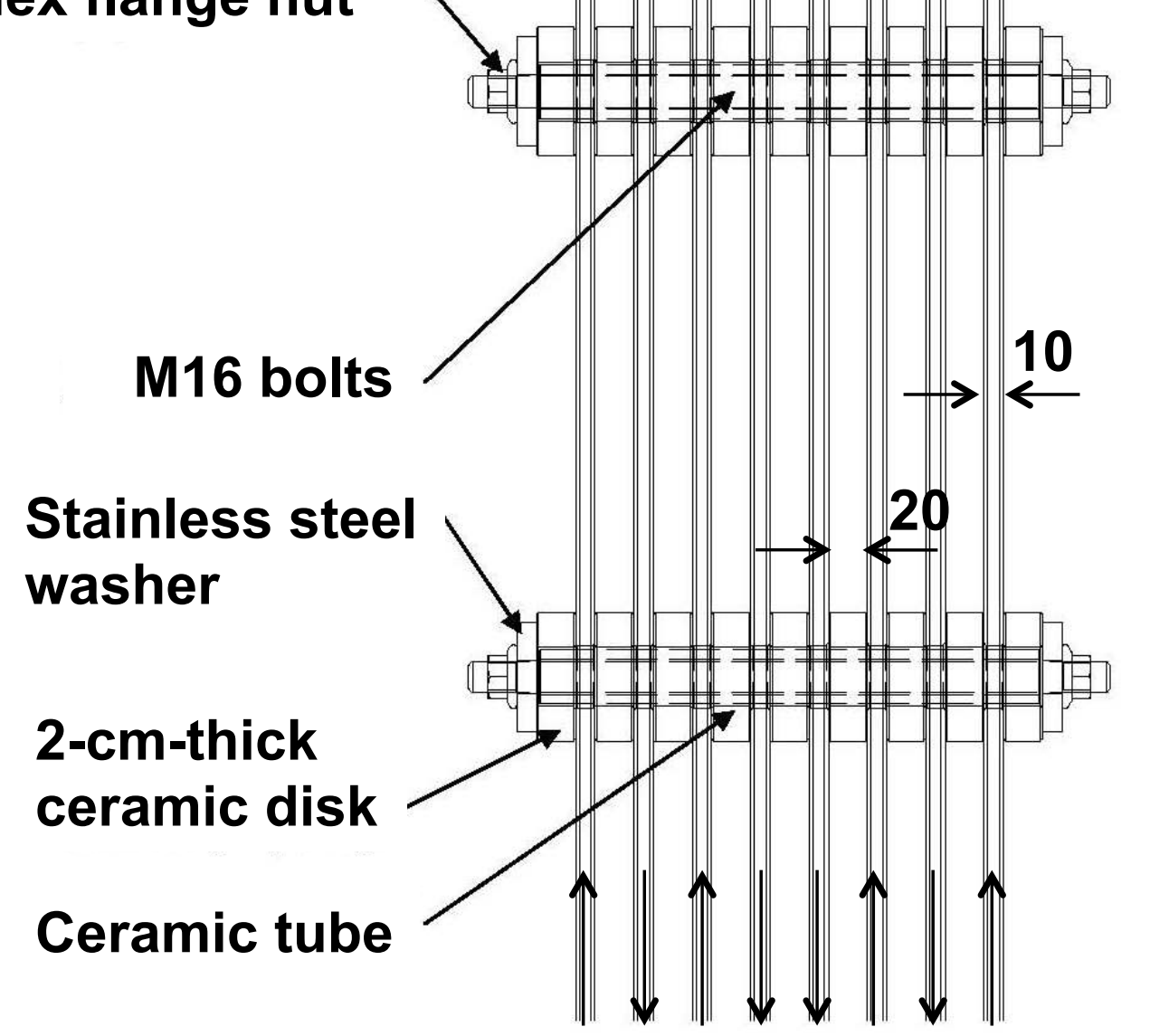




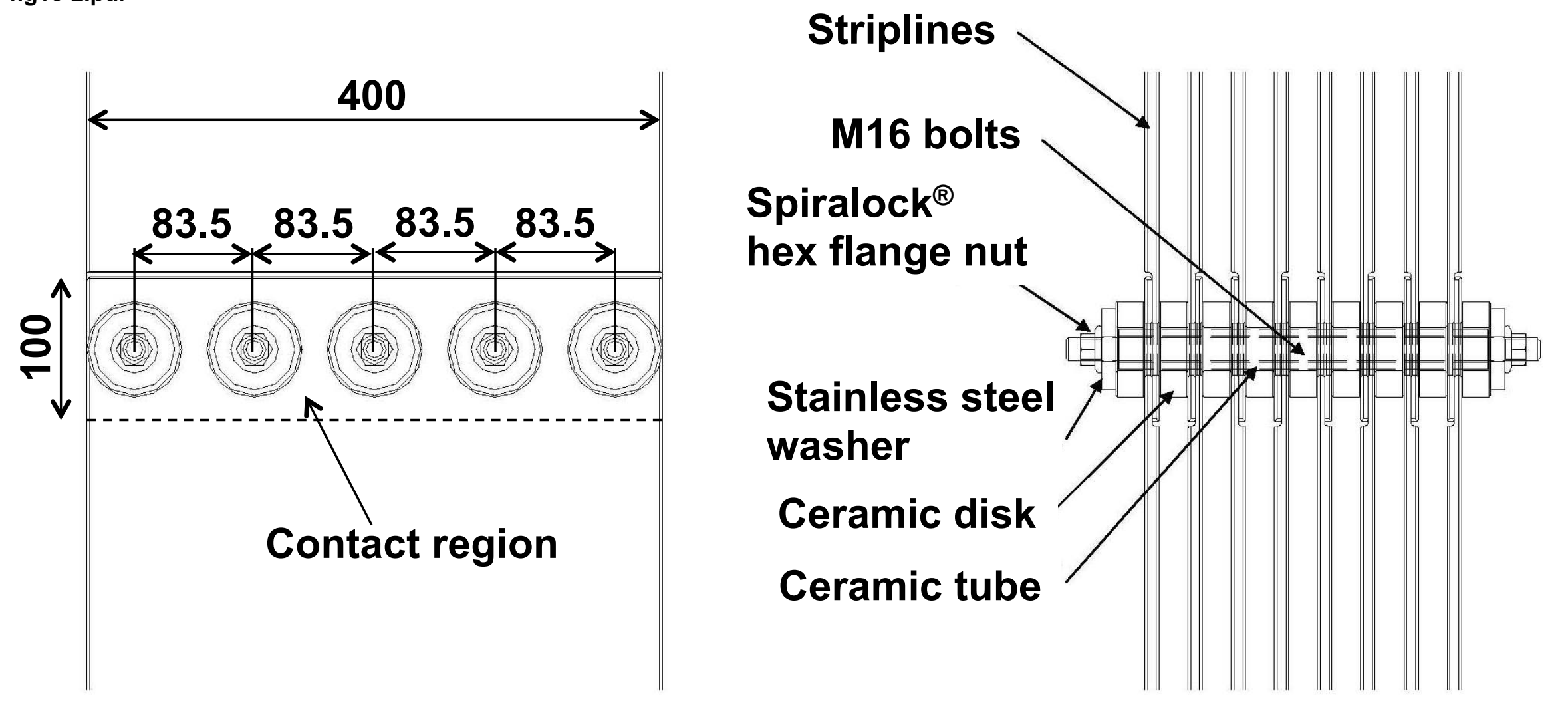

Striplines

M16 bolts

Spiralock ${ }^{\circledR}$

hex flange nut

Stainless steel washer

Ceramic disk Ceramic tube

\section{Unit: $\mathbf{m m}$}




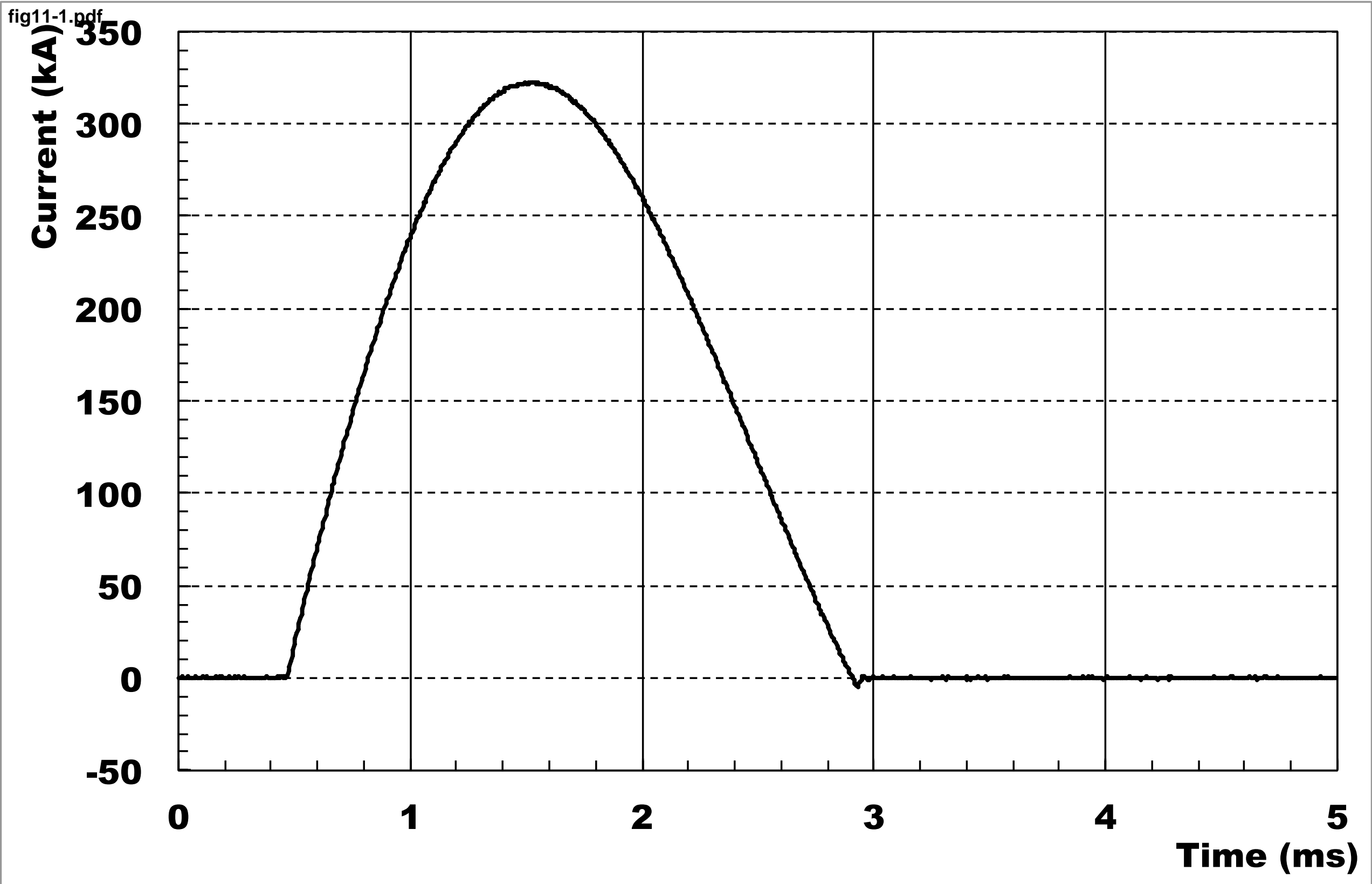




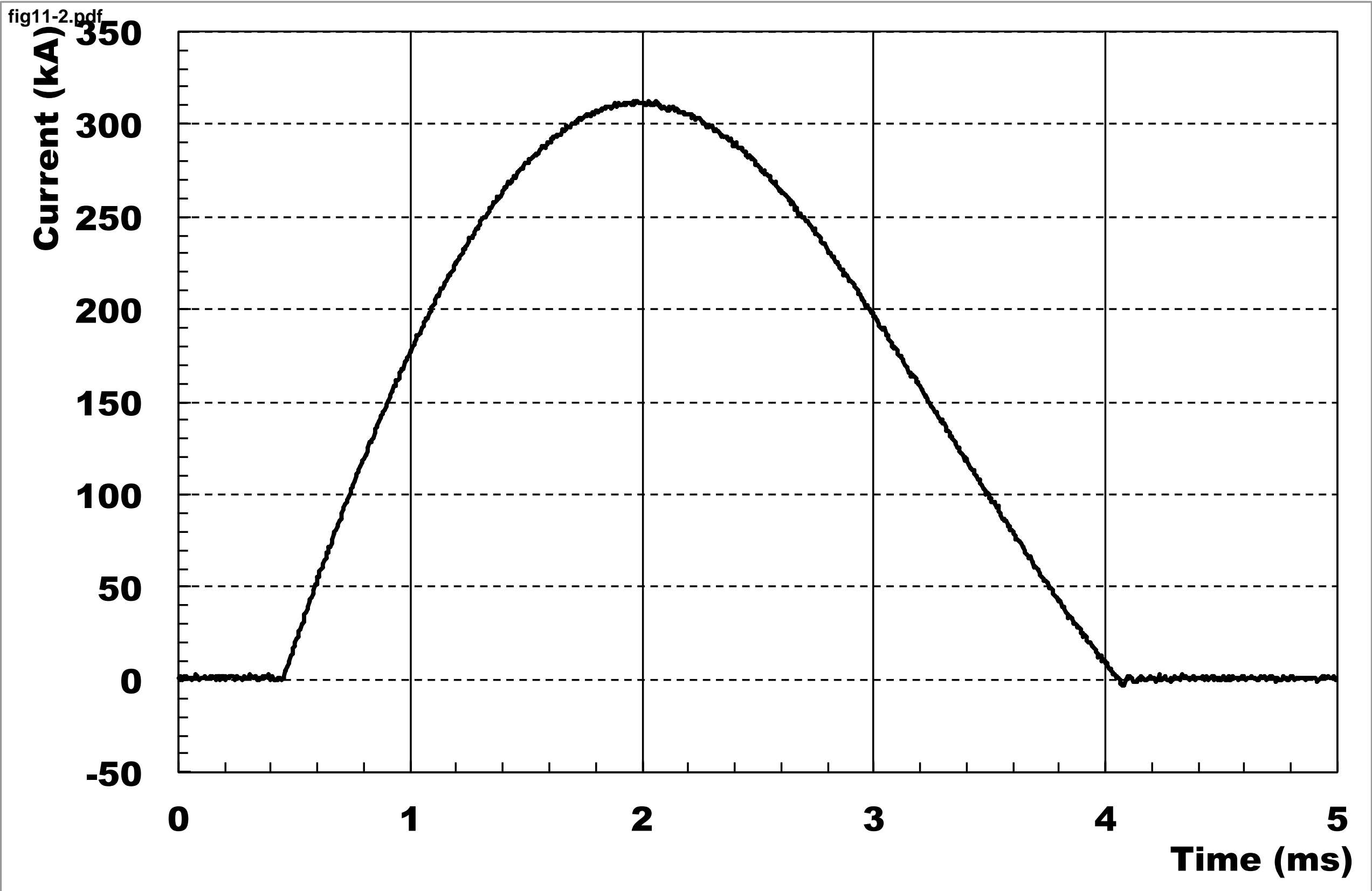




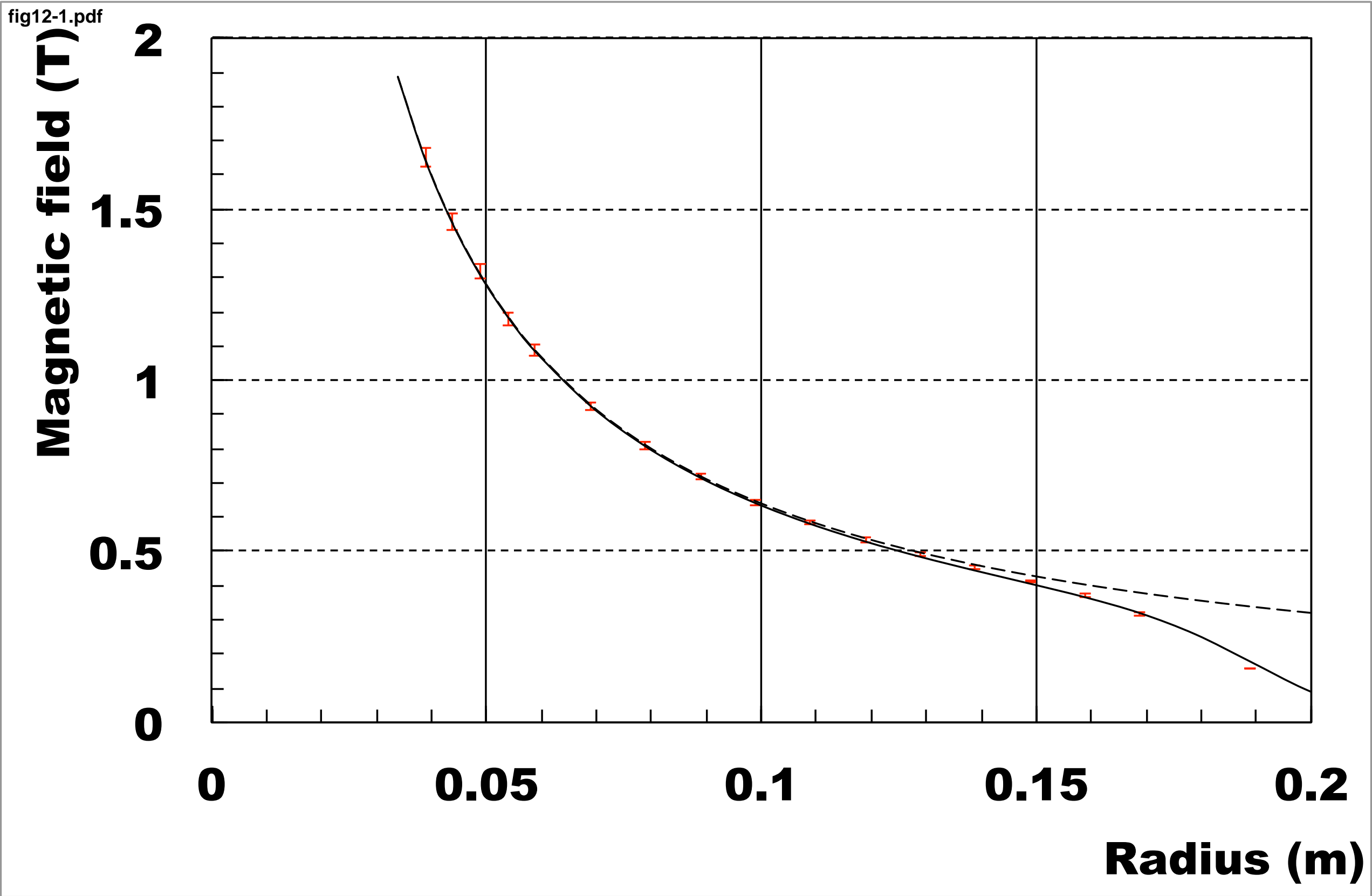

fig12-1.pdf 


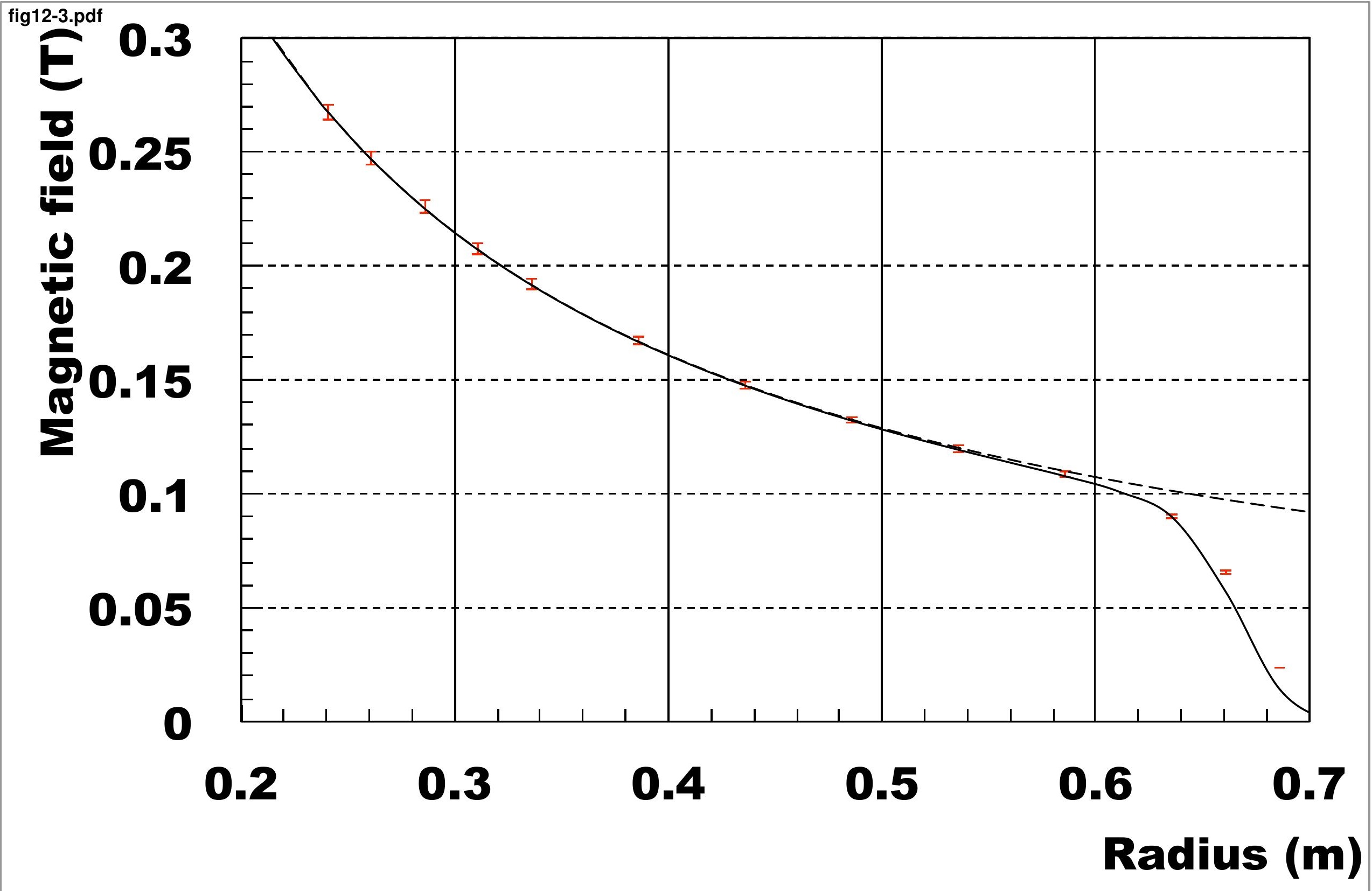

fig12-3.pdf 


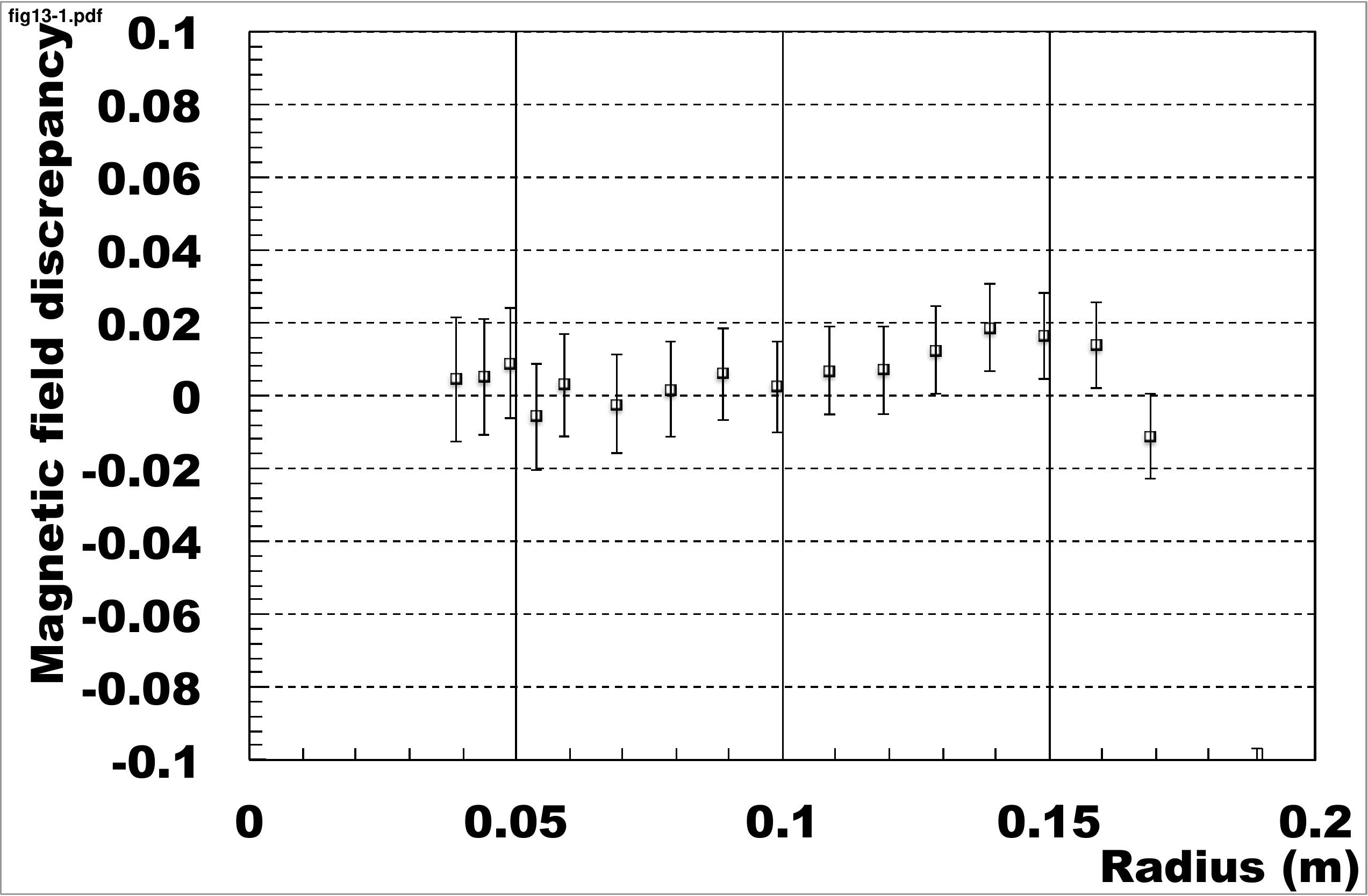




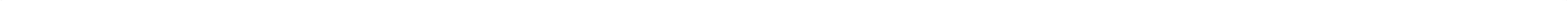




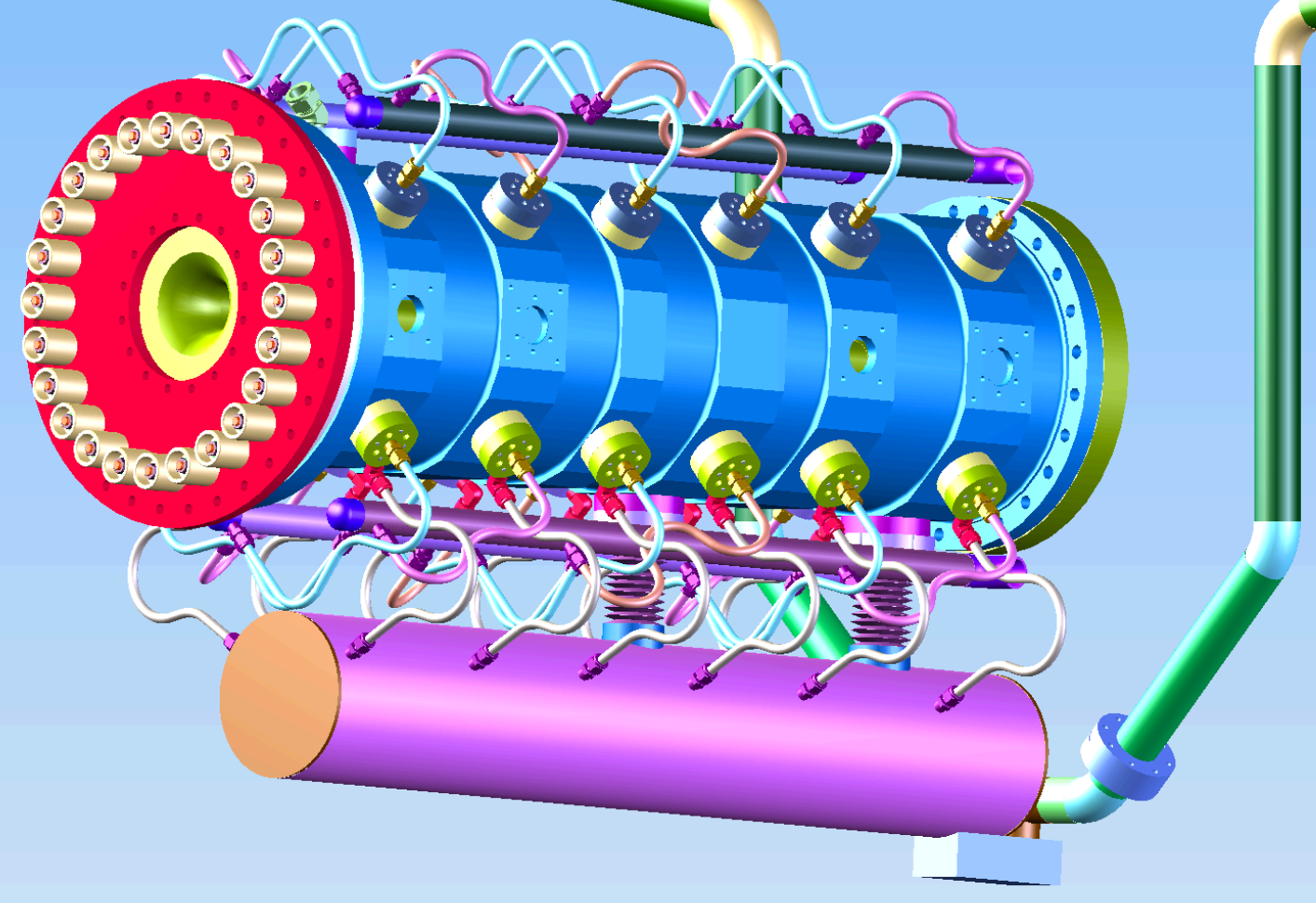


fig15-2.pdf

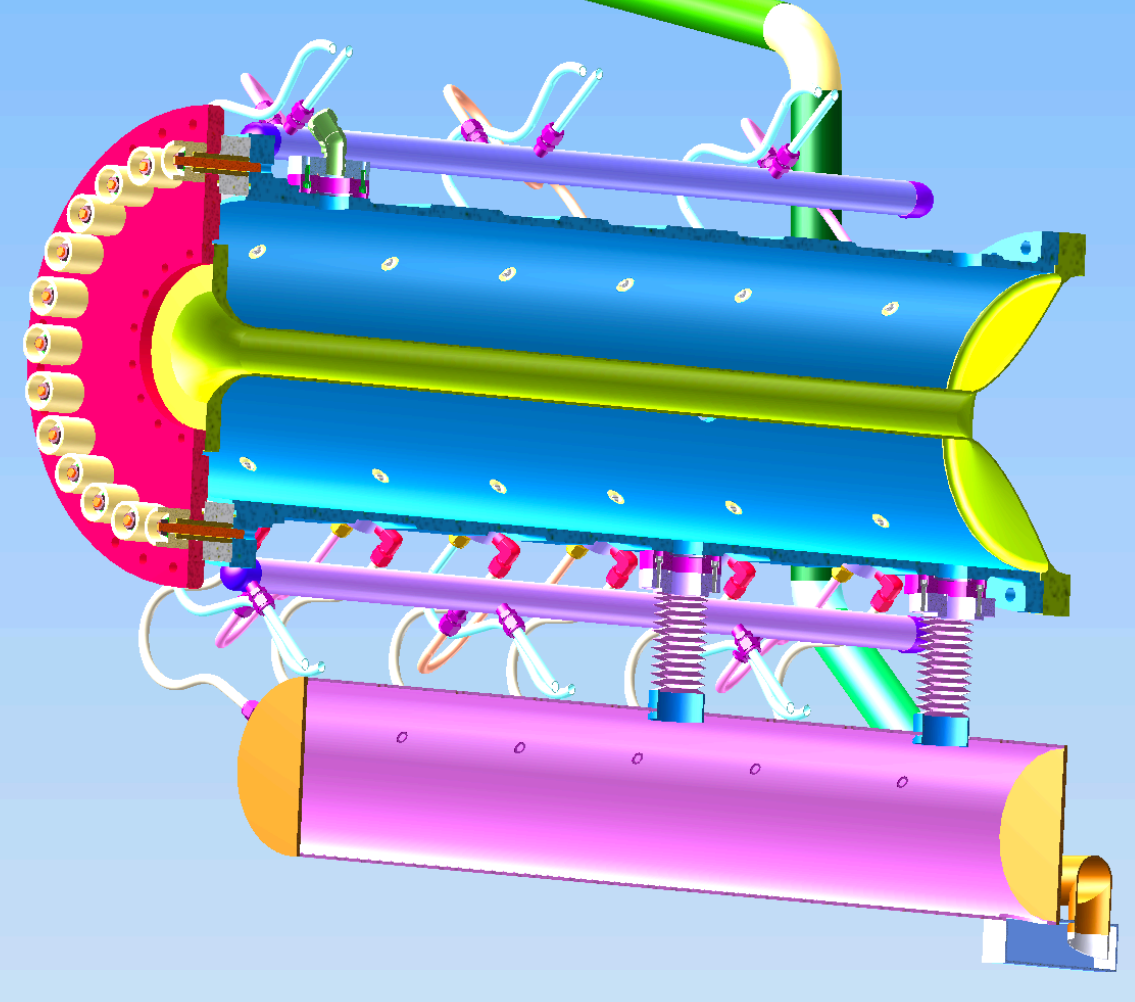




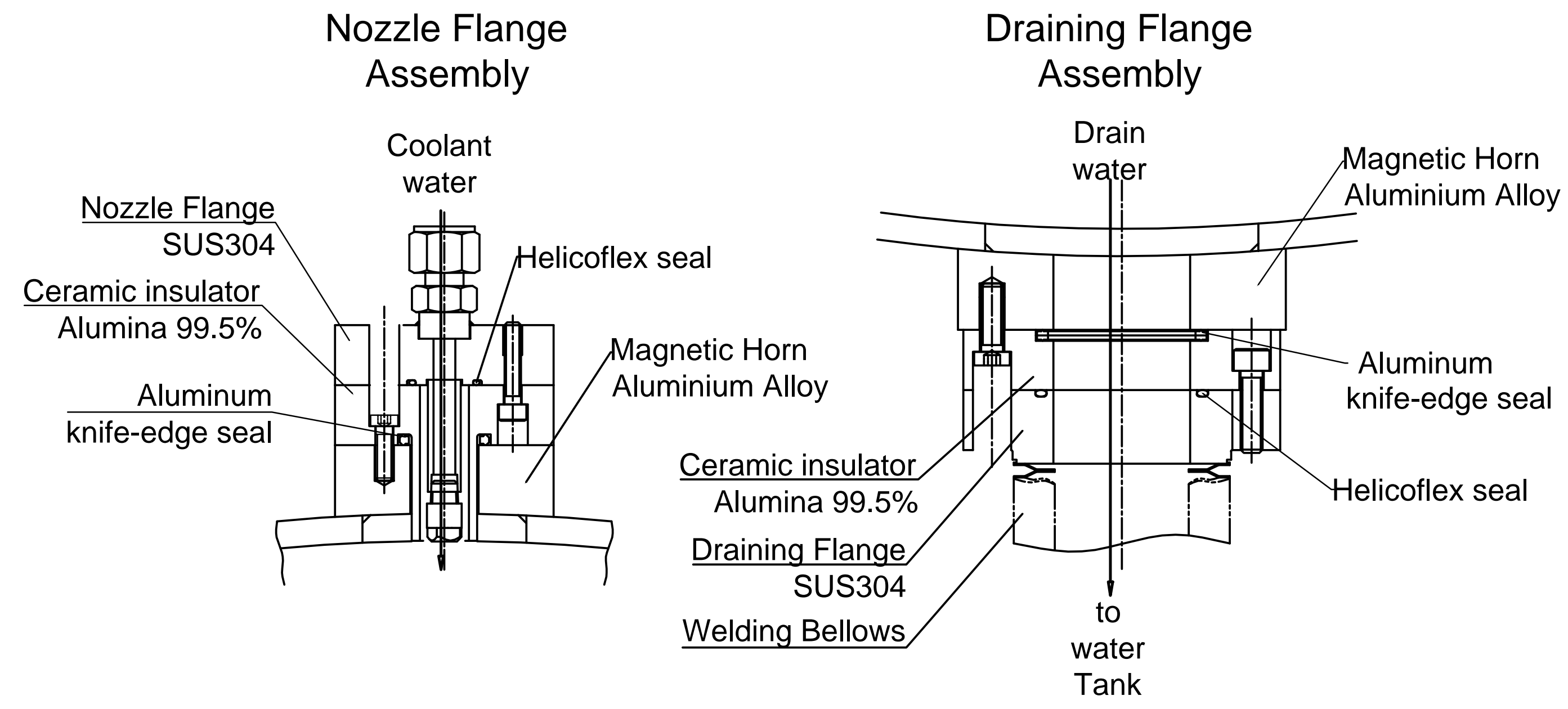


fig17.pdf Aluminum conductor

Ceramic insulator

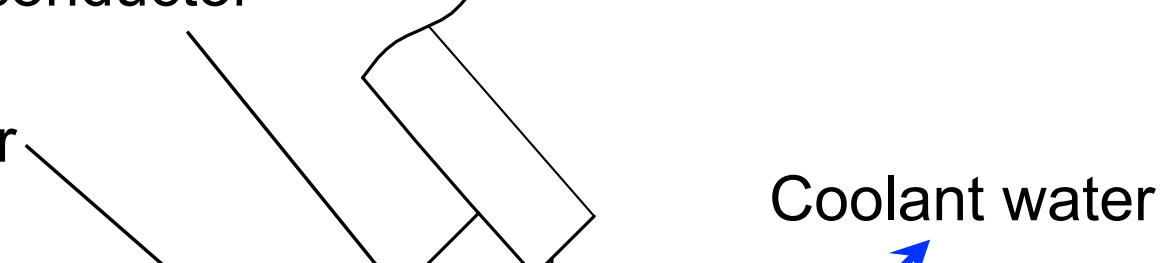

Aluminum knife-edge seal

Nozzle flange

Helicoflex seal

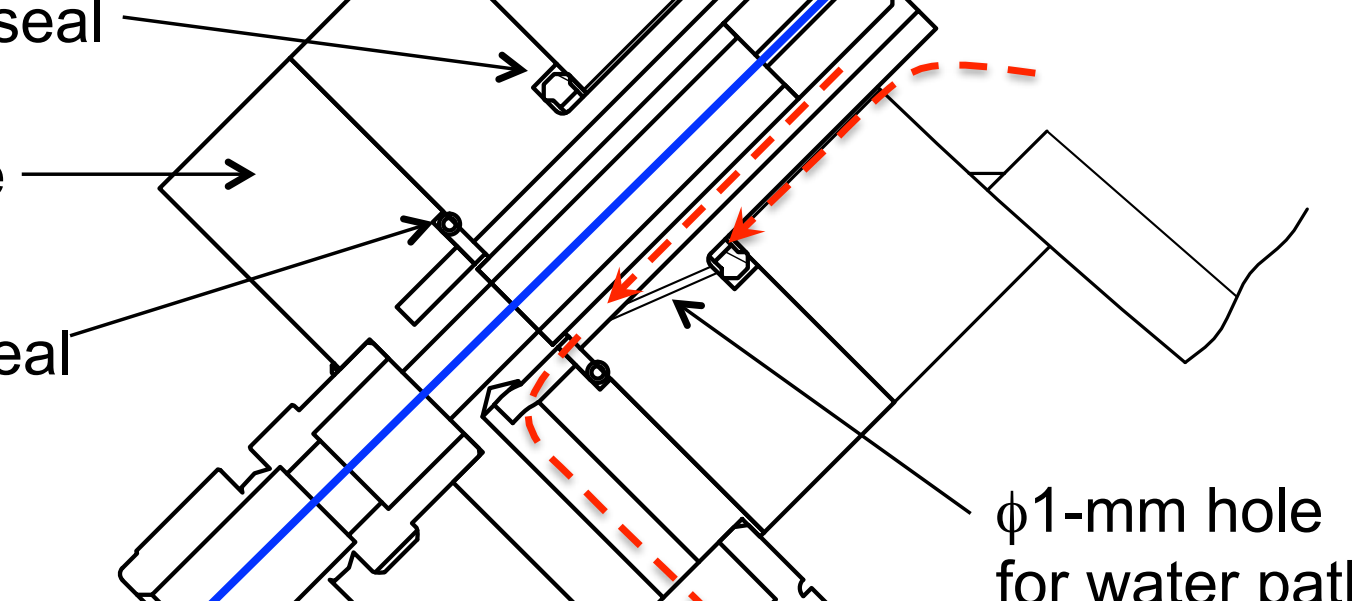

To drain tank Auxiliary drain path 
$\longleftarrow$ Ceramic insulator ring

Outer conductor

O
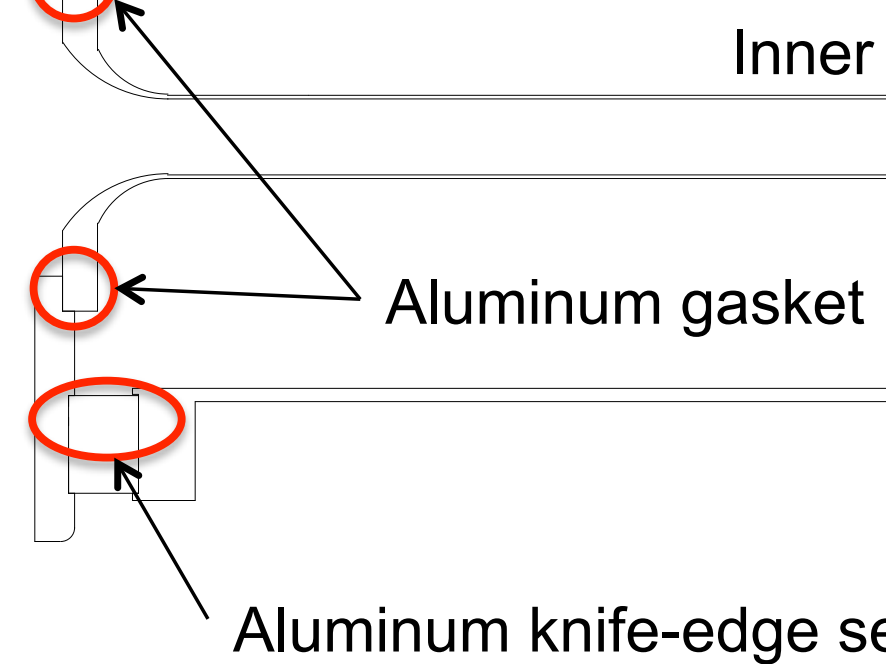

Aluminum knife-edge seal or Helicoflex seal with aluminum jacket

Aluminum gasket or Helicoflex seal with aluminum jacket 


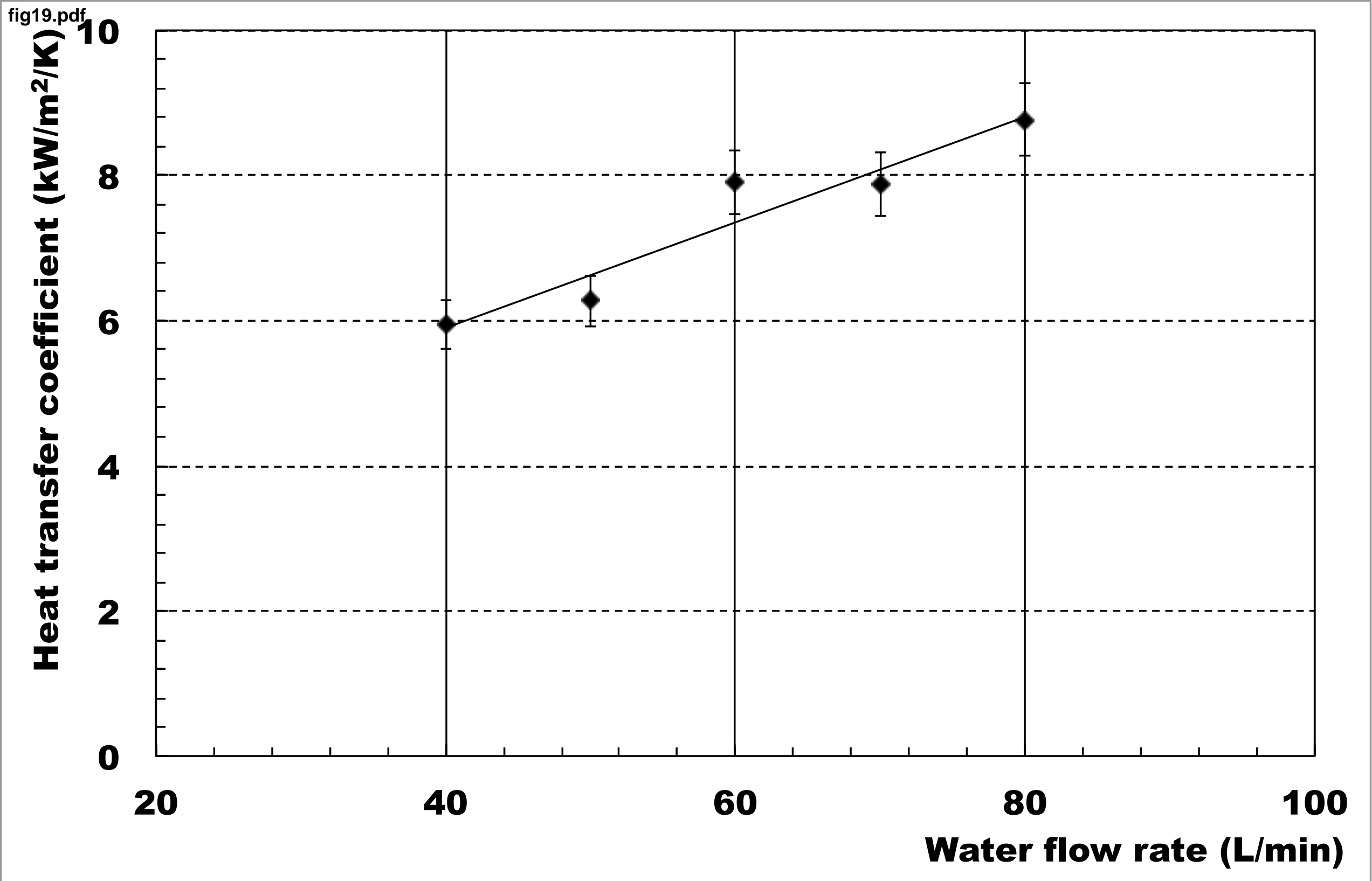




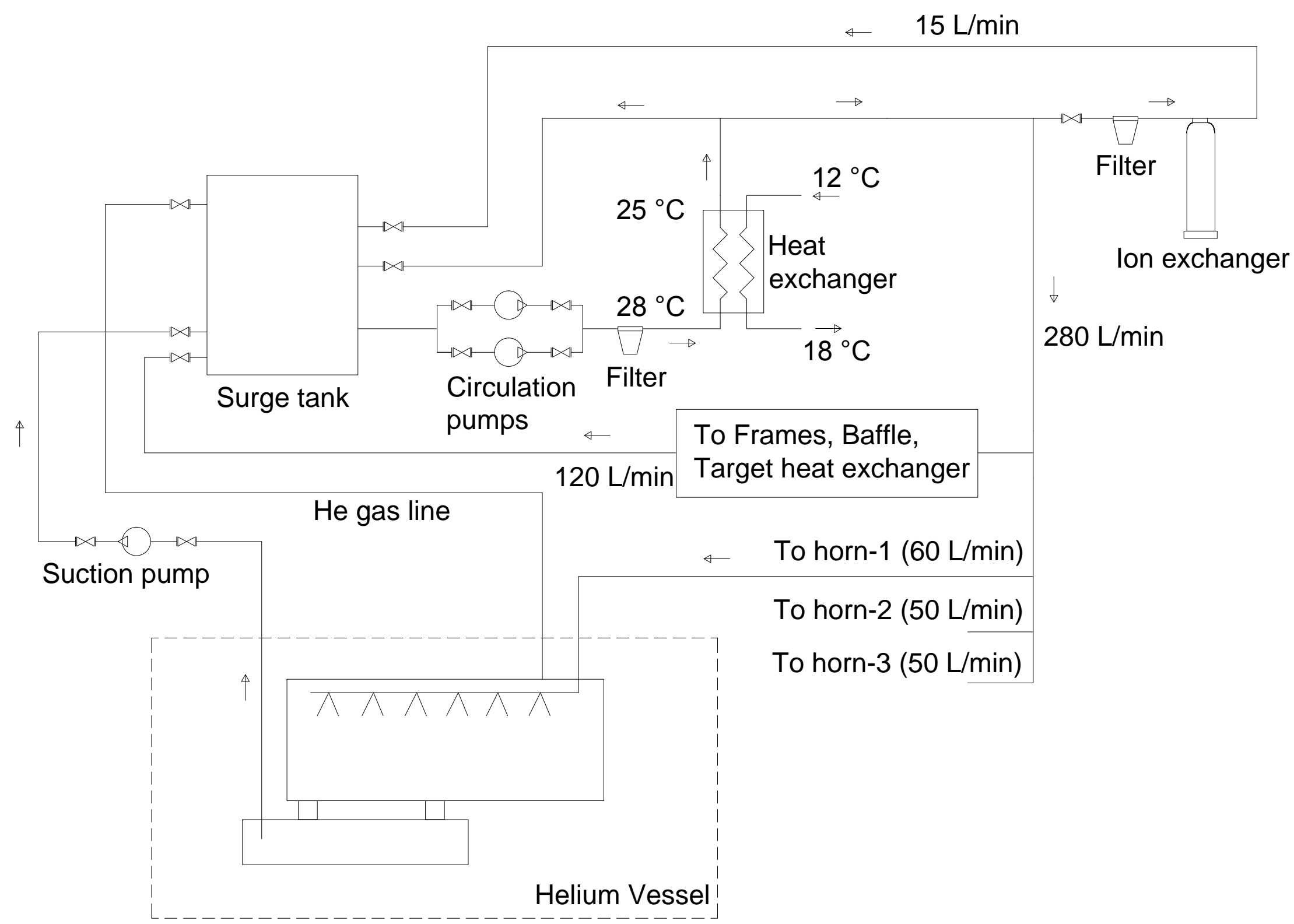




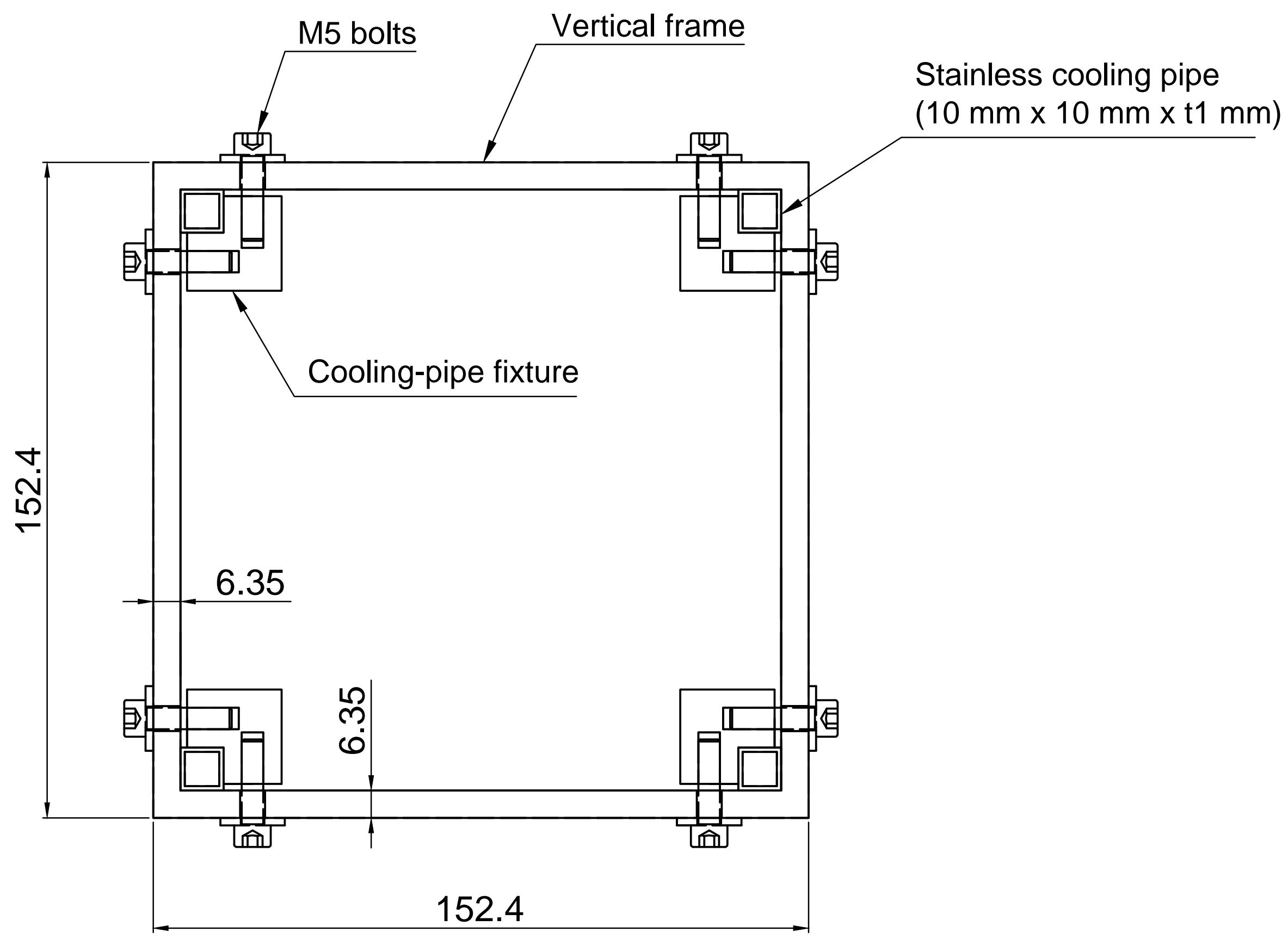




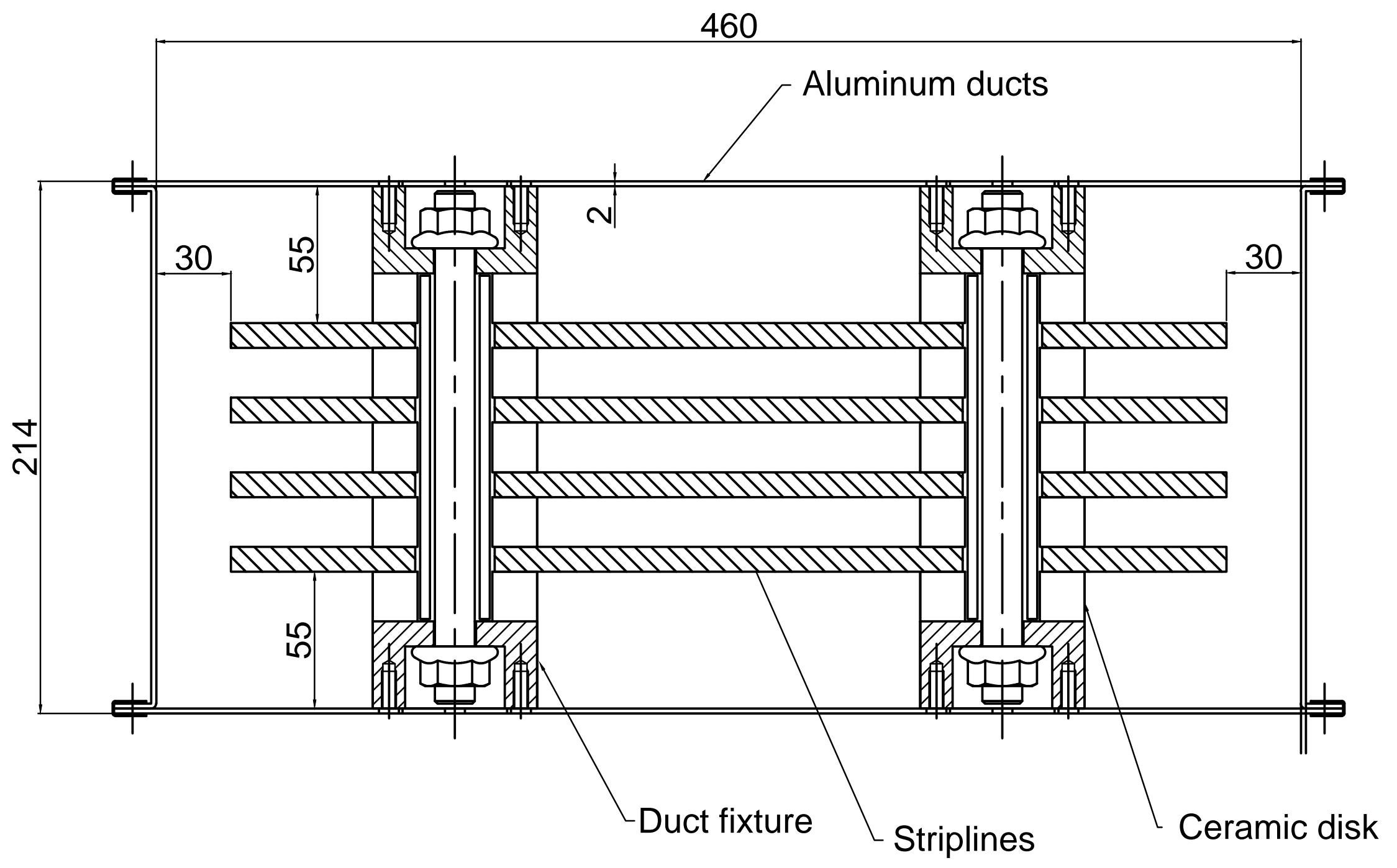




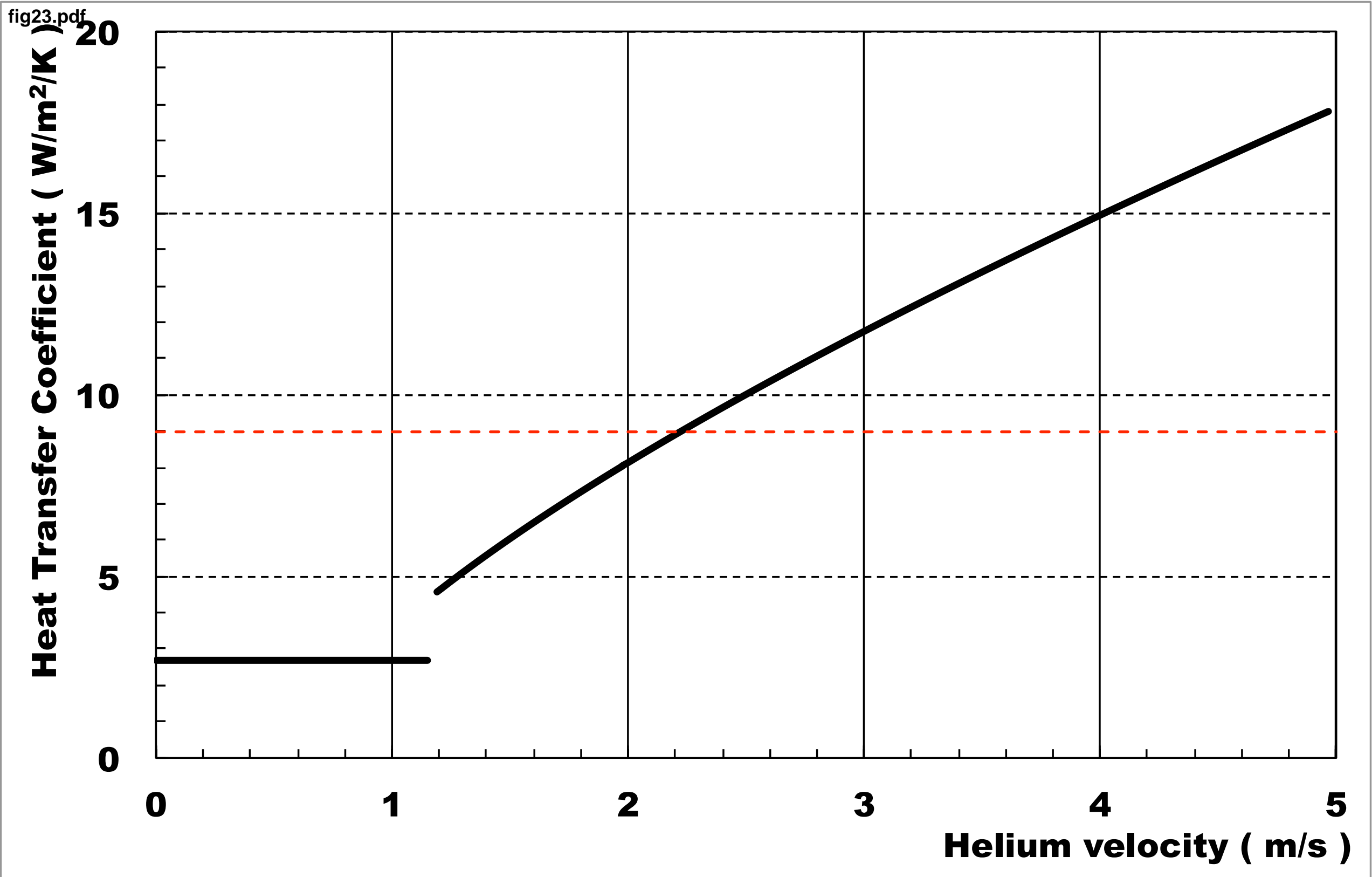


fig25.pdf

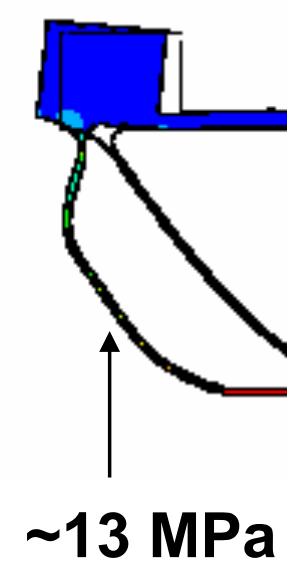

19.2 MPa (max.)

$\sim 13 \mathrm{MPa}$

\section{Beqam}

$\sim 10 \mathrm{MPa}$ 
NODAL SOLUTION

STEP $=1$

SUB $=1$

TIME $=1$

SEQV

DMX = 159

$\mathrm{SMN}=42076$

$\mathrm{SMX}=.244 \mathrm{E}+08$
NN

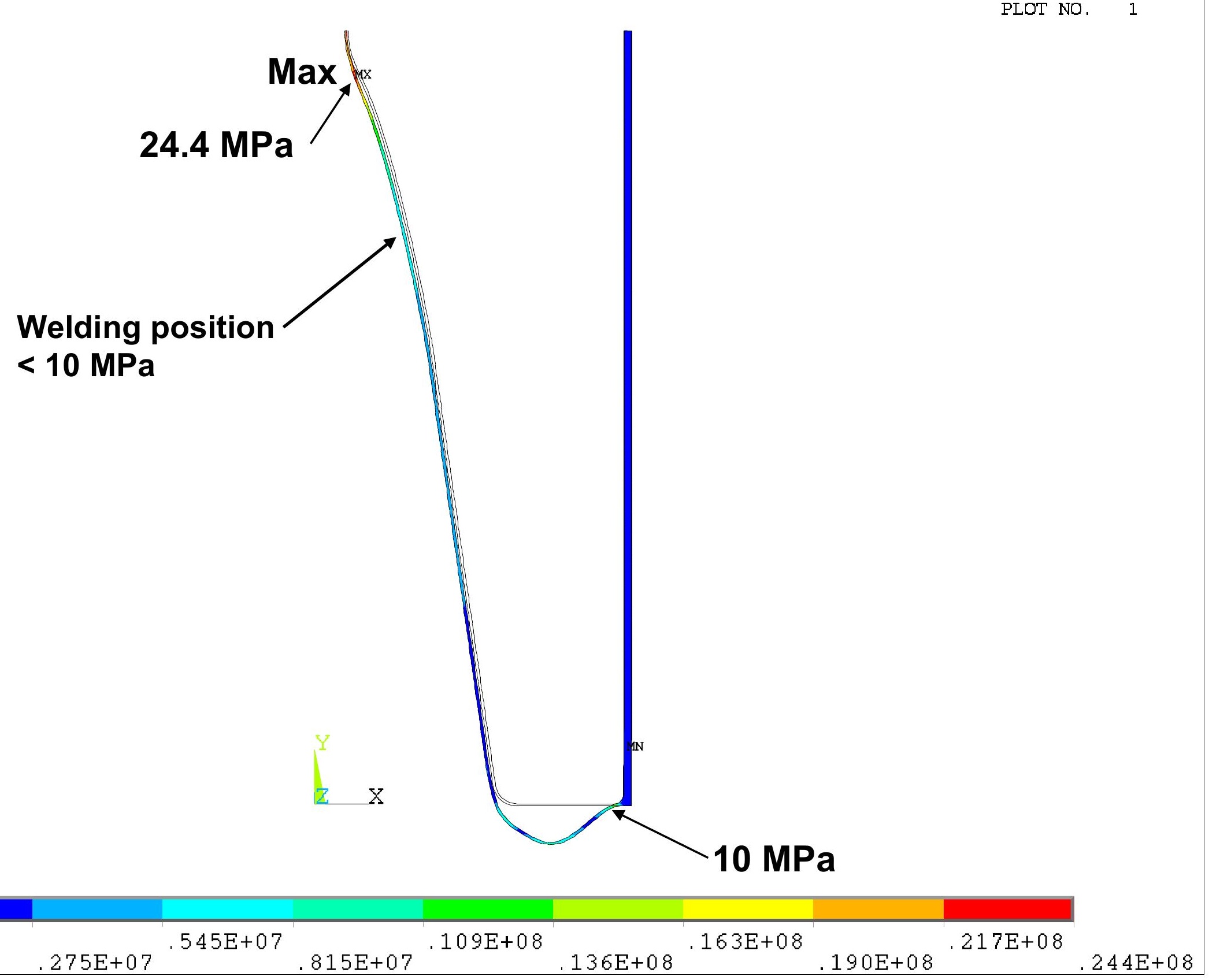


STEP $=1$

SUB $=1$

$T$ IME $=1$ SEQV

$\mathrm{DMX}=245$

$5 \mathrm{MIT}=25777$

$S M X=.195 E+08$
FEB 32004 $10: 56: 05$

PLOT NO. 1

\section{$10 \mathrm{MPa}$}


ing26r4 .pdf

(MID)

(Elem )

( $* 1 . E+01)$

$\mathbf{+ 3 . 0 0 3 5}$
$\mathbf{+ 2 . 6 2 8 7}$

$+\mathbf{+ 2 . 6 2 8 7}$

$+1.8791$

$+1.5043$

$+1.1294$

$+0.7546$

$+0.3798$

$+\mathbf{0 . 0 0 5 0}$

+30 MPa @T=0.208 ms

Max

CONTOUR. STEP $=208$ TIME $=5.00020 E+00$

J-PARC_THERMAL_STRESS/CADAS TO LS-DYNA 
fig28.2.pdf

(MID)

$\left(\begin{array}{lll}(\text { Elem }) \\ (* 1 . E+01)\end{array}\right.$

$+0.8679$

$+0.3461$

$-0.1757$

$-0.6975$

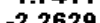

$-3.3065$

-33 MPa @T=0.208 ms

Min

$\sum_{Y} \mathrm{Y}$ CONTOUR. STEP $=208$ TIME $=5.00020 \mathrm{E}+00$

J-PARC_THERMAL_STRESS/CADAS TO LS-DYNA

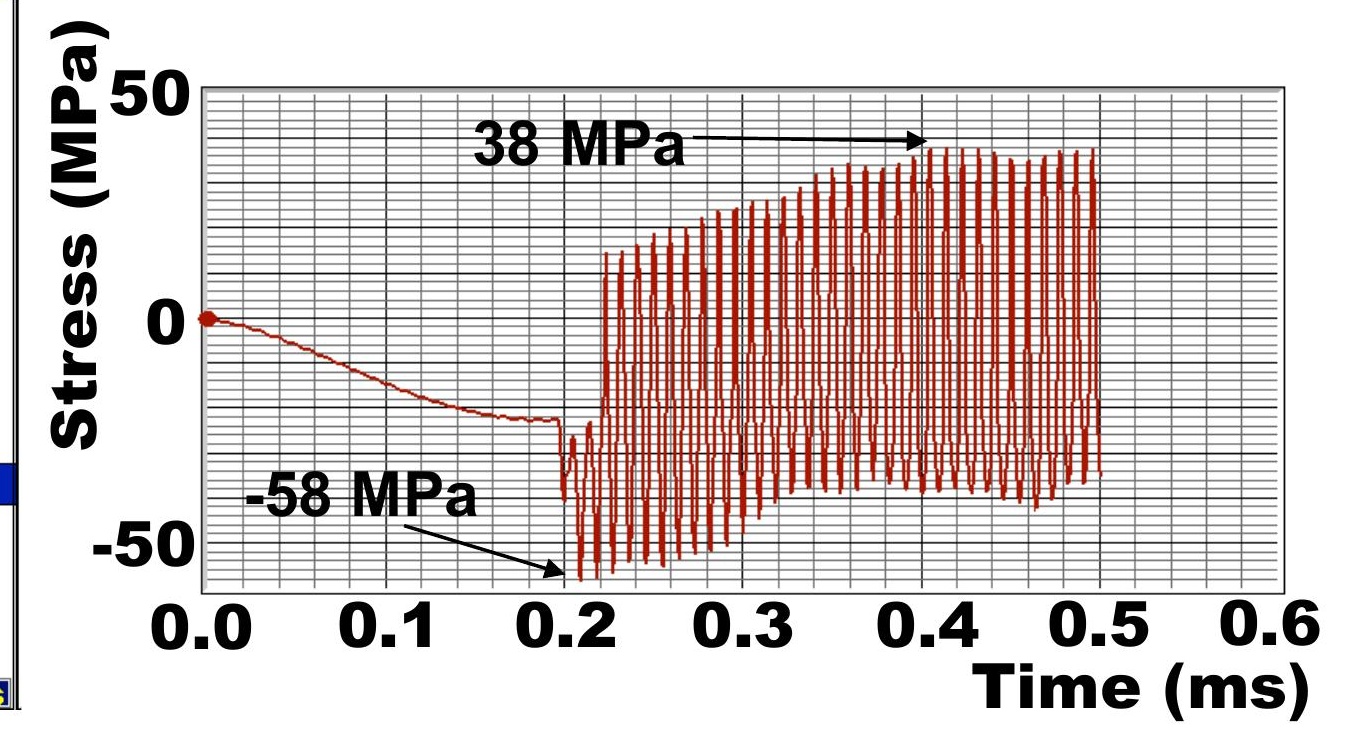




\section{fif29-1}

\section{(MID}

(Elem)

(*1.E+01)

$+1.8251$

$+1.5971$

$+1.3691$

$+1.1411$

$+0.9131$

$+0.6851$

$+0.4570$

$+0.2290$

$+0.0010$

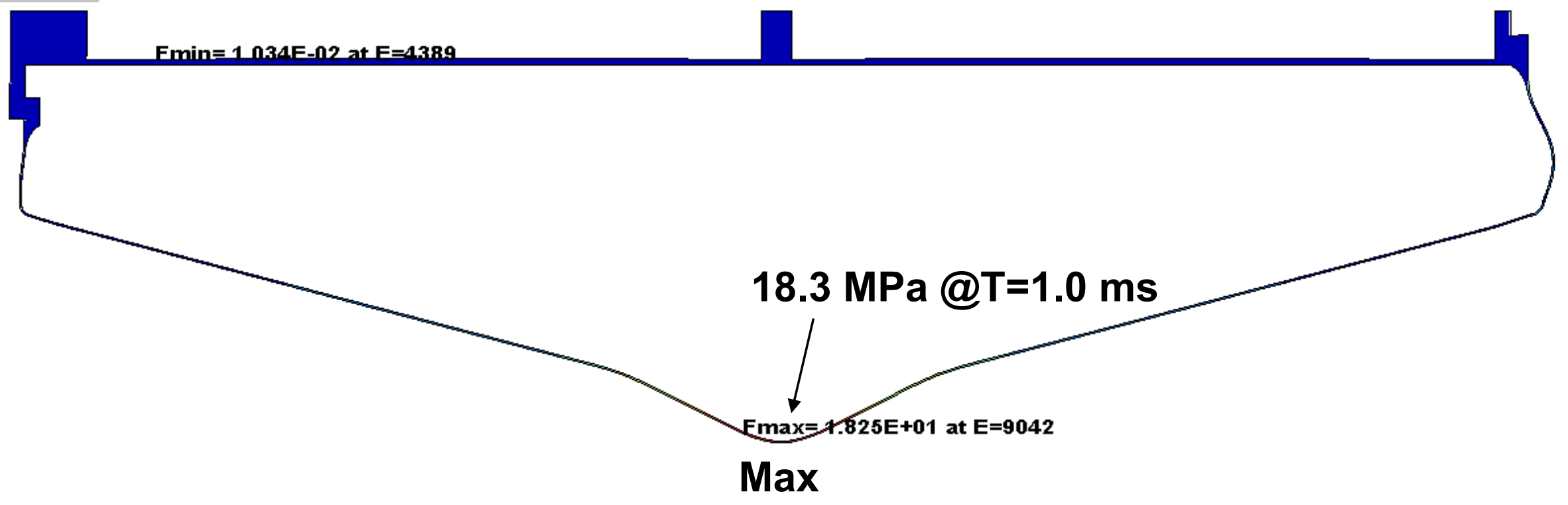

$\int_{Y}^{X}$

CONTOUR. STEP $=101$ TIME $=1.00999 E-03$

ICADAS 
figrg-2.pdf (MID)

(Elem)

(*1.E+01)

$+1.8251$

$+1.6555$

$+1.4860$

$+1.3164$

$+1.1469$

$+0.9773$

$+0.8078$

$+0.6382$

$+0.4687$
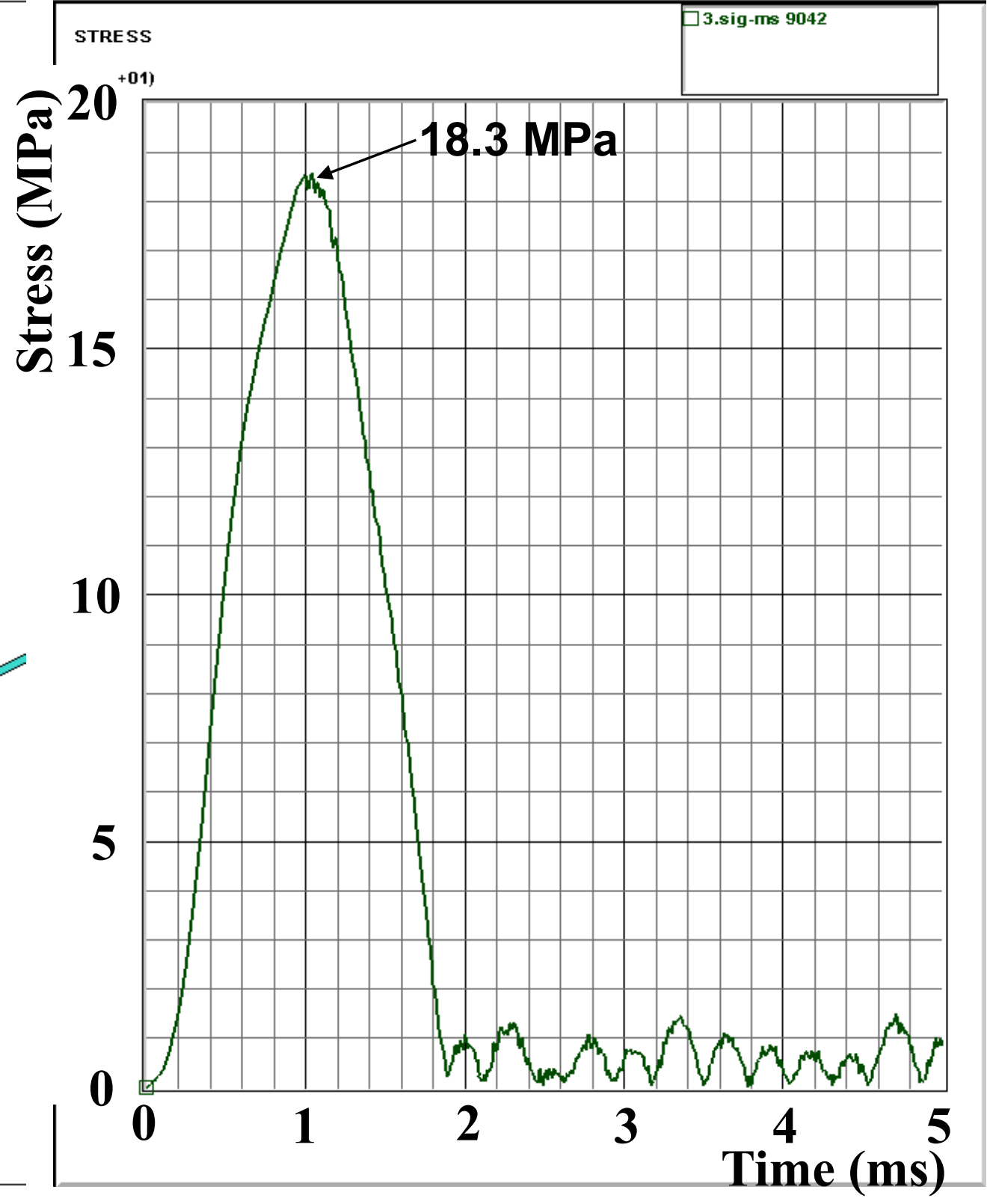

18.3 MPa @T=1.0 ms
$\operatorname{Max}$

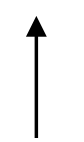

\section{ax}
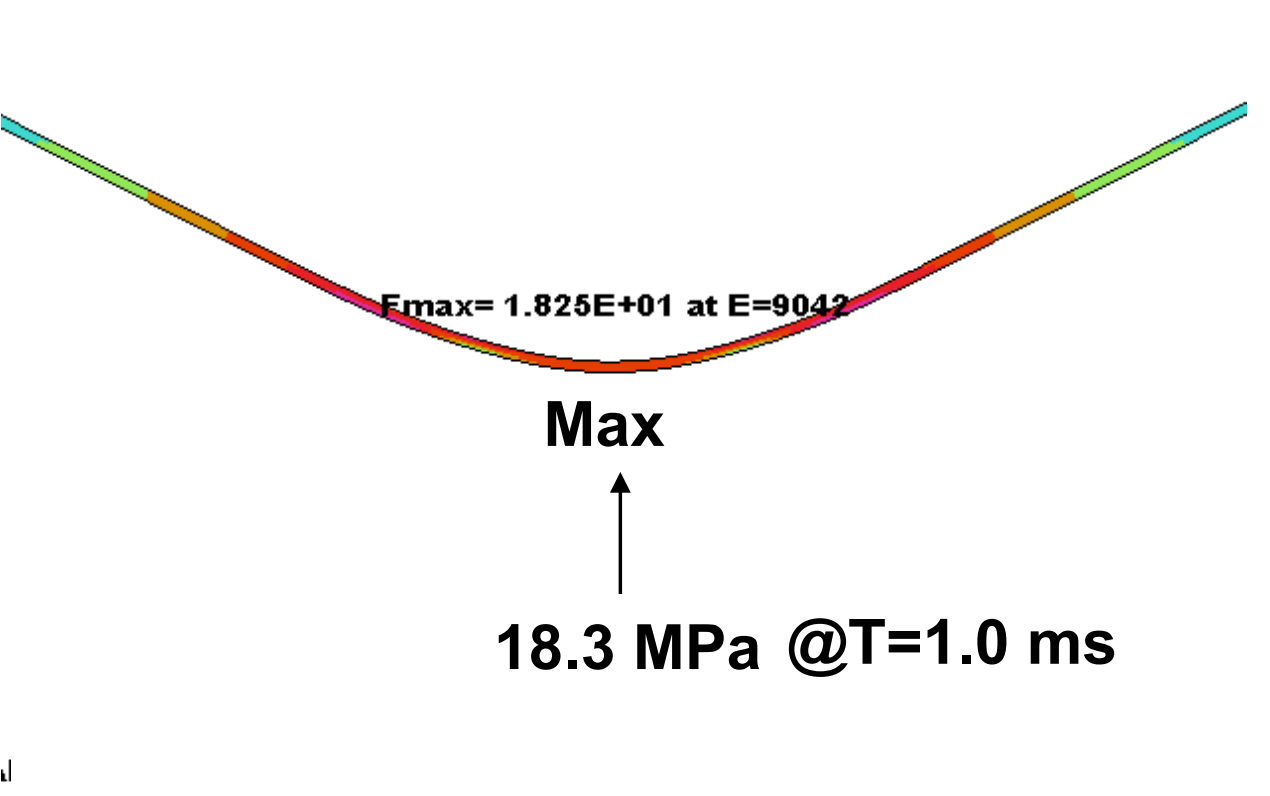


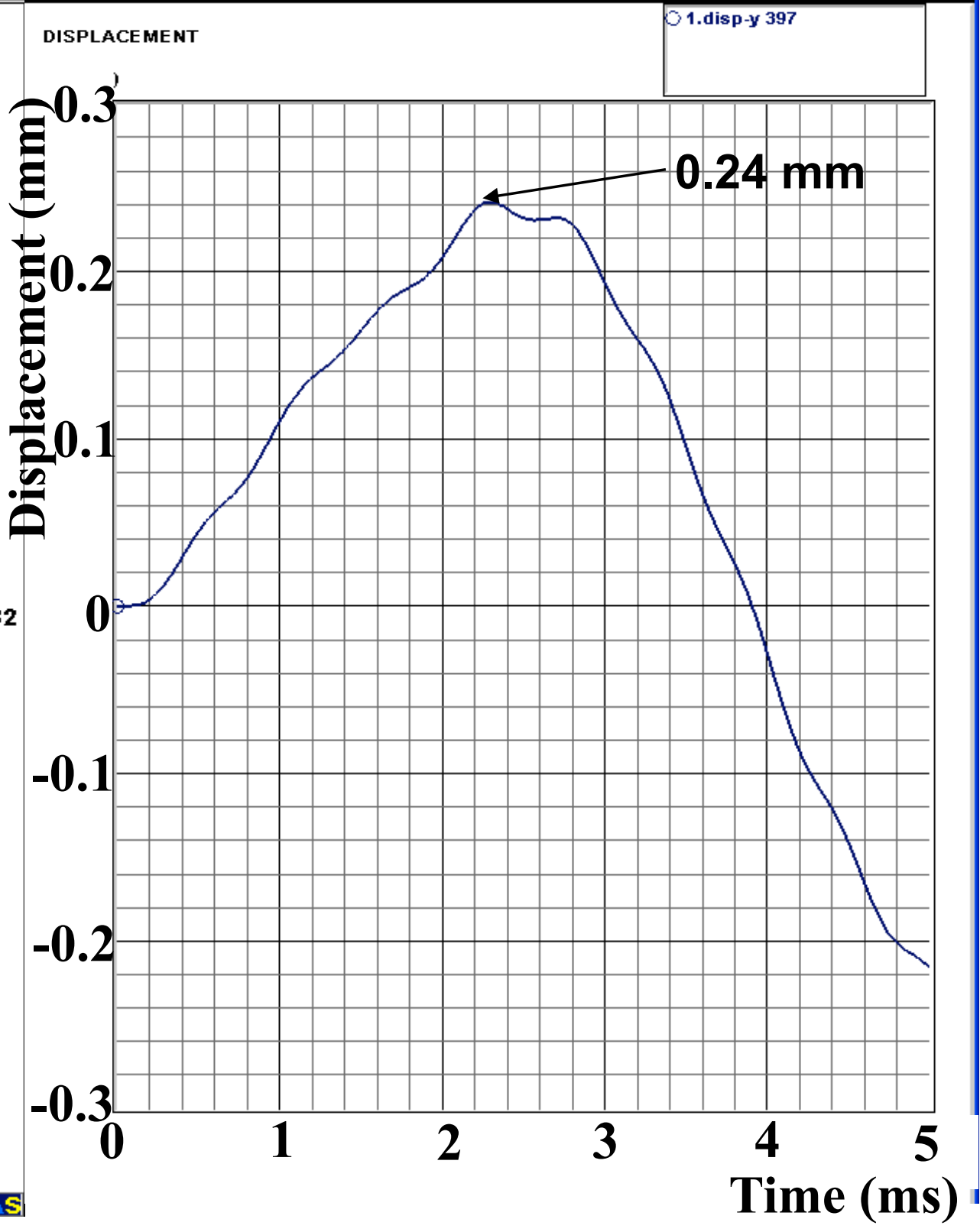




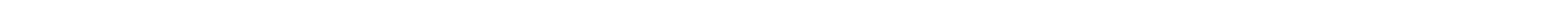


$-1$

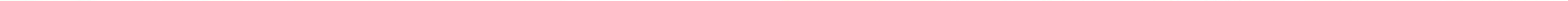

\section{handling machine}
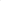

\section{Guide frames for horn}
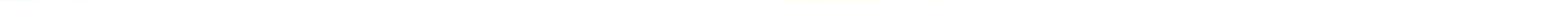

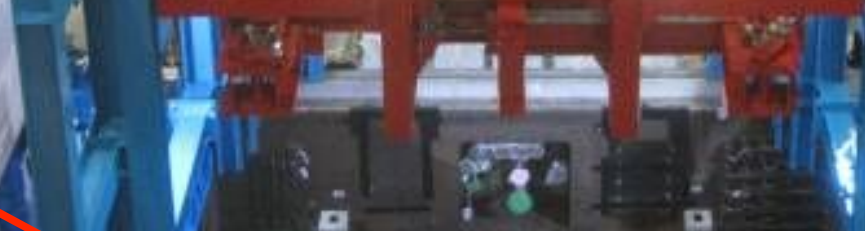

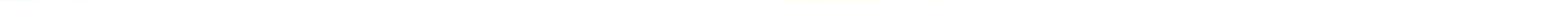

$2 x-5=1.10$
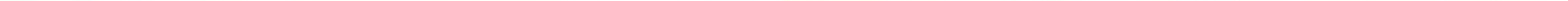


\section{fig32.pdf}

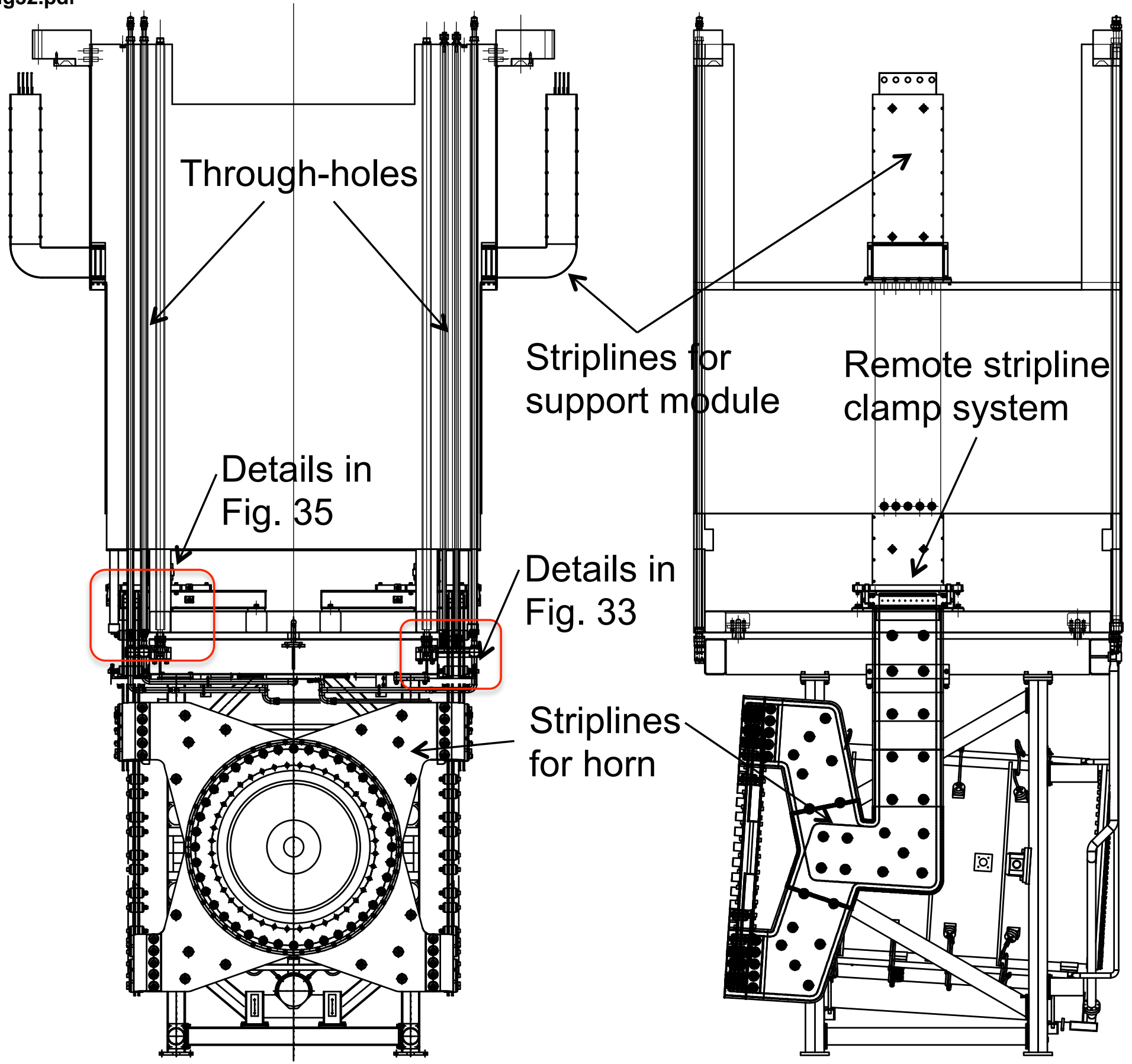




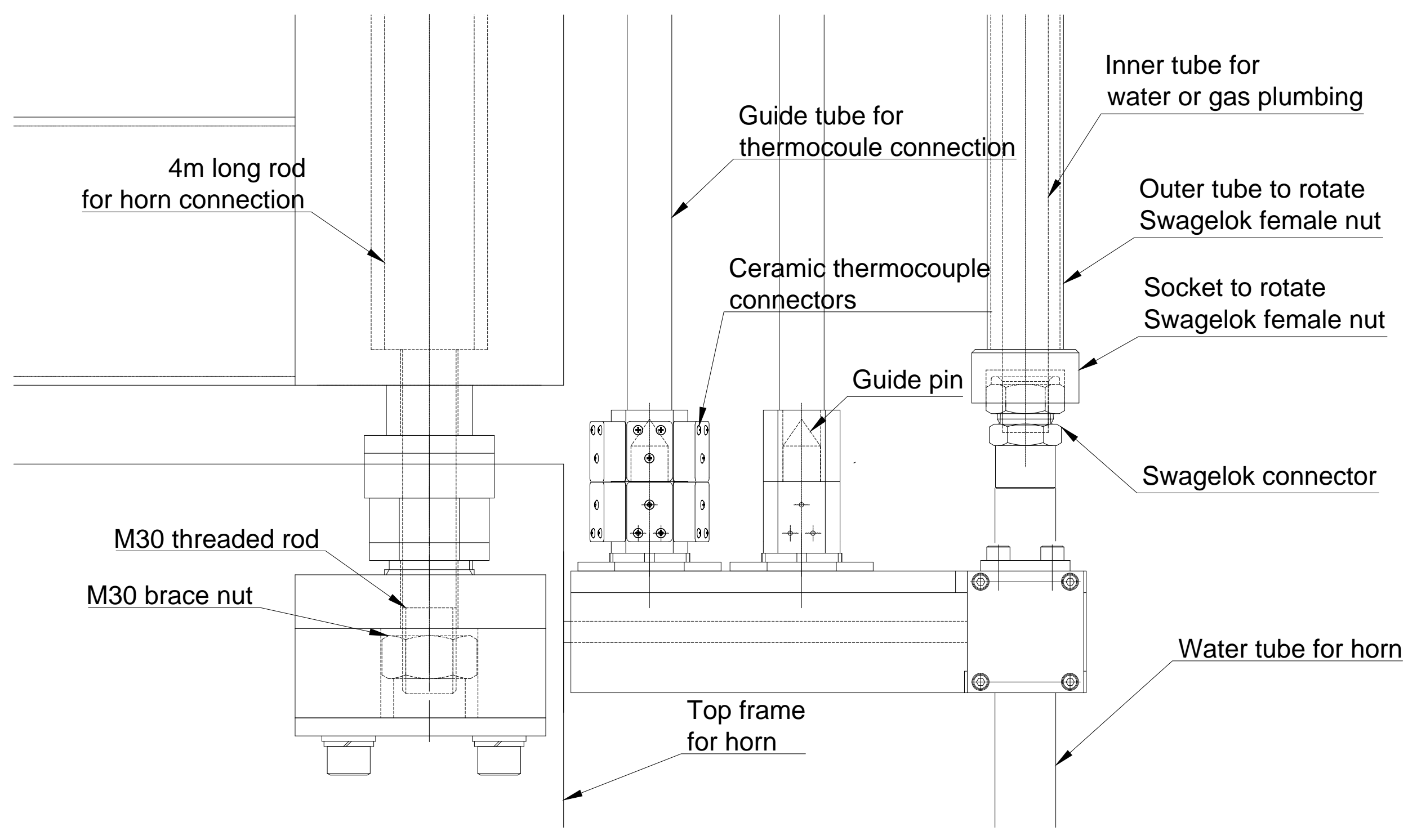

30 threaded rod
Guide tube for thermocoule connection

Outer tube to rotate

Socket to rotate

Swagelok female nut

Swagelok connector

water or gas plumbing 


\section{fig34-\$pdf}

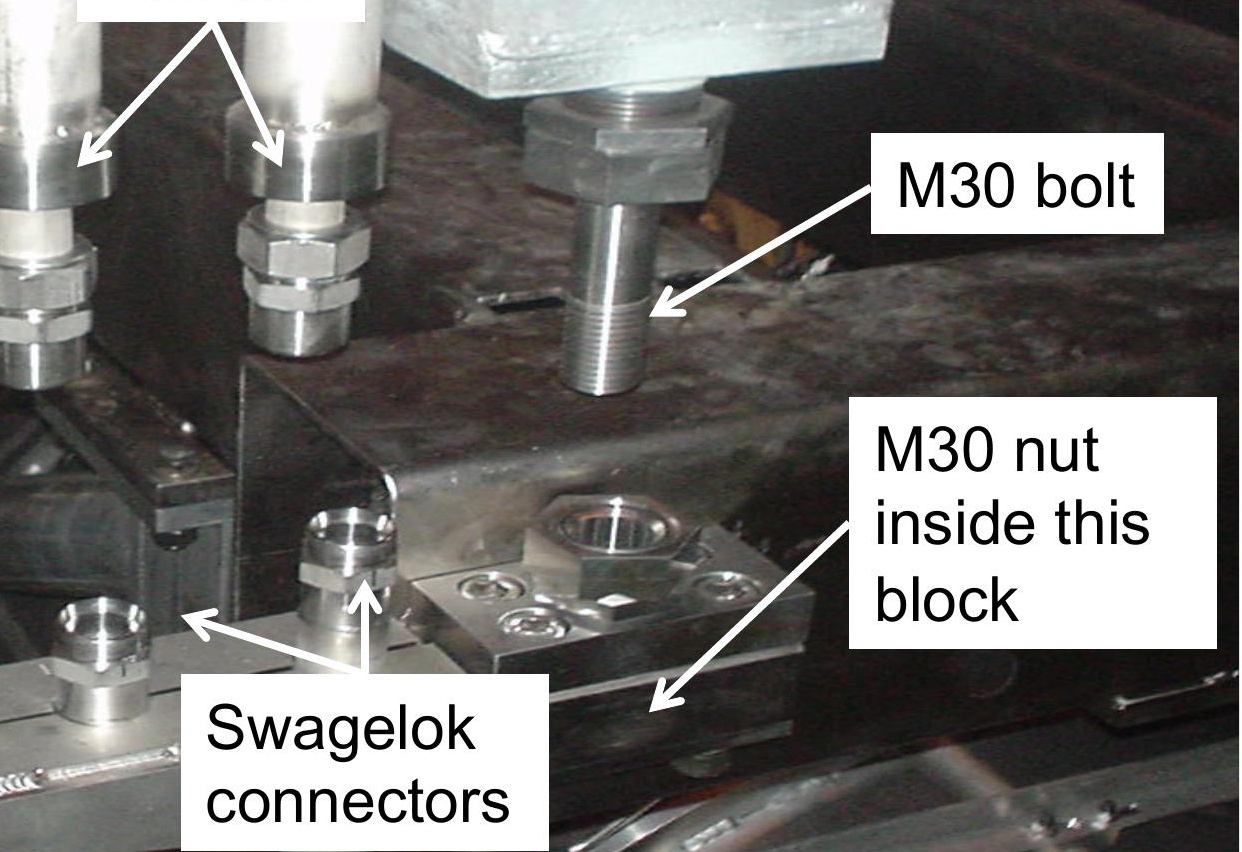




\section{fig34-2.pdf}
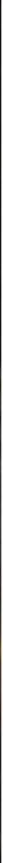


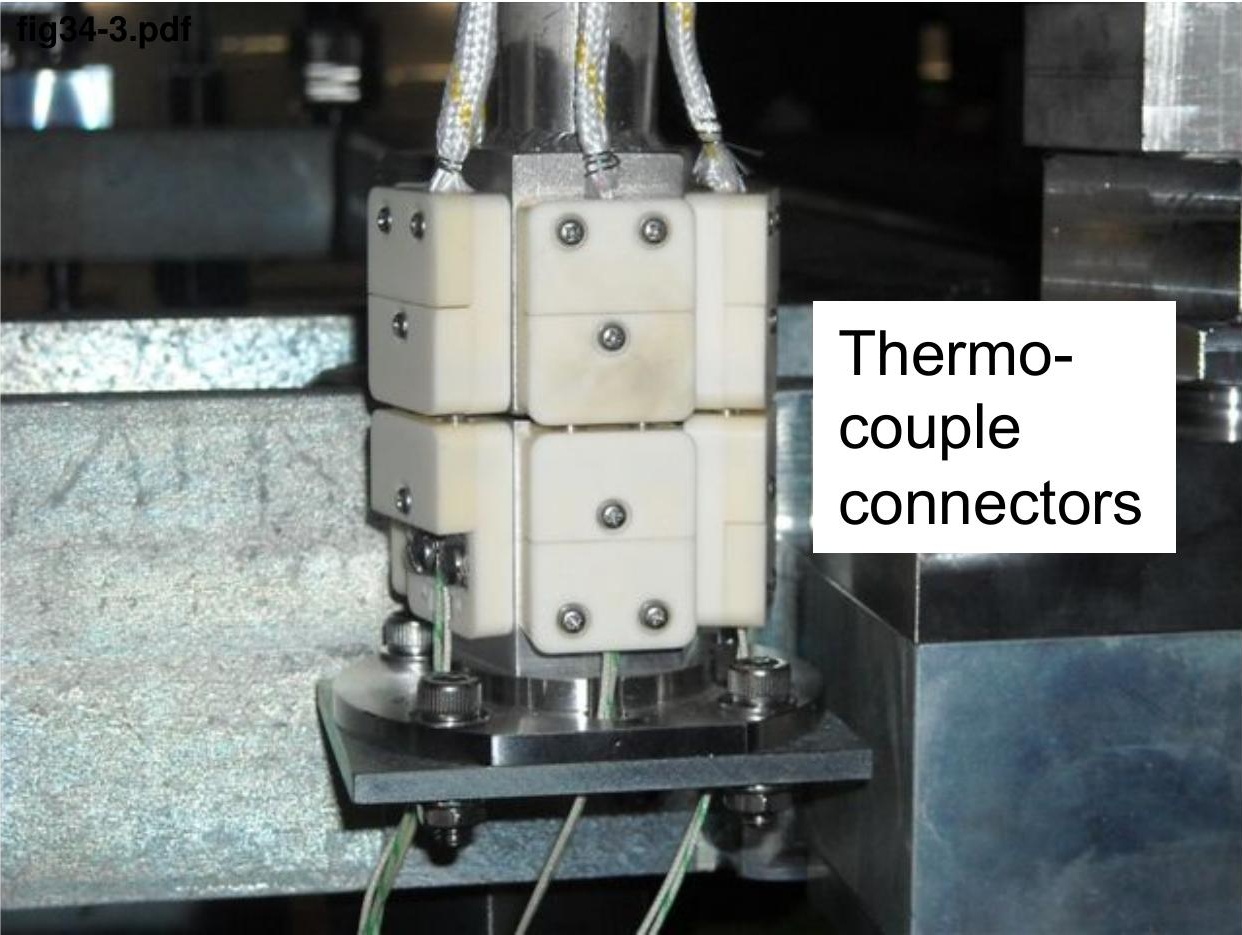



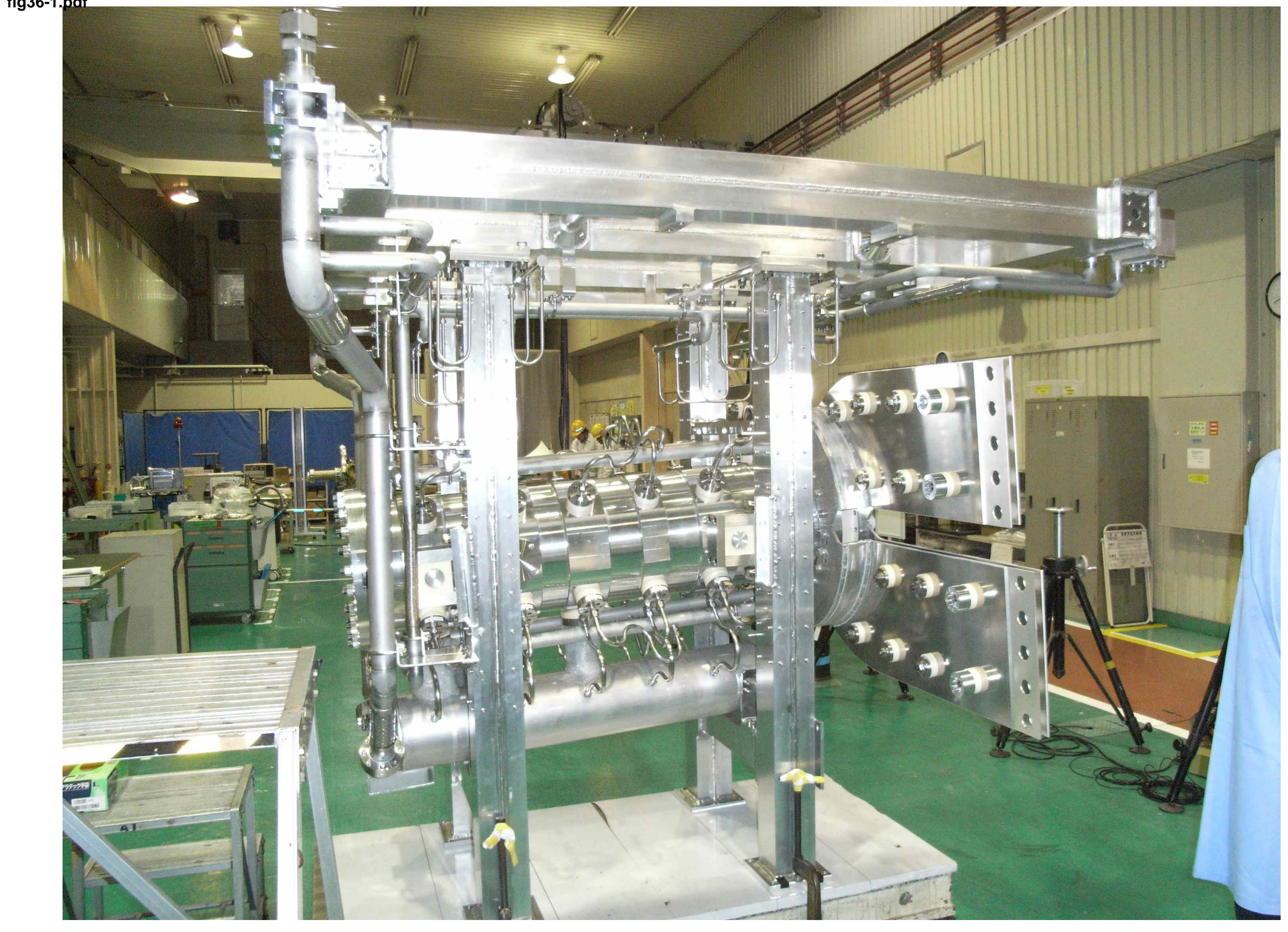

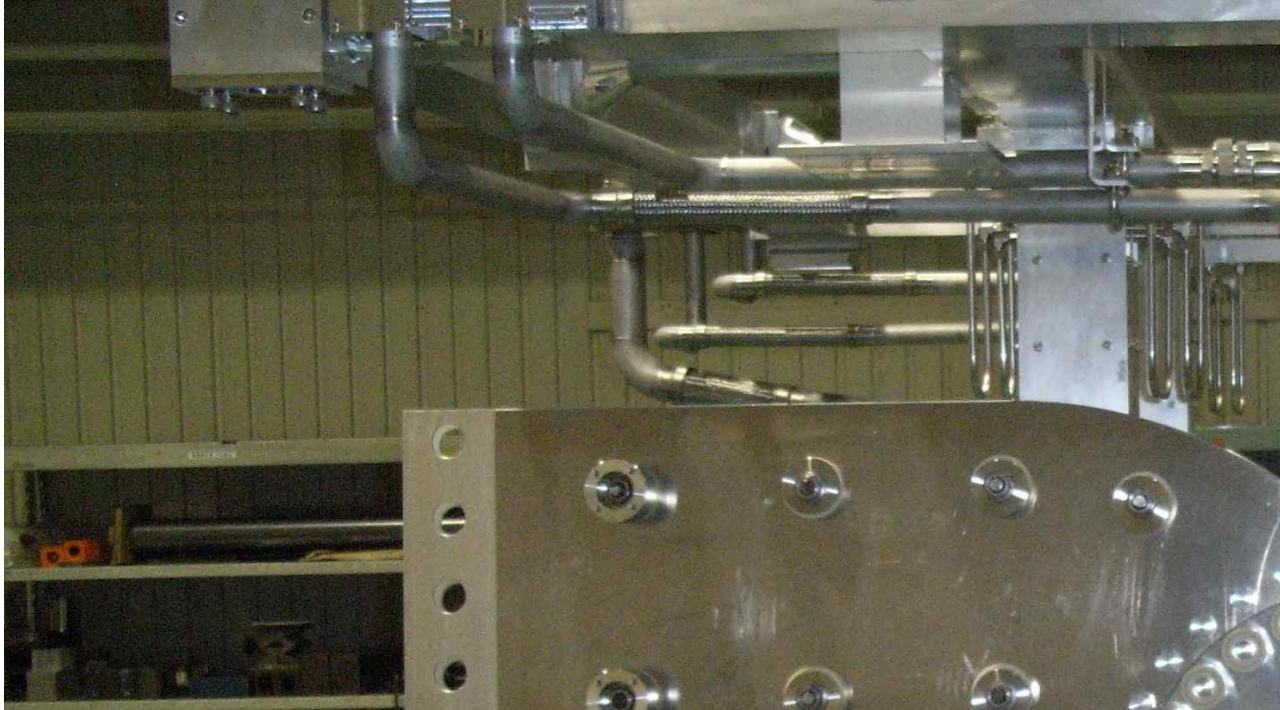

$=5,-3 \quad 9 \quad 0$

i.

e. $\cdots$

त):(Q): as :

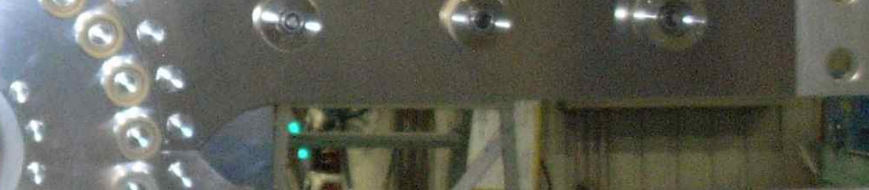

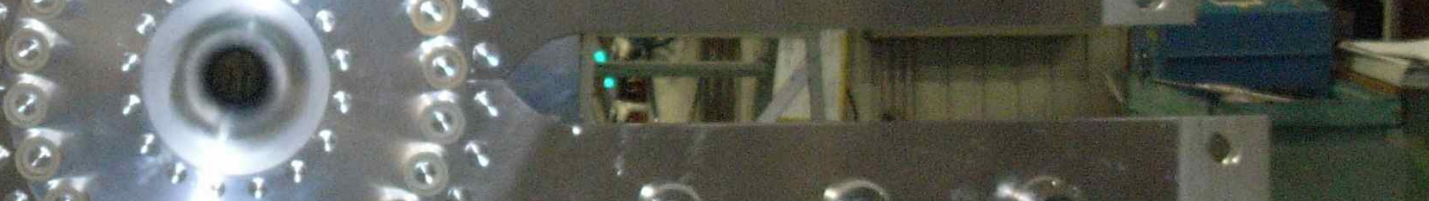

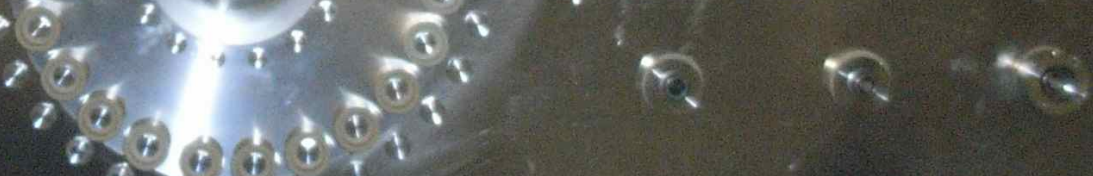

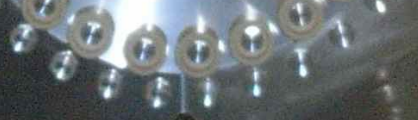
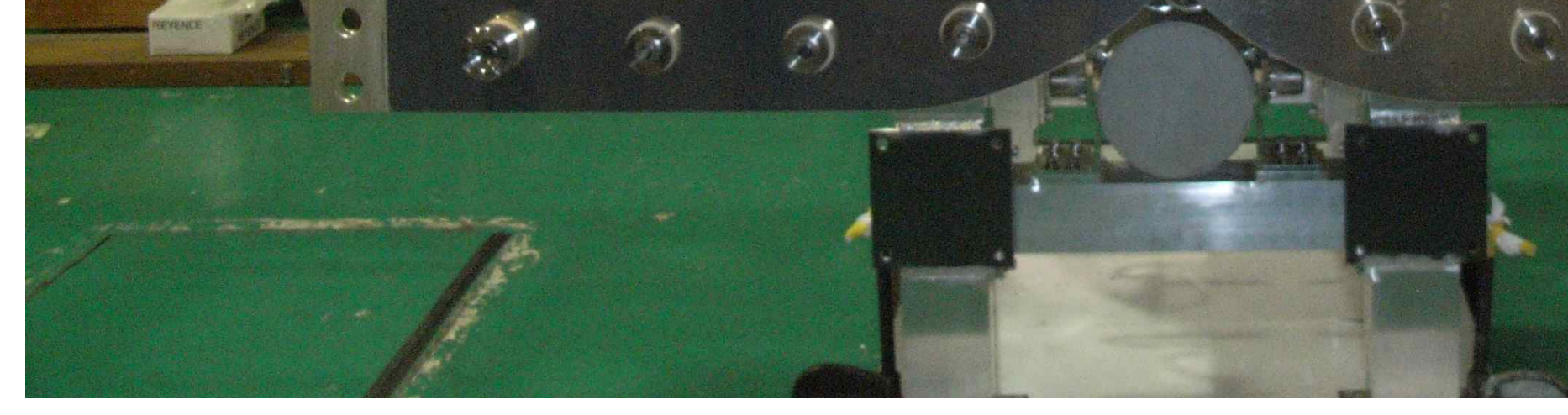

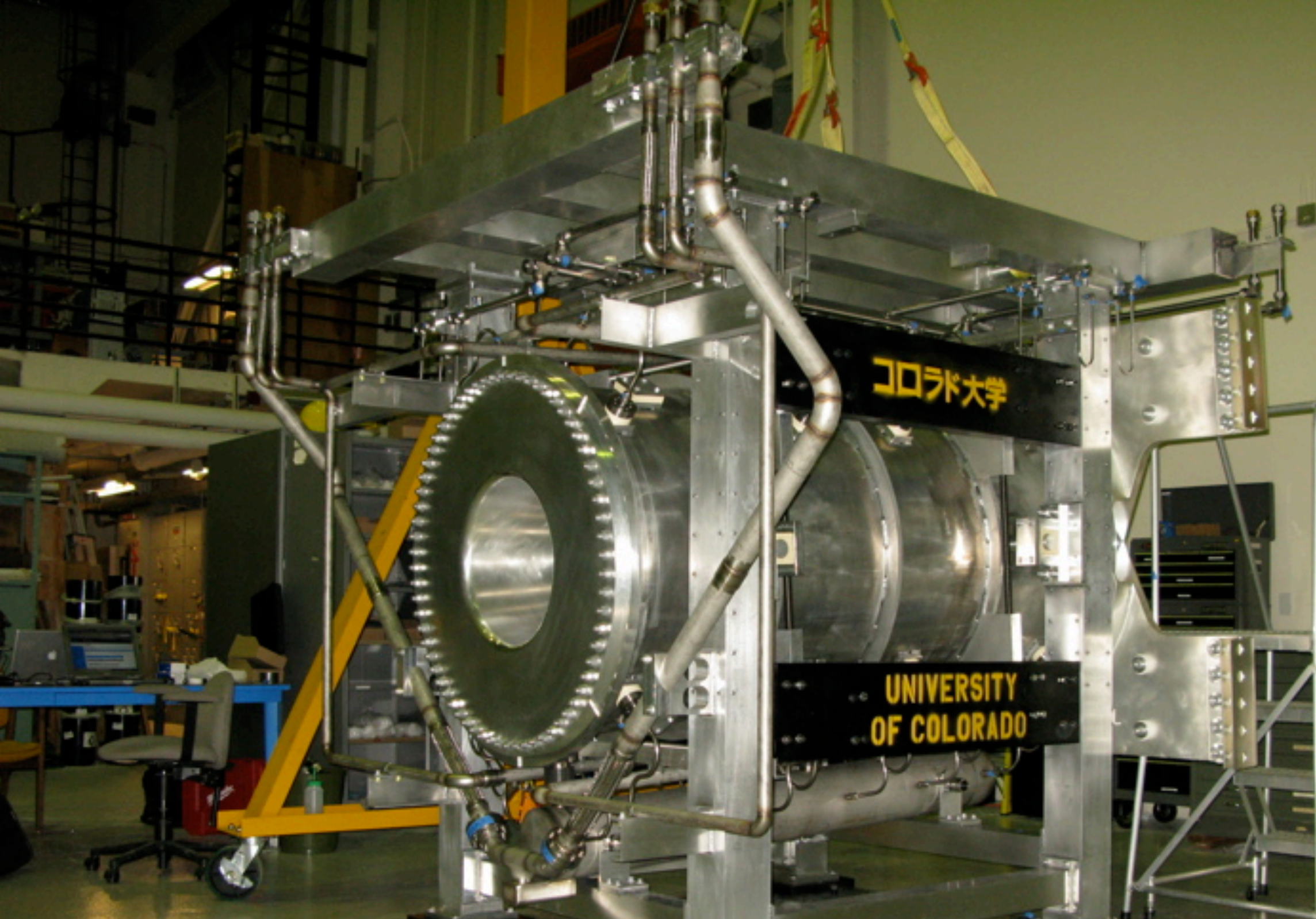
$x$ - $x$ .
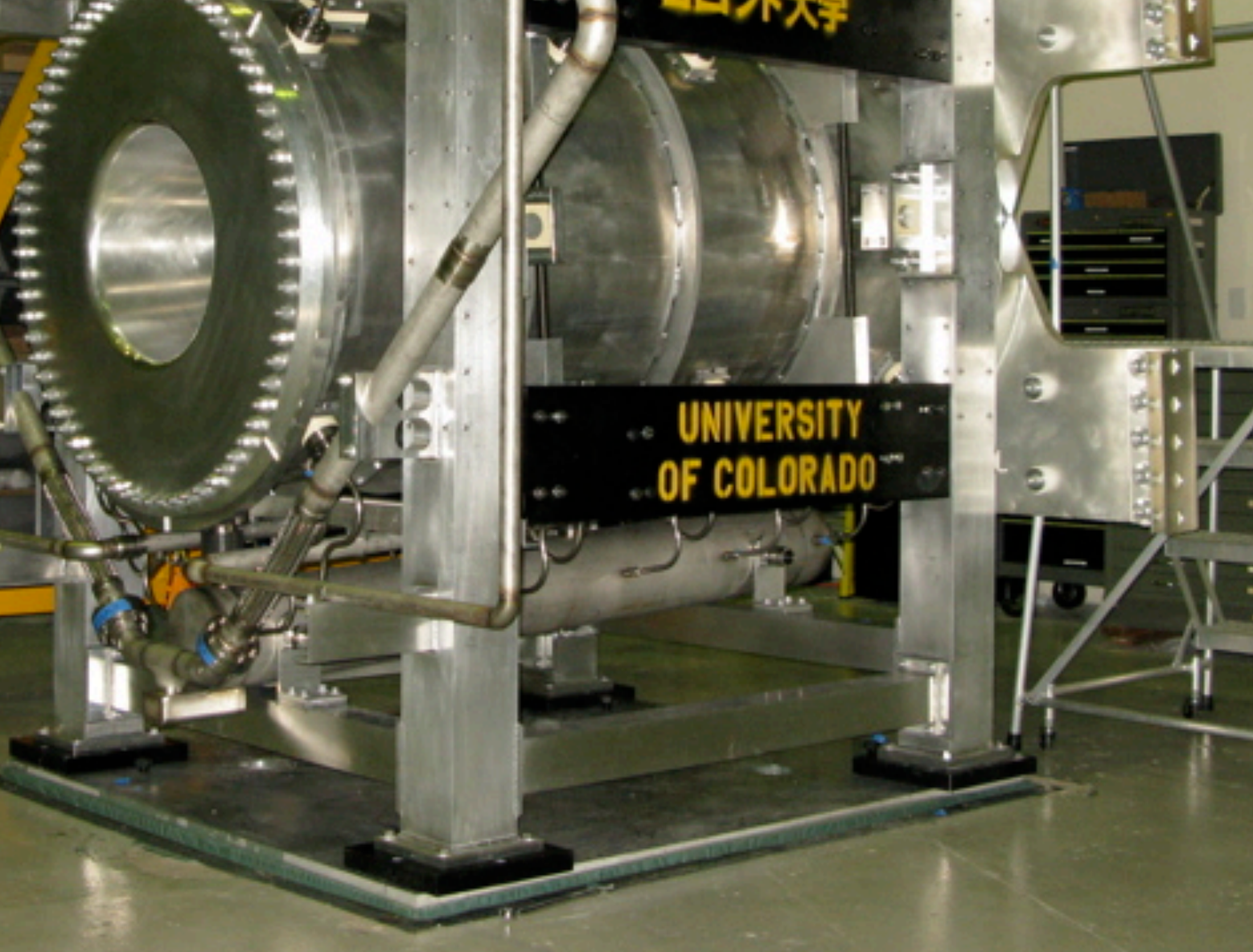

$\frac{1}{2}$
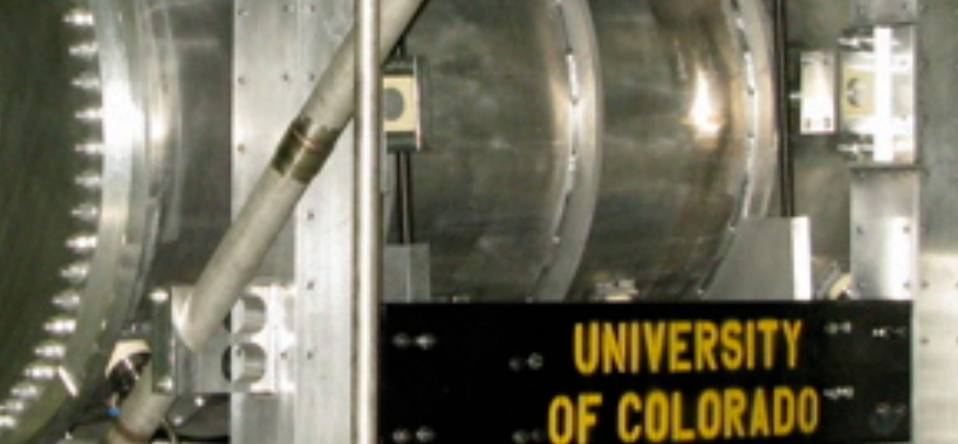

*. UNIVERSITY

- . OF COLORADO

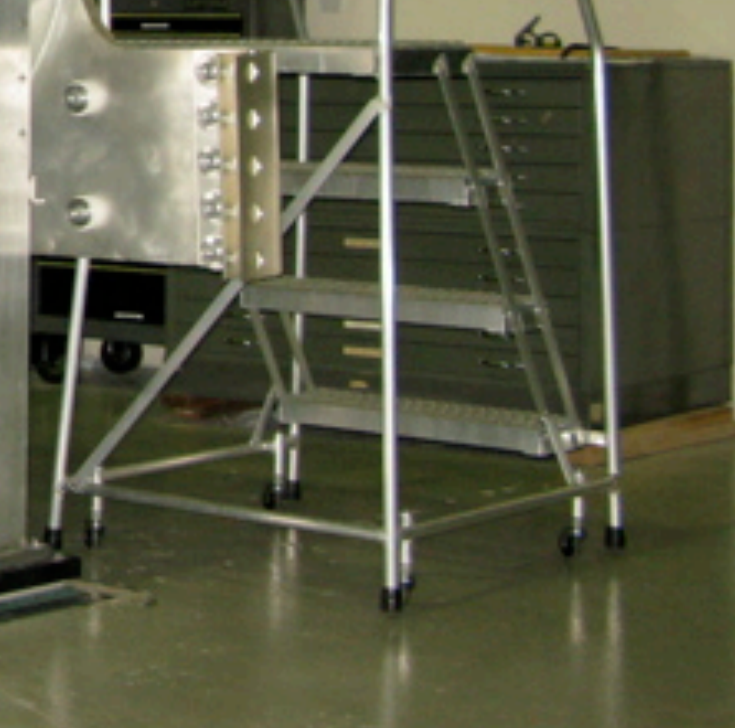




\section{fig $36-5 . p d f$}

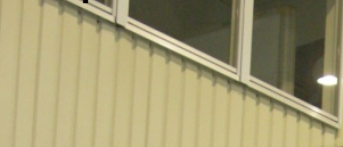

SP

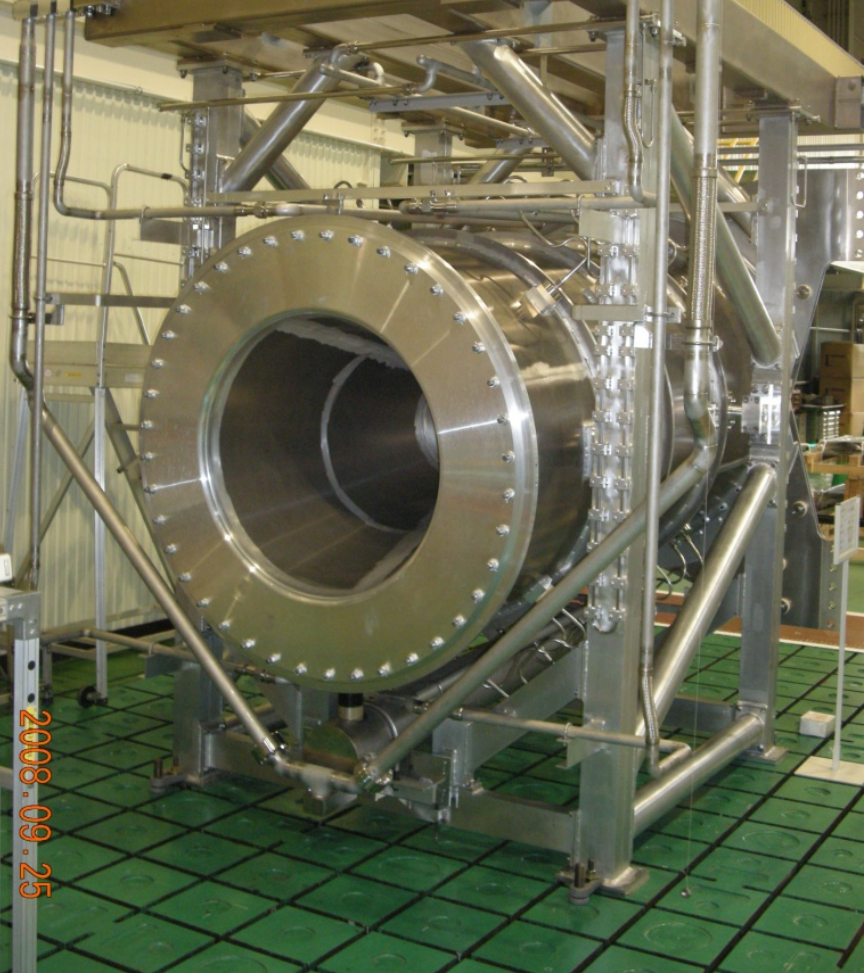




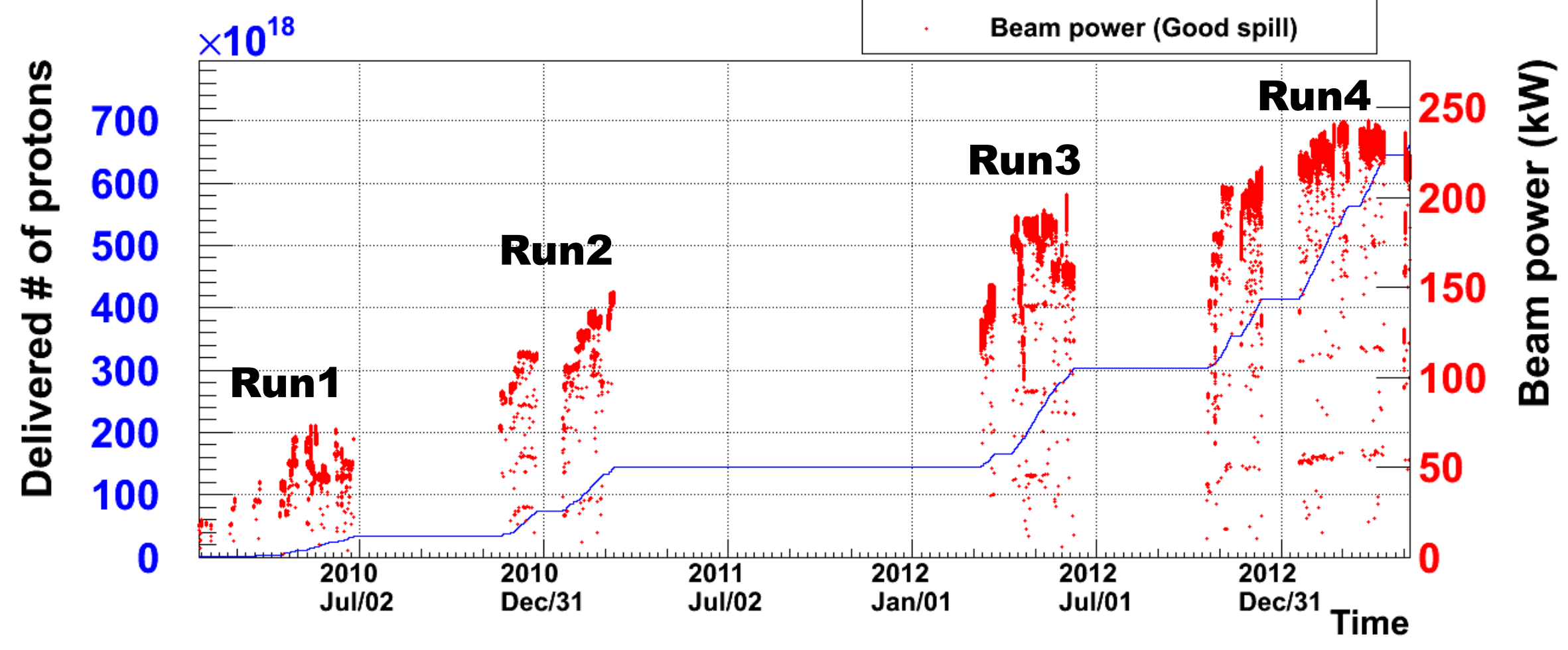




\section{He gas}

Hydrogen recombination system

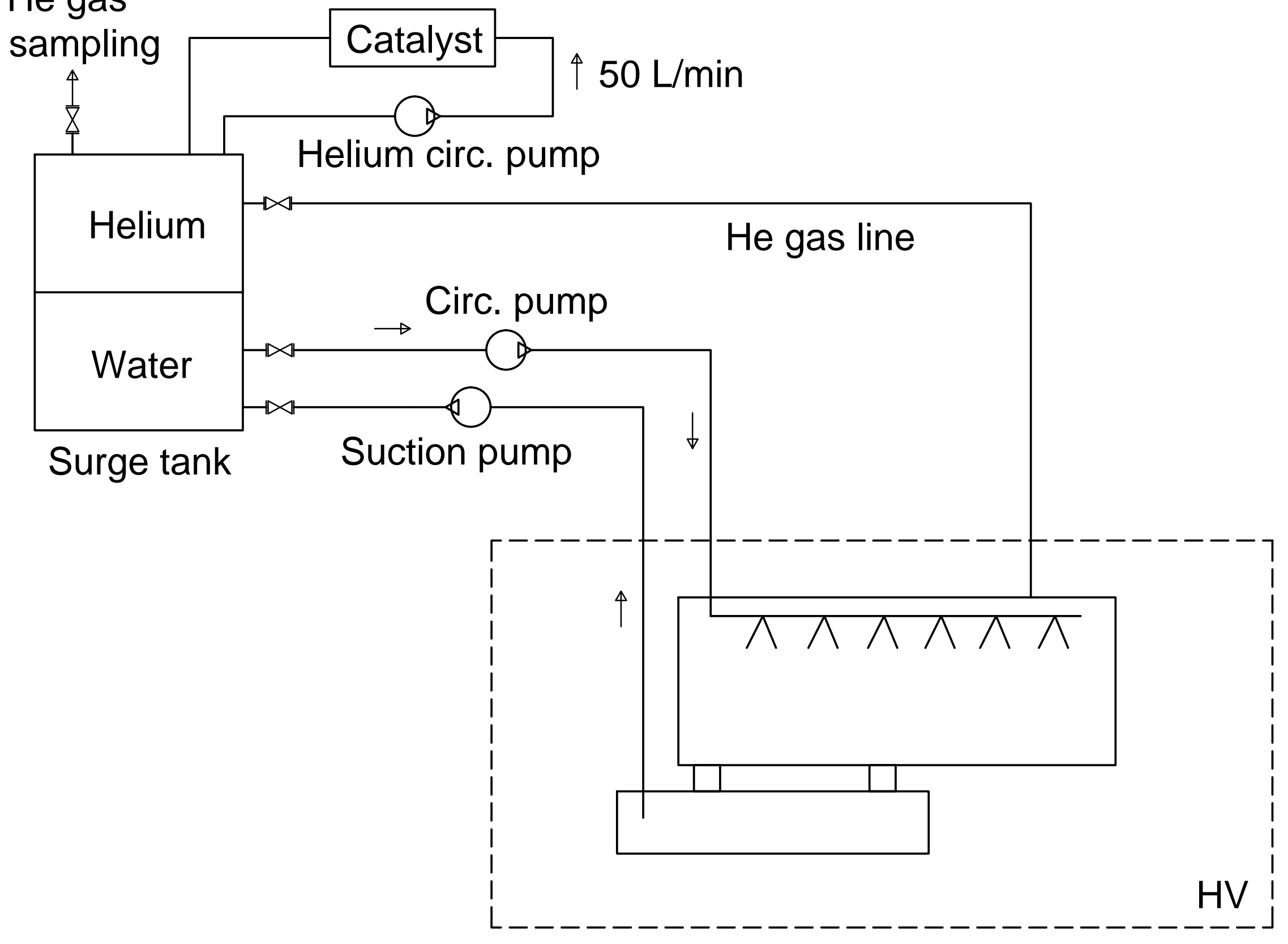




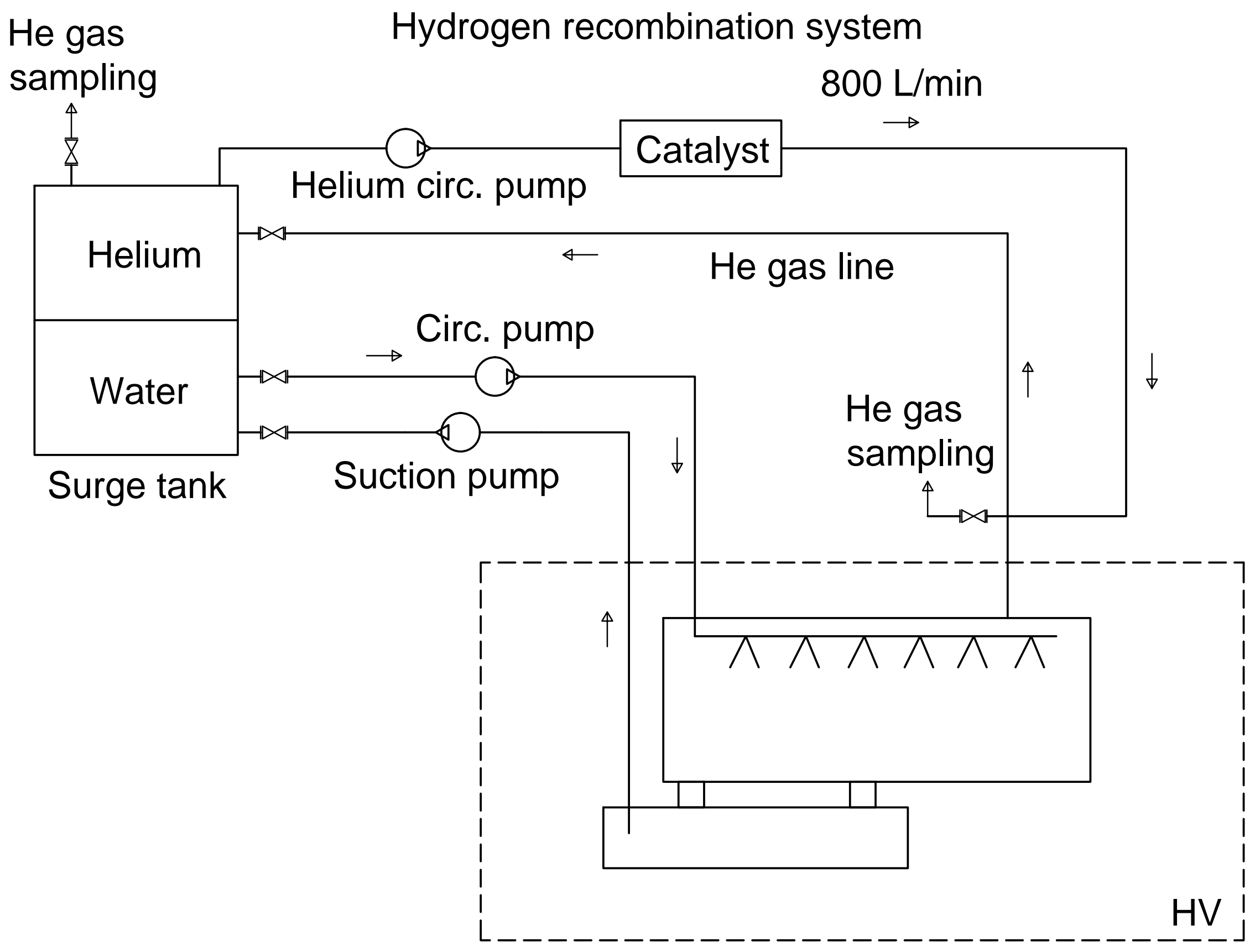

sampling

Hydrogen recombination system 
